This item was submitted to Loughborough's Research Repository by the author.

Items in Figshare are protected by copyright, with all rights reserved, unless otherwise indicated.

\title{
Cool-temperature-mediated activation of phospholipase C-[gamma]2 in the human hereditary disease PLAID
}

\section{PLEASE CITE THE PUBLISHED VERSION}

http://dx.doi.org/10.1016/j.cellsig.2016.05.010

\section{PUBLISHER}

(C) Elsevier

VERSION

AM (Accepted Manuscript)

\section{PUBLISHER STATEMENT}

This work is made available according to the conditions of the Creative Commons Attribution-NonCommercialNoDerivatives 4.0 International (CC BY-NC-ND 4.0) licence. Full details of this licence are available at: https://creativecommons.org/licenses/by-nc-nd/4.0/

\section{LICENCE}

CC BY-NC-ND 4.0

\section{REPOSITORY RECORD}

Schade, Anja, Claudia Walliser, Martin Wist, Jennifer Haas, Petra Vatter, Johann M. Kraus, Davide Filingeri, et al.. 2019. "Cool-temperature-mediated Activation of Phospholipase C-[gamma]2 in the Human Hereditary Disease PLAID”. figshare. https://hdl.handle.net/2134/21459. 


\section{University of Ulm Medical Center}

Institute of Pharmacology and Toxicology

Prof. Dr. Peter Gierschik

Institute of Pharmacology and Toxicology, University of Ulm Medical Center 89070 Ulm, Germany

To

Professor Donald H. Maurice, Ph.D.

Editor

Cellular Signalling

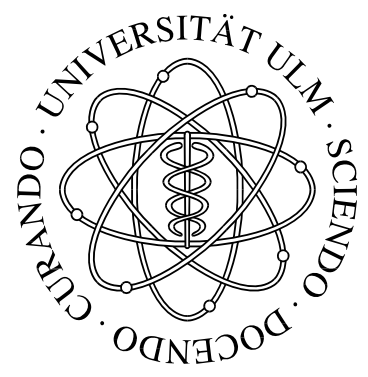

Delivery Address:

Albert-Einstein-Allee 11

89081 Ulm, Germany

$\begin{array}{ll}\text { Tel.: } & +49-731-500-65500 \\ \text { Fax: } & +49-731-500-65502 \\ \text { E-Mail: } & \text { peter.gierschik@ } \\ & \text { uni-ulm.de }\end{array}$

10.5.2016

Dear Professor Maurice,

thank you very much for the evaluation of and very positive response to our manuscript "Cooltemperature-mediated activation of phospholipase $\mathrm{C}-\gamma_{2}$ in the human hereditary disease PLAID" by three expert reviewers of Cellular Signalling and for allowing us to submit a revised version of our work to the Journal. Thank you also very much for the extension of the deadline (hoping that you will allow me to use Canadian time and date for the submission).

In the following, we provide a point-by-point reply to the critical points raised by the reviewers:

(i) Reviewer 1: "The results section of the manuscript lacks subtitles. Addition of these would enhance the stringency of the presentation of the results and help the reader to digest the data more easily."

Authors' response: This was done in the revised manuscript.

(ii) Reviewer 1: "In all the figures where temperature shifts were analyzed, the authors choose the conventional way, where left starts with the lower temperature and right on the $x$ axis are the higher temperature values. However, my personal opinion is that it would be more intuitive for the reader to put it the other way round. Left the physiologic temperature and right the reduced temperatures, which than lead to enhanced mutant signals. At least for me this would be a more intuitive way to show the data."

Authors' response: Although we clearly see and understand the point of the reviewer, we would very much like to adhere to the previous mode of presentation. This is mostly due to the fact that we feel that gradual changes in the temperature, such as those used in many of the figures (rather than the step changes used in the other figures) are clearer in the low to high temperature left to right presentation commonly used in physics. In particular, this format is commonly used for $\mathrm{Q}_{10}$ presentations such as the one in Fig. 3 in the field of temperature regulation of other proteins, e.g. of TRP channels.

(ii) Reviewer 1: "At least in the discussion the authors should address the question of temperature vs. ligand induced activation of Plcg2. The experiment with the constitutive Rac as activator is not entirely convincing. In vivo in mutant mice and in the patient the disease phenotype might be a mixture of temperature and ligand induce overreactivity, as the different mutants suggest." This point is related to Minor Point of Reviewer 2: "It would be interesting to know if upon stimulation (BCR triggering) at low temperature the highly active mutants can be further stimulated." 
Authors' response: We have followed these important suggestions as much as we could possibly do in the COS-7 cell context, by analyzing the activation of exogenous wild-type versus $\Delta 20-22$ and $\Delta 19$ mutant PLC $\gamma_{2}$ by EGF receptors endogenously present in these cells. The results, which are shown in Fig. 11 of the revised manuscript, are intriguing because they imply that that the mutant PLC $\gamma_{2}$ enzymes are resistant to stimulation by EGFR activation, both at $31^{\circ} \mathrm{C}$ and $37^{\circ} \mathrm{C}$. This is behavior is in striking contrast to that of wild-type PLC $\gamma_{2}$ with approx. 12-fold stimulation by EFGR activation at both $31^{\circ} \mathrm{C}$ and $37^{\circ} \mathrm{C}$. Although activation of PLC $\gamma_{2}$ in COS-7 by activated EGFR differs from its activation in B lymphocytes by antigen-activated $\mathrm{BCR}$ or in other cells by other receptor tyrosine kinases, these results are similar to the loss of function effects seen in cells of PLAID patients and could provide hints to the mechanistic basis of the apparently disparate effects of the PLAID mutations, gain and loss of PLC $\gamma_{2}$ function.

(iii) Reviewer 1: "The octamer peptide $\mathrm{PCl}$ is fully conserved in $\mathrm{PLC}<$ gamma $>1$ and mediates cold sensitivity in PLC $<$ gamma $>2$. Which effect causes its deletion in PLC $<$ gamma $>1$."

Authors' response: We have not specifically addressed this question. However, since the $\mathrm{PCl}$ peptide is contained in the region deleted in the PLC $\gamma_{1}$ mutant " $\triangle 20-22$ ", we would predict that that the functions of PLC $\gamma_{1} \Delta \mathrm{PCl}$ would be similar to those of $\mathrm{PLC} \gamma_{1} \Delta 20-22$ (cf. Fig. 4A), such as the functions of $\mathrm{PLC} \gamma_{2} \Delta \mathrm{PCl}$ resemble those of $\mathrm{PLC} \gamma_{2} \Delta 20-22$ (cf. Fig. 4B, left). However, we do not feel that the octamer mediates cold sensitivity in PLC $\gamma_{2}$, since it is maintained in PLC $\gamma_{2} \Delta 19$, which is nevertheless sensitive to activation by cooling (cf. Fig. 8B).

(iv) Reviewer 1: "The authors could provide data on the mobilization of $\mathrm{Ca} 2+$ upon the temperature shift. This would strengthen the data on IP3 measurements."

Authors' response: We appreciate this suggestion of the reviewer. However, in other studies that we have performed on PLC $\gamma_{2}$, we have always seen a close correlation between inositol phosphate formation and increase in cytosolic $\mathrm{Ca}^{2+}$, at least upon acute activation of the enzyme. In the chronic activation setting used in most of the experiments shown here, we would anticipate technical difficulties in observing reliable changes in $\left[\mathrm{Ca}^{2+}\right]_{i}$ for the PLC $\gamma_{2}$ PLAID mutants.

(v) Reviewer 3: "Attempts were made to provide a structural rational for the activation mediated by cool temperatures. The main limitation here is that the work relies on indirect experiments that measure enzyme activity of PLCgamma2 variants in transfected cells without any further support from other approaches. Conceptual schemes are helpful but experimental limitations have to be pointed out. This should be emphasized in discussion."

Authors' response: This was explicitly done on p. 19 of the revised manuscript.

(vi) Reviewer 3: "Several observations deserve some more emphasis even if they can not be easily explained at present. These include: -The data suggesting that PLCgamma1 variants harboring deletions are not regulated by cool temperatures and that regions corresponding to deletions in PLAID have a bigger role in auto-inhibition in this enzyme. -The data related to Ali5 mutation and activation by cool temperatures. This mutation is not in the region affected by PLAID, actually not in the regulatory region at all. Some link to the $\mathrm{PH}$ domain has been suggested but this is mechanistically unclear. Unexpected behavior of Ali5 variant on its own and the distinct position of the mutation need to be pointed out. -The fact that many deletions in PLCgamma2 SH region are further activated by cool temperatures."

Authors' response: All three points have been addressed in the text of the revised manuscript on pp. 11, 13 (top paragraph), and 13 (bottom paragraph).

(vii) Reviewer 3: "It should be stated that assumption (or expectation) has been made that observations based on COS cell transfections will be relevant for endogenous expression levels in B-cells." 
Authors' response: This was done in the revised manuscript on p. 20 in the context of discussing the resistance of the two deletion mutants to activated EGFR in COS-7 cells [cf. (ii)].

An additional point not requested by the reviewers was the examination of the requirement of the spPH domain per se for cool temperature regulation of PLC $\gamma_{2}$. We felt that this experiment needed to be done and think that its results should be reported in this manuscript (now in Fig. $10 \mathrm{~B}$ ) to avoid misinterpretations of the role of spPH in mediating the enzyme's response to cooling. The results are intriguing: while spPH exerts a striking regulatory role within the PLAID PLC $\gamma_{2}$ mutant PLC $\gamma_{2} \Delta 19$, it is not required for the cool temperature response of further truncated mutants, such as the bipartite mutant made up of fragments $X$ and $Y$. We would be happy, if you allowed us to show this data and an accordingly revised version of the model now shown in Fig. 10C-H.

In summary, we believe that we have carefully considered and taken care of most, if not all of the referees' critical points. We sincerely hope that these changes make our work acceptable for publication in Cellular Signalling. Needless to say, we are extremely grateful to all three reviewers for their expert opinions and invaluable and important advice on the manuscript.

Yours sincerely,

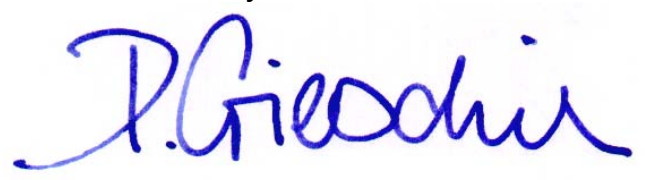

Peter Gierschik 


\title{
Cool-temperature-mediated activation of phospholipase $\mathrm{C}-\boldsymbol{\gamma}_{2}$ in the human hereditary disease PLAID
}

\author{
Anja Schade ${ }^{\mathrm{a}}$, Claudia Walliser ${ }^{\mathrm{a}}$, Martin Wist ${ }^{\mathrm{a}}$, \\ Jennifer Haas ${ }^{\text {a }}$, Petra Vatter $^{\text {a }}$, Johann M. Kraus ${ }^{\text {b }}$, Davide Filingeri ${ }^{\mathrm{c}, 1}$, \\ George Havenith $^{\mathrm{c}}$, Hans A. Kestler ${ }^{\mathrm{d}}$, Joshua D. Milner ${ }^{\mathrm{e}}$, Peter Gierschik ${ }^{\mathrm{a}, *}$ \\ ${ }^{a}$ Institute of Pharmacology and Toxicology, Ulm University Medical Center, 89070 Ulm, Germany \\ ${ }^{b}$ Medical Systems Biology, Ulm University, 89081 Ulm, Germany \\ ${ }^{c}$ Environmental Ergonomics Research Centre, Loughborough University, Leicestershire, LE11 3TU, \\ United Kingdom \\ ${ }^{d}$ Friedrich Schiller University Jena and Leibniz Institute for Age Research, Fritz Lipmann Institute, \\ 07745 Jena, Germany \\ ${ }^{e}$ Allergic Inflammation Unit, Laboratory of Allergic Diseases, NIAID, NIH, Bethesda, MD 20892, \\ U.S.A.
}

Abbreviations: PLC, inositol-phospholipid-specific phospholipase C; SH2, Src homology domain 2; SH3, Src homology domain 3; PH, pleckstrin homology domain; spPH, split PH domain; PCI, phospholipase $\mathrm{C}$ inhibitor peptide; Rac, Ras-related C3 botulinum toxin substrate; BCR, B cell receptor; SA, specific array; PLAID, PLC $\gamma_{2}$-associated antibody deficiency and immune dysregulation; TRP, transient receptor potential; PtdIns, phosphatidylinositol; PtdIns(4)P, phosphatidylinositol 4-phosphate; PtdIns $(4,5) P_{2}$, phosphatidylinositol 4,5-bisphosphate; Co., control; aa, amino acid

* Corresponding author at: Institute of Pharmacology and Toxicology, Ulm University Medical Center, Albert-Einstein-Allee 11, 89081 Ulm, Germany

E-mail address: peter.gierschik@uni-ulm.de (P. Gierschik).

\footnotetext{
${ }^{1}$ Present address: Center for Environmental Design Research, University of California, Berkeley, CA 94720-1839, U.S.A.
} 
A B S T RA C T

Deletions in the gene encoding signal-transducing inositol phospholipid-specific phospholipase $\mathrm{C}-\gamma_{2}\left(\mathrm{PLC} \gamma_{2}\right)$ are associated with the novel human hereditary disease PLAID (PLC $\gamma_{2}$-associated antibody deficiency and immune dysregulation). PLAID is characterized by a rather puzzling concurrence of augmented and diminished functions of the immune system, such as cold urticaria triggered by only minimal decreases in temperature, autoimmunity, and immunodeficiency. Understanding of the functional effects of the genomic alterations at the level of the affected enzyme, $\operatorname{PLC} \gamma_{2}$, is currently lacking. PLC $\gamma_{2}$ is critically involved in coupling various cell surface receptors to regulation of important functions of immune cells such as mast cells, B cells, monocytes/macrophages, and neutrophils. PLC $\gamma_{2}$ is unique by carrying three $\mathrm{Src}(\mathrm{SH})$ and one split pleckstrin homology domain (spPH) between the two catalytic subdomains (spPHn-SH2n-SH2c-SH3-spPHc). Prevailing evidence suggests that activation of $\mathrm{PLC} \gamma_{2}$ is primarily due to loss of SH-region-mediated autoinhibition and/or enhanced plasma membrane translocation. Here, we show that the two PLAID PLC $\gamma_{2}$ mutants lacking portions of the SH region are strongly (> 100-fold), rapidly, and reversibly activated by cooling by only a few degrees. We found that the mechanism(s) underlying PLC $\gamma_{2}$ PLAID mutant activation by cool temperatures is distinct from a mere loss of $\mathrm{SH}$-region-mediated autoinhibition and dependent on both the integrity and the pliability of the spPH domain. The results suggest a new mechanism of PLC $\gamma$ activation with unique thermodynamic features and assign a novel regulatory role to its spPH domain. Involvement of this mechanism in other human disease states associated with cooling such as exertional asthma and certain acute coronary events appears an intriguing possibility.

Keywords: Phospholipase C- $\gamma_{2}$; Inositol phospholipid; Rac2 GTPase; Split PH domain; Autoinhibition; Cold temperature sensitivity 


\section{Introduction}

Inositol-phospholipid-specific phospholipases C (PLCs) catalyse the formation of inositol 1,4,5trisphosphate and diacylglycerol, and, at the same time, decrease the local or general plasma membrane abundance of their substrate, phosphatidylinositol 4,5-bisphosphate (PtdIns $\left.P_{2}\right)$ [1]. The latter three molecules are important mediators of cellular signaling. An enormous variety of cell surface receptors regulates important cellular functions utilizing PLCs, ranging from G-proteincoupled receptors over certain ion channels to many transmembrane non-enzymes and enzymes, e.g. receptor tyrosine kinases. The mammalian PLCs are divided into six subfamilies, $\beta, \gamma, \delta, \varepsilon, \zeta$, and $\eta$. Analyses of PLC crystal structures have revealed that the catalytic mechanism of PLCs is well conserved between all PLC family members. Their activation by cell surface receptors involves both translocation of the soluble PLC enzymes to the plasma membrane, i.e. the site of their phospholipid substrate(s), and removal of intramolecular autoinhibition [2-5]. However, certain findings suggest further, still unknown regulatory mechanisms of PLC isozyme activation [1].

The two members of the PLC $\gamma$ subfamily, PLC $\gamma_{1}$ and PLC $\gamma_{2}$, control functions represented in many, if not all cell types, such as cell growth and differentiation, as well as migratory responses, but are also involved in highly specialized tasks [6]. Examples of the latter are those regulated by PLC $\gamma_{2}$ in cells of the immune system. PLC $\gamma_{1}$ and PLC $\gamma_{2}$ are activated by receptor and nonreceptor tyrosine kinases; PLC $\gamma_{2}$ is also activated by Rac GTPases [7]. In B lymphocytes, this interaction amplifies Bcell-receptor-mediated $\mathrm{Ca}^{2+}$ signalling [8]. The structures of the two PLC $\gamma$ isozymes are unique in that the two catalytic subdomains $\mathrm{X}$ and $\mathrm{Y}$ are separated by a modular assembly comprising a split $\mathrm{PH}$ domain (spPHn and spPHc), two SH2 (SH2n and SH2c), and one SH3 domain. The whole assembly (spPHn-SH2n-SH2c-SH3-spPHc) is also referred to as specific array ( $\gamma \mathrm{SA})$. Studies on isolated $\gamma \mathrm{SA}$ structures showed that the split PH domains of PLC $\gamma_{1}$ and PLC $\gamma_{2}$ do not alter their three-dimensional shapes upon insertion of the entire PLC $\gamma_{1}$ SH2n-SH2c-SH3 region between the two PLC $\gamma_{1}$ spPH halves and upon peptide ligand binding to the insertion [9] or, in case of $\mathrm{spPH}$ of $\mathrm{PLC} \gamma_{2}$, upon its interaction with activated Rac2 [10]. These findings suggested that the PLC $\gamma$ split PH domain is a more rigid, conformationally stiff element of $\gamma \mathrm{SA}$ and that it mediates PLC $\gamma_{2}$ activation mainly by allowing Rac2 to translocate the enzyme to the plasma membrane. Recent evidence suggests that the $\mathrm{SH} 2 \mathrm{c}$ domain is a major determinant of $\mathrm{PLC} \gamma_{1}$ autoinhibition and that activation of the enzyme by tyrosine phosphorylation at a site immediately downstream of the domain $\left(\mathrm{Y}^{783}\right)$ proceeds by competition of the phosphorylated peptide with a so far unidentified site on the catalytic XY TIM barrel for binding to SH2c [11,12]. 
Alterations of the primary structures of $\operatorname{PLC} \gamma_{1}$ and $\operatorname{PLC} \gamma_{2}$ are involved in disease, both in humans and in animal models. Thus, point mutations in the human PLCG1 gene have been linked to secondary, radiation-associated angiosarcoma [13] and to cutaneous T cell lymphoma [14]. Two mouse models of autoimmunity and autoinflammation, designated Ali5 and Ali14, have been described, which are caused by gain-of-function point mutations of $P L C \gamma_{2}, D^{993} \mathrm{G}$ and $\mathrm{Y}^{495} \mathrm{C}$, respectively [15-17]. The Ali5 mutation also gives rise to platelet hyperreactivity and a prothrombotic phenotype in mice [18]. Recently, deletion of exon 19 or exons 20-22 of the human PLCG2 gene has been shown to cause a novel human hereditary disease characterized by cold urticaria, immunodeficiency, and autoimmunity, designated PLAID for PLC $\gamma_{2}$-associated antibody deficiency and immune dysregulation [19]. In affected individuals, only very subtle skin cooling, such as the one caused by a single tear rolling down the cheek at room temperature, causes urticarial wheals and flares within one minute [20]. A related, but distinct human disease, predominantly characterized by autoinflammation and designated APLAID for autoinflammatory PLAID, is caused by a gain-offunction point mutation, $\mathrm{S}^{707} \mathrm{Y}$, located in $\mathrm{SH} 2 \mathrm{c}$ of $\mathrm{PLC} \gamma_{2}$ ([21], $c f$. [22], for a more comprehensive review). Although some effects of decreasing temperature on functions downstream of PLC $\gamma_{2}$ have been documented in cells from PLAID patients [19], understanding of cool temperature regulation of the enzyme that is affected by the deletion mutations at first hand, $\operatorname{PLC} \gamma_{2}$, is currently lacking. Here, we show that the two PLC $\gamma_{2}$ mutants identified in PLAID patients, $\mathrm{PLC} \gamma_{2} \Delta 19$ and PLC $\gamma_{2} \Delta 20-22$ (Fig. 1A), are exquisitely sensitive to cooling and that the magnitude of the response is unprecedented in that it goes far beyond those previously observed for many other signaling proteins sensitive to temperature changes, such as the transient receptor potential (TRP) cation channels [23]. The results suggest that PLAID PLC $\gamma_{2}$ mutants are activated by only minute decreases in temperature by a novel mechanism that is primarily mediated by the split $\mathrm{PH}$ domain and distinct from a loss of autoinhibition.

\section{Material and methods}

\subsection{Material}

The mouse monoclonal antibody 9B11 reactive against the c-Myc epitope (EQKLISEEDL) and the polyclonal antiserum reactive against human PLC $\gamma_{2}$ raised in rabbits (sc-407) were obtained from Cell Signaling Technology and Santa Cruz, respectively. The mouse monoclonal antibody AC-15 reactive against $\beta$-actin (A1978), human epidermal growth factor (E9644), and cycloheximide (C7698) were obtained from Sigma. 


\subsection{Construction of vectors}

The construction of complementary DNAs encoding c-Myc-epitope-tagged human PLC $\gamma_{1}$ (1291 aa, accession number ABB84466), human PLC $\gamma_{2}$ (1265 aa, accession number NP_002652), and the spPH domain chimera PLC $\gamma_{2}-\mathrm{PH} 11$ is described in [24]. The cDNAs of PLC $\gamma_{2} \Delta 19$ (deletion of exon 19, aa 646-685), PLC $\gamma_{2} \Delta 19-\mathrm{PH} 12, \operatorname{PLC} \gamma_{2} \Delta 19-\mathrm{PH} 21, \mathrm{PLC} \gamma_{2} \Delta 19-\mathrm{PH} 11$ [with one or both portions of the PLC $\gamma_{2}$ spPH domain (aa 468-513 and aa 849-914, respectively) replaced in PLC $\gamma_{2} \Delta 19$ by the corresponding regions of $\mathrm{PLC} \gamma_{1}$ (aa 482-527 and aa 872-937, respectively)], PLC $\gamma_{1} " \Delta 19$ " [deletion of $\operatorname{PLC} \gamma_{1}$ residues corresponding to residues 646 to 685 of $\mathrm{PLC} \gamma_{2}$ (aa 668-707)], $\mathrm{PLC} \gamma_{2} \Delta \mathrm{SH}$ (deletion of the SH2n-SH2c-SH3 region, aa 515-840), $\mathrm{PLC} \gamma_{2} \Delta \mathrm{SH} 2 \mathrm{c}$ (deletion of the C-terminal SH2 domain, aa 639-766), and PLC $\gamma_{2} \Delta \mathrm{PCI}$ (aa 726-733) were constructed by in vitro mutagenesis using the QuikChange II XL Site-Directed Mutagenesis Kit (200521, Agilent Technologies). The deletion of exons 20-22 in $\mathrm{PLC} \gamma_{2}\left(\mathrm{PLC} \gamma_{2} \Delta 20-22\right.$, aa 686-806), of the $\mathrm{PLC} \gamma_{1}$ residues corresponding to residues 686 to 806 of PLC $\gamma_{2}$ (aa 708-828; PLC $\left.\left.\gamma_{1} " \Delta 20-22 "\right)\right]$, and of the PLC $\gamma_{2}$ specific array (PLC $\gamma_{2} \Delta$ SA, aa 476-908) was performed using the PCR overlap extension method. The introduction of point mutations was performed by in vitro mutagenesis using the QuikChange II XL Site-Directed Mutagenesis Kit according to the manufacturer's instructions. For the insertion of $\gamma_{2}$ SH domains into PLC $\gamma_{2} \Delta \mathrm{SH}$, a linker containing an AvrII restriction site (GCCCTAGG, AvrII site underlined) was introduced into the deletion site of PLC $\gamma_{2} \Delta \mathrm{SH}$. The SH domains (SH2n, aa 515-638, SH2n, aa 637747, SH3, aa 767-839, SH2n-SH2c, aa 515-747, SH2c-SH3, aa 637-840 were amplified with primers containing an AvrII restriction site on either end and inserted into $\mathrm{PLC} \gamma_{2} \Delta \mathrm{SH}$ by restriction and ligation. The linker introduced five additional residues in positions 515-519 of the protein. There were no functional differences between the PLC $\gamma_{2} \Delta \mathrm{SH}$ mutants with and without these residues. Complementary DNAs encoding PLC $\gamma_{2}-\mathrm{X}^{\mathrm{PHn}}$ (aa 1-514) and $\mathrm{PLC} \gamma_{2}-\mathrm{Y}^{\mathrm{PHc}}$ (aa 841-1265) were amplified by PCR. Both fragments were c-Myc-tagged at their C-termini. DNAs encoding PLC $\gamma_{2}-X$ (aa 1-470) and PLC $\gamma_{2}-Y$ (aa 914-1265) were amplified by PCR. PLC $\gamma_{2}-X$ and PLC $\gamma 2-Y$ were c-Myctagged at their $\mathrm{N}$ - and $\mathrm{C}$-termini, respectively. The primer sequences and PCR protocols are available from the authors upon request.

\subsection{Cell culture and transfection}

COS-7 cells were maintained at $37{ }^{\circ} \mathrm{C}$ in a humidified atmosphere of $90 \%$ air and $10 \% \mathrm{CO}_{2}$ in Dulbecco's modified Eagle's medium (41965-039, Gibco) supplemented with $10 \%$ (v/v) fetal calf serum (10270-106, Gibco) and $2 \mathrm{mM}$ glutamine, $100 \mathrm{units} / \mathrm{ml}$ penicillin, and $100 \mu \mathrm{g} / \mathrm{ml}$ streptomycin (all from PAA Laboratories, Cölbe, Germany). Prior to transfection, COS-7 cells were seeded into 24well plates at a density of $0.75 \times 10^{5}$ cells/well, and grown for $24 \mathrm{~h}$ in $0.5 \mathrm{ml}$ of medium/well. For 
transfection, plasmid DNA (500 ng/well) was diluted in $50 \mu 1$ jetPRIME ${ }^{\circledR}$ buffer and $1 \mu 1$ of jetPRIME ${ }^{\circledR}$ Reagent (114-15, Polyplus Transfection, Illkirch, France) was added according to the manufacturer's instructions. The total amount of DNA was maintained constant by adding empty vector. Four h after the addition of the DNA-jetPRIME ${ }^{\circledR}$ complexes to the dishes, the medium was replaced by fresh medium, and the cells were incubated for a further $20 \mathrm{~h}$ at $37{ }^{\circ} \mathrm{C}$ and $10 \% \mathrm{CO}_{2}$.

\subsection{Radiolabeling of inositol phospholipids and analysis of inositol phosphate formation}

Twenty four hours after transfection, COS-7 cells were washed once with $0.3 \mathrm{ml} /$ well of Dulbecco's PBS (PAA Laboratories) and then supplied with $0.2 \mathrm{ml} /$ well of Dulbecco's modified Eagle's medium containing supplements as described under Cell culture and transfection, and additionally supplemented with $25 \mathrm{mM}$ HEPES and $2 \mathrm{mM}$ sodium pyruvate (both from PAA Laboratories) to maintain the $\mathrm{pH}$ of the medium [25], $2.5 \mu \mathrm{Ci} / \mathrm{ml}$ myo-[2- $\left.{ }^{3} \mathrm{H}\right]$ inositol

(NET1156005MC, Perkin-Elmer), and $10 \mathrm{mM} \mathrm{LiCl}$. The cells were incubated for $20 \mathrm{~h}$ in this medium in individual incubation chambers in ambient atmosphere at temperatures ranging from $25{ }^{\circ} \mathrm{C}$ to $39{ }^{\circ} \mathrm{C}$, washed once with $0.2 \mathrm{ml} /$ well of Dulbecco's PBS, and then lysed by addition of $0.2 \mathrm{ml} /$ well of $10 \mathrm{mM}$ ice-cold formic acid. After keeping the samples for $30 \mathrm{~min}$ at $4{ }^{\circ} \mathrm{C}, 0.3 \mathrm{ml} /$ well of $10 \mathrm{mM} \mathrm{NH}_{4} \mathrm{OH}$ was added for neutralization, and the sample was centrifuged for $5 \mathrm{~min}$ at $20,000 \mathrm{x}$. The supernatants were loaded onto columns containing $0.5 \mathrm{ml}$ of Dowex ${ }^{\circledR} 1$ x 8-200 ion exchange resin (217425, Sigma) that had been converted to the formate form and equilibrated with $\mathrm{H}_{2} \mathrm{O}$. The columns were washed once with $3 \mathrm{ml}$ of $\mathrm{H}_{2} \mathrm{O}$ and twice with $3.5 \mathrm{ml}$ each of $60 \mathrm{mM}$ sodium formate and $5 \mathrm{mM}$ sodium tetraborate. Inositol phosphates were eluted with $3 \mathrm{ml}$ of $1 \mathrm{M}$ ammonium formate and $100 \mathrm{mM}$ formic acid. The eluate was supplemented with $15 \mathrm{ml}$ of scintillation fluid (Quicksafe A, 1008000, Zinsser Analytic, Frankfurt, Germany) and the radioactivity was quantified by liquid scintillation counting.

\subsection{Construction of individual incubation chambers}

Chambers allowing the temperature-controlled incubation of individual 24-well tissue culture plates (92424; TPP, Switzerland) were custom assembled using 15 x 12 x $23 \mathrm{~cm}$ Styrofoam containers (Schaumaplast, Reilingen, Germany) equipped with circuits made up of one Velleman VM148 thermostat control module (190655-62) and one Dallas DS18S20-55 temperature sensor with digital output (176168-62) to control two serially connected heating foils (532878-62; all from Conrad Electronic, http://www.conrad.de) to be placed on either side of the tissue culture plate during incubation. To allow for additional external, analogous control of the temperature, a $\varnothing 10 \mathrm{~mm}$ hole was drilled into the wall of the container and the tissue culture plate to allow insertion of a thermometer into one well. Power supply to up to 8 individual chambers was through a TDK-Lambda 
LS75-12 AC/DC converter unit (511823-62; Conrad). A construction guidance including a circuit diagram is available from the authors on request.

\subsection{Inositol phospholipid analysis}

Inositol phospholipids were extracted from transfected cells and analyzed as before [17]. COS-7 cells were grown and radiolabeled in 6-well plates. At the end of the radiolabeling procedure, $10 \mu \mathrm{l}$ of the medium supernatant were placed in a scintillation vial with $3 \mathrm{ml}$ of Quicksafe A liquid scintillator (Zinsser Analytic) and the radioactivity was quantified by liquid scintillation counting. The radiolabeled cells were lysed by addition of $1.2 \mathrm{ml}$ of $4.5 \%(\mathrm{v} / \mathrm{v})$ perchloric acid. After incubating the samples for $30 \mathrm{~min}$ on ice, they were scraped into $1.5 \mathrm{ml}$ reaction tubes and centrifuged at $4{ }^{\circ} \mathrm{C}$ for 20 min at $3,700 \times g$. Supernatants and pellets were separated. The pellets were resuspended in $100 \mu \mathrm{l}$ of water and $375 \mu \mathrm{l}$ of chloroform $/$ methanol/HCl (100:200:15) was added. The samples were vortexed, and an additional $125 \mu \mathrm{l}$ of chloroform and $125 \mu \mathrm{l}$ of $0.1 \mathrm{M} \mathrm{HCl}$ were added. After further vortexing, the samples were centrifuged at room temperature for $10 \mathrm{~min}$ at $700 \times \mathrm{g}$. Fifty $\mu \mathrm{l}$ each of the lower, chloroformic phase containing the inositol phospholipids were subjected to liquid scintillation counting as described above.

\subsection{Determination of the 10-degree temperature coefficients}

According to Hille [26], the 10-degree temperature coefficient, $Q_{10}$, of a biological process can be calculated for an arbitrary temperature interval $\Delta T$ from

$$
Q_{\Delta T}=\left(Q_{10}\right)^{\Delta T / 10}
$$

Using $\Delta T=T_{i}-T_{r e f}$ and $Q_{\Delta T}=\frac{A_{i}}{A_{r e f}}$, where $T_{i}$ and $T_{r e f}$ are the individual and a reference temperatures and $A_{i}$ and $A_{r e f}$ are the individual and a reference activity, this equation can be rewritten to

$$
\begin{gathered}
\log _{10}\left(\frac{A_{i}}{A_{\text {ref }}}\right)=0.1\left(T_{i}-T_{\text {ref }}\right) \log _{10}\left(Q_{10}\right) \\
\log _{10}\left(\frac{A_{i}}{A_{\text {ref }}}\right)=0.1 \log _{10}\left(Q_{10}\right) T_{i}-0.1 \log _{10}\left(Q_{10}\right) T_{\text {ref }}
\end{gathered}
$$

Upon plotting the $T_{\mathrm{i}} v s$. the $\log _{10}\left(\frac{A_{i}}{A_{\text {ref }}}\right)$, the $Q_{10}$ value(s) can be calculated from the slopes of the linear portions of the resultant graphs. 


\subsection{Miscellaneous}

Curve fitting was done using GraphPad Prism, version 4.03 (GraphPad Software, San Diego, CA, USA). In Fig. 3, the global curve fitting procedure was applied, where the extra sum of squares F-test is employed to determine whether the best-fit values of the two parameters differ between data sets. The simpler model was selected unless the $\mathrm{P}$ value was less than 0.05 . The propagation of errors was calculated as outlined in [27]. The various PLC $\gamma$ isoforms were tested in this study multiple times in many different combinations, including many that are not presented in this work. The experiments specifically shown herein were repeated two to three times throughout. Data from representative experiments are presented as means \pm standard error of triplicate determinations. Control curves were done in Figs. 4B and 7 to confirm that results shown in different panels of the same figure are comparable. The intensities of immunoreactive bands on Western blots corresponding to PLC $\gamma_{2}$ isozymes carrying a c-Myc epitope were within the range allowing semiquantitative comparisons, as shown by control experiments using purified c-Myc-tagged wild-type PLC $\gamma_{2}$. Samples to be analyzed by Western blotting were taken, quasi as a fourth replicate, from the same plate as and immediately adjacent to the samples taken in triplicate for functional analysis. Using this protocol and paying meticulous attention to experimental detail, we have not experienced variations in gel loading of these samples (cf. Fig. 5B).

\section{Results}

\subsection{The PLC $\gamma_{2}$ deletion mutants PLC $\gamma 2 D 19$ and PLC $\gamma 2 D 20-22$ are specifically activated by cool temperatures}

PLC $\gamma_{2} \Delta 19$ and PLC $\gamma_{2} \Delta 20-22$ were expressed in COS- 7 cells at $37{ }^{\circ} \mathrm{C}$ and the cells were then radiolabeled with $\left[{ }^{3} \mathrm{H}\right]$ inositol at temperatures ranging from $39{ }^{\circ} \mathrm{C}$ to $25^{\circ} \mathrm{C}$, followed by measurement of inositol phosphate formation. Fig. 1B shows that the two PLC $\gamma_{2}$ deletion mutants caused slight increases in inositol phosphate formation in comparison to the wild-type enzyme at $37{ }^{\circ} \mathrm{C}$. Consistent with earlier results [19], these increases were approximately 2.8- and 3.6-fold for PLC $\gamma_{2} \Delta 19$ and PLC $\gamma_{2} \Delta 20-22$, respectively, relative to the increase over basal activity observed for wild-type PLC $\gamma_{2}$. Much more strikingly, however, there was a marked stimulation of inositol phosphate formation when cells expressing either deletion mutant were incubated at only slightly lower temperatures. In both cases, there was a biphasic stimulatory response with declining temperatures, with a maximum at 31 ${ }^{\circ} \mathrm{C}$ and a gradual reduction upon further cooling to $25{ }^{\circ} \mathrm{C}$. There was only a modest monophasic decrease in inositol phosphate formation in cells expressing wild-type PLC $\gamma_{2}$ and in control cells when the temperature was reduced from $39{ }^{\circ} \mathrm{C}$ to $25{ }^{\circ} \mathrm{C}$. Strikingly, at $31{ }^{\circ} \mathrm{C}$, the absolute increase in inositol phosphate formation in cells expressing PLC $\gamma_{2} \Delta 19$ and PLC $\gamma_{2} \Delta 20-22$ over basal activity of mock- 
transfected control cells was enhanced approx. $480 \pm 91$ - and $430 \pm 84$-fold (means \pm SEM) relative to the increase over basal inositol phosphate formation observed in cells expressing wild-type PLC $\gamma_{2}$. Fig. 1C shows that the expression of wild-type PLC $\gamma_{2}$ decreased with decreasing incubation temperature, while the expression of both PLC $\gamma_{2} \Delta 19$ and PLC $\gamma_{2} \Delta 20-22$ took slight increases at intermediate temperatures ranging from $35{ }^{\circ} \mathrm{C}$ to $31{ }^{\circ} \mathrm{C}$ and from $35{ }^{\circ} \mathrm{C}$ to $25{ }^{\circ} \mathrm{C}$, respectively. While reduced expression of wild-type $\mathrm{PLC} \gamma_{2}$ at lower temperatures may explain, at least in part, the monophasic decrease in inositol phosphate formation by this enzyme, the limited magnitude of the changes observed in Fig. 1C for PLC $\gamma_{2} \Delta 19$ and PLC $\gamma_{2} \Delta 20-22$ argues against a critical role of fluctuating enzyme expression in the marked changes of inositol phosphate formation enzyme activity evident in Fig. 1B.

\subsection{The activation of $P L C \gamma_{2} \Delta 19$ and $P L C \gamma_{2} \Delta 20-22$ by subphysiological temperatures occurs after protein synthesis and is reversible.}

The influence of a decrease in incubation temperature on the abundance of inositol phospholipids in mock-transfected COS-7 cells and cells expressing either wild-type or $\Delta 19$ mutant PLC $\gamma_{2}$ is shown in Figs. 1D and E. PLC $\gamma$ is capable of hydrolyzing PtdIns, PtdIns(4)P, PtdIns(4,5) $P_{2}$ [28]. There was no increase in the abundance of PLC $\gamma$ substrate inositol phospholipids upon cooling. Instead, a monophasic loss was apparent in all three cases upon decreasing the temperature to $25^{\circ} \mathrm{C}$ to approximately $13 \%$ of the levels observed at $37{ }^{\circ} \mathrm{C}$. This behavior was largely independent of whether or not wild-type PLC $\gamma_{2}$ or PLC $\gamma_{2} \Delta 19$ was expressed in the cells. While this loss may reflect slower synthesis of the substrate phospholipids at lower temperatures and may explain some of the decline in inositol phosphate formation by PLC $\gamma_{2} \Delta 19$ and $\operatorname{PLC} \gamma_{2} \Delta 20-22$ at temperatures below $31^{\circ} \mathrm{C}$ ( $c f$. Fig. 1B), it argues against increased substrate availability causing the dramatic stimulation of the PLC $\gamma_{2}$ deletion mutants upon cooling from $37{ }^{\circ} \mathrm{C}$ to $31^{\circ} \mathrm{C}$ ( $c f$. Fig. 1B).

The next experiment was designed to examine whether stimulation of PLC $\gamma_{2} \Delta 19$ and PLC $\gamma_{2} \Delta 20$ 22 by cool temperatures occurs before or after synthesis of the mutant PLC $\gamma_{2}$ proteins. To this end, cells already containing either wild-type PLC $\gamma_{2}, \operatorname{PLC} \gamma_{2} \Delta 19$, or PLC $\gamma_{2} \Delta 20-22$ (as a result of a 24-htransfection period at $37{ }^{\circ} \mathrm{C}$ ) were treated for a further $20 \mathrm{~h}$ (i.e. during the $\left[{ }^{3} \mathrm{H}\right]$ inositol radiolabeling phase) with or without cooling from $37{ }^{\circ} \mathrm{C}$ or $31{ }^{\circ} \mathrm{C}$, both in the absence and in the presence of 100 $\mu \mathrm{g} / \mathrm{ml}$ cycloheximide. Using this protocol, we expected that cycloheximide would block the stimulatory effect of cooling on inositol phospholipid hydrolysis by the mutants, if cooling were to be effective prior to or during recombinant protein synthesis. Fig. 2A shows that this was not the case. Thus, cooling to $31^{\circ} \mathrm{C}$ caused marked increases in inositol phosphate formation, regardless of whether cycloheximide was absent or present during the second phase. Fig. $2 \mathrm{~B}$ shows that, both at $37^{\circ} \mathrm{C}$ and 
at $31{ }^{\circ} \mathrm{C}$, cycloheximide prevented the increase in abundance of wild-type and deletion mutant PLC $\gamma_{2}$ during the second phase (in comparison to the control samples obtained after the initial phase), indicating that cycloheximide was in fact effective as a protein biosynthesis inhibitor in this experiment. Taken together, these results indicate that the stimulatory effect of subphysiologic temperatures on deletion mutant PLC $\gamma_{2}$ activity occurs after protein synthesis.

To examine whether the stimulatory effects of the $\Delta 19$ and $\Delta 20-22$ deletions on PLC $\gamma_{2}$ activity were reversible, wild-type PLC $\gamma_{2}, \operatorname{PLC} \gamma_{2} \Delta 19$, and PLC $\gamma_{2} \Delta 20-22$ were incubated for the last four hours of the transfection protocol, i.e. in the absence of radiolabeled inositol phospholipid substrate, at either $37{ }^{\circ} \mathrm{C}$ or $31{ }^{\circ} \mathrm{C}$ and then radiolabeled with $\left[{ }^{3} \mathrm{H}\right]$ inositol at one of the two temperatures. Fig. 2D shows that the three different incubation protocols had little, if any, effect on the expression of each of the three enzymes. As shown in Fig. $2 \mathrm{C}$, preincubation of the three enzymes at $31^{\circ} \mathrm{C}$ had no effect on their ability to promote inositol phosphate formation. Only when cells were incubated at $31{ }^{\circ} \mathrm{C}$ in the presence of $\left[{ }^{3} \mathrm{H}\right]$ inositol, enhanced inositol phosphate formation was evident by the two deletion mutants, in contrast to wild-type PLC $\gamma_{2}$. A time-course of the changes of inositol phosphate formation by wild-type and mutant PLC $\gamma_{2}$ upon changes in incubation temperature from $37{ }^{\circ} \mathrm{C}$ to $31{ }^{\circ} \mathrm{C}$ and vice versa is shown in Figs. $2 \mathrm{E}$ and $2 \mathrm{~F}$. Both deletion mutants were activated with no apparent lag time with cooling to $31{ }^{\circ} \mathrm{C}$. However, deactivation of both enzymes by warming to $37{ }^{\circ} \mathrm{C}$ required a lag time of approximately 10 min to come into effect. Thus, activation of $P L C \gamma_{2} \Delta 19$ and $P L C \gamma_{2} \Delta 20-22$ by cool temperatures is a rapid and slowly, but fully reversible process.

The determination of the $10{ }^{\circ} \mathrm{C}$ temperature coefficient $\left(Q_{10}\right)$ value, widely used to characterize the regulation of TRP channels by temperature [23], for wild-type PLC $\gamma_{2}, \operatorname{PLC} \gamma_{2} \Delta 19$, and PLC $\gamma_{2} \Delta 20$ 22 is shown in Fig. 3. While only a single linear component with a $Q_{10}$ value of 4.6 was evident for wild-type PLC $\gamma_{2}$ between $39{ }^{\circ} \mathrm{C}$ and $25{ }^{\circ} \mathrm{C}$, both PLC $\gamma_{2} \Delta 19$ and PLC $\gamma_{2} \Delta 20-22$ displayed two separate phases of opposite signs and markedly distinct $Q_{10}$ values. Specifically, while $Q_{10}$ was as high as 6745 for the marked increase in activity between $39{ }^{\circ} \mathrm{C}$ and $33{ }^{\circ} \mathrm{C}$, it was lower by more than three orders of magnitude and not different, by sign and by magnitude, from the $Q_{10}$ value describing the decrease in activity of the wild-type enzyme, 4.6 , between $31{ }^{\circ} \mathrm{C}$ and $25{ }^{\circ} \mathrm{C}$. Thus, it appears that the major functional consequence of the two deletions is their increased activity upon cooling from $37{ }^{\circ} \mathrm{C}$ to approximately $31{ }^{\circ} \mathrm{C}$. The decrease in activity observed at temperatures below $31{ }^{\circ} \mathrm{C}$ appears to be a property inherently present in the remaining elements of wild-type $\operatorname{PLC} \gamma_{2}$. The $Q_{10}$ values of PLC $\gamma_{2} \Delta 19$ and PLC $\gamma_{2} \Delta 20-22$ exceed those reported for other temperature-regulated proteins, such as thermoTRPs (with values ranging from 10 to > 100 [23]). However, higher $Q_{10}$ values are not without precedence. For example, the step of heat damage to the development of the posterior crossvein of Drosophila that is most sensitive to increasing temperature showed a $Q_{10}$ of about 360 [29]. 


\subsection{Cool-temperature-mediated activation of PLC $22 D 19$ and PLC $22 D 20-22$ is distinct from loss of SH-region-mediated autoinhibition.}

The structural organization of PLC $\gamma_{2}$ between its two catalytic subdomains $\mathrm{X}$ and $\mathrm{Y}$ is very similar to that of its close relative PLC $\gamma_{1}[6]$. To address the question, whether deletion in PLC $\gamma_{1}$ of residues corresponding to those encoded by exons 19 and 20-22 of PLCG2 has similar functional consequences, the relevant mutants of human PLC $\gamma_{1}$ were produced. Since the human PLCGI and PLCG2 genes exhibit distinct patterns of genomic organization, the deletions in PLC $\gamma_{1}$ do not correspond to specific exons in PLCG1. Hence, the mutants are designated PLC $\gamma_{1} " \Delta 19 "$ and PLC $\gamma_{1} " \Delta 20-22 "$. Fig. 4A shows that both PLC $\gamma_{1} " \Delta 19 "$ and PLC $\gamma_{1} " \Delta 20-22 "$, in contrast to their PLC $\gamma_{2}$ counterparts, were already highly constitutively active at $37{ }^{\circ} \mathrm{C}(54-$ and 37 -fold increases in inositol phosphate formation, respectively, in comparison to the increase caused by wild-type PLC $\gamma_{1}$ relative to control). Furthermore, only minor changes in their activity were observed upon reduction of the incubation temperature from $37{ }^{\circ} \mathrm{C}$ to $27{ }^{\circ} \mathrm{C}$. There were only minor changes in inositol phosphate formation by wild-type PLC $\gamma_{1}$. Fig. S1A shows that there were minor, if any changes in protein expression of the PLC $\gamma$ enzymes with decreasing temperatures, except for PLC $\gamma_{1} " \Delta 20-22$ " and PLC $\gamma_{2} \Delta 20-22$, which showed increased expression. It seems possible on the basis of these findings that the regions of PLC $\gamma_{1}$ corresponding to the regions deleted in PLC $\gamma_{2}$ in PLAID exert a stronger autoinhibitory influence on PLC $\gamma_{1}$ than their PLC $\gamma_{2}$ counterparts on PLC $\gamma_{2}$ and that this difference blunts the stimulatory response of PLC $\gamma_{1} " \Delta 19 "$ and PLC $\gamma_{1} " \Delta 20-22 "$ to cooling. This possibility notwithstanding, the results indicate that the temperature sensitivities of PLC $\gamma_{1}$ and PLC $\gamma_{2}$ carrying deletions corresponding to exons 19 and 20-22 of PLCG2 are distinct.

The region encoded by exons 20 to 22 of PLCG2 contains an octapeptide (YRKMRLRY) at the end of SH2c that is absolutely conserved in $\mathrm{PLC} \gamma_{1}$ and has previously been shown to mediate inhibition of PLC $\gamma_{2}$ in trans and in cis [30,31]. To determine whether deletion of the octamer, designated PCI (for phospholipase $\underline{\mathrm{C}}$ inhibitor), is sufficient to mediate sensitivity of PLC $\gamma_{2}$ to cool temperatures, the deletion mutant PLC $\gamma_{2} \Delta \mathrm{PCI}$ was functionally compared to PLC $\gamma_{2} \Delta 20-22$ and wildtype PLC $\gamma_{2}$ (Fig. 4B, left panel). In addition, three other mutants carrying deletions known to promote constitutive activity of PLC $\gamma_{2}$ at $37{ }^{\circ} \mathrm{C}, \operatorname{PLC} \gamma_{2} \Delta \mathrm{SA}, \operatorname{PLC} \gamma_{2} \Delta \mathrm{SH}$, and $\mathrm{PLC} \gamma_{2} \Delta \mathrm{SH} 2 \mathrm{c}$, were characterized (Fig. $4 \mathrm{C}$, right panel). PLC $\gamma_{2} \Delta \mathrm{PCI}$ was analyzed again in the latter experiment as a control to ensure that the results shown in the two panels of Fig. 4B are comparable. Figs. 4B and S1B show that PLC $\gamma_{2} \Delta$ PCI shared most features of its temperature sensitivity with PLC $\gamma_{2} \Delta 20-22$ and, by extension, with PLC $\gamma_{2} \Delta 19$ ( $c f$. Fig. 1B): only a limited enhancement of its activity at $37^{\circ} \mathrm{C}$, a marked activation upon lowering the incubation temperature from $37^{\circ} \mathrm{C}$ to $31^{\circ} \mathrm{C}$, and a decrease in activity at 
temperatures below $31{ }^{\circ} \mathrm{C}$. In contrast, $\operatorname{PLC} \gamma_{2} \Delta \mathrm{SA}, \operatorname{PLC} \gamma_{2} \Delta \mathrm{SH}$, and $\mathrm{PLC} \gamma_{2} \Delta \mathrm{SH} 2 \mathrm{c}$, although exhibiting constitutive activity at $37{ }^{\circ} \mathrm{C}$, showed an only modest, further increase in activity with cooling, which was monophasic for PLC $\gamma_{2} \Delta \mathrm{SH} 2 \mathrm{c}$ and only vaguely biphasic for $\mathrm{PLC} \gamma_{2} \Delta \mathrm{SA}$ and $\mathrm{PLC} \gamma_{2} \Delta \mathrm{SH}$.

At first sight, the constitutive activities of the mutants PLC $\gamma_{2} \Delta \mathrm{SA}, \mathrm{PLC} \gamma_{2} \Delta \mathrm{SH}$, and PLC $\gamma_{2} \Delta \mathrm{SH} 2 \mathrm{c}$ observed at $37{ }^{\circ} \mathrm{C}$ in Fig. 4B, right panel, appeared rather limited in comparison to the constitutive activities reported earlier for similar mutants of PLC $\gamma_{1}$ and $\operatorname{PLC} \gamma_{2}[31,32]$. Therefore, the activities at $37^{\circ} \mathrm{C}$ of wild-type PLC $\gamma_{2}, \operatorname{PLC} \gamma_{2} \Delta 19$, PLC $\gamma_{2} \Delta 20-22, \operatorname{PLC} \gamma_{2} \Delta$ PCI, PLC $\gamma_{2} \Delta$ SH2c, PLC $\gamma_{2} \Delta$ SH, and PLC $\gamma_{2} \Delta$ SA were compared as a function of their expression levels in a more comprehensive analysis (Figs. 5A and B). The results show that, taking the relative abundance of the $\operatorname{PLC} \gamma_{2}$ variants into account (Fig. 5B), PLC $\gamma_{2} \Delta \mathrm{PCI}, \mathrm{PLC} \gamma_{2} \Delta \mathrm{SA}$, PLC $\gamma_{2} \Delta \mathrm{SH} 2 \mathrm{c}$, and $\mathrm{PLC} \gamma_{2} \Delta \mathrm{SH}$ exhibited higher constitutive activity at $37{ }^{\circ} \mathrm{C}$ than PLC $\gamma_{2} \Delta 19$ and PLC $\gamma_{2} \Delta 20-22$.

The fact that either of the two PLC $\gamma_{2}$ mutants, PLC $\gamma_{2} \Delta 19$ and PLC $\gamma_{2} \Delta 20-22$, were activated by cool temperatures to a similar degree raised the question as to the effect of a combined deletion of the residues encoded by exons 19 through 22. Fig. 6 shows that, at $37{ }^{\circ} \mathrm{C}$, the compound deletion mutant PLC $\gamma_{2} \Delta 19-22$ displayed a markedly enhanced activity in comparison to either PLC $\gamma_{2} \Delta 19$ or PLC $\gamma_{2} \Delta 20-22$ alone, showing only marginal enhancements of their basal activities. The stimulatory effect of cooling to $31{ }^{\circ} \mathrm{C}$ was assayed at two expression levels of the deletion mutants. At both expression levels, the activity of $\operatorname{PLC} \gamma_{2} \Delta 19-22$ at $31^{\circ} \mathrm{C}$ was much higher than the sum of the activities of PLC $\gamma_{2} \Delta 19$ and PLC $\gamma_{2} \Delta 20-22$. Hence, at both temperatures, $37{ }^{\circ} \mathrm{C}$ and $31{ }^{\circ} \mathrm{C}$, and at the expression levels tested in this experiment, the deletions of PLCG2 exons 19 and 20-22 synergized to promote activation of PLC $\gamma_{2}$.

\subsection{The mouse PLC $\gamma_{2}$ mutant Ali5 is also sensitive to activation by cool temperatures.}

The symptoms observed in the mouse Ali5 and Ali14 disease models bear resemblance to the PLAID phenotype in some, but not in all respects $[15,16,19,20]$. In transfected COS-7 cells, the corresponding PLC $\gamma_{2}$ mutants, PLC $\gamma_{2}{ }^{\text {Ali5 }}$ and PLC $\gamma_{2}{ }^{\text {Ali14 }}$ displayed only slightly enhanced basal activity at $37^{\circ} \mathrm{C}$, whereas the compound mutant, PLC $\gamma_{2}{ }^{\text {Ali5/Ali14 }}$ clearly showed constitutively enhanced activity [17]. In Ali5 mice, autoinflammatory dermatitis commenced in the superficial layers of the paws and ears, i.e. in cool body regions [15]. This distribution resembles those of cutaneous granulomatous lesions in PLAID patients [19]. We therefore compared the effect of cool temperatures on the activity of the mutants PLC $\gamma_{2}{ }^{A l i 5}$, PLC $\gamma_{2}{ }^{\text {Ali14 }}$, and the compound mutant PLC $\gamma_{2}{ }^{\text {Alis/Ali14 }}$. Figs. 7, left panel, and S2A show that all three mutants exhibited moderately enhanced activity at $37{ }^{\circ} \mathrm{C}\left(\mathrm{PLC} \gamma_{2}{ }^{\mathrm{Ali} 5 / \mathrm{Ali} 14}>\right.$ 
PLC $\gamma_{2}{ }^{A l i 5}>$ PLC $\gamma_{2}{ }^{A l i 14}$ ) as described before [17]. Importantly, however, the three mutants displayed considerable differences in their sensitivities to cool temperatures, both in quantitative and in qualitative terms. Thus, while the response of $\mathrm{PLC} \gamma_{2}{ }^{\text {Ali5/Ali14 }}$ to decreasing temperatures closely resembled the pattern observed for PLC $\gamma_{2} \Delta 20-22$ (Figs. 7, center panel, and S2B), PLC $\gamma_{2}{ }^{\text {Ali14 }}$ showed only a minor, monophasic increase in activity, which was opposite to the decrease observed for wildtype PLC $\gamma_{2}$ (Figs. 7, right panel, and S2C). PLC $\gamma_{2}{ }^{\text {Alis }}$ displayed an intermediate phenotype, nonetheless showing an almost 7-fold activation upon cooling from $37{ }^{\circ} \mathrm{C}$ to $31{ }^{\circ} \mathrm{C}$ (Fig. 7 , right panel). These results are surprising since the Plcg2 mutations underlying the Ali5 and Ali14 phenotypes cause point mutations at positions outside of the $\mathrm{SH} 2 \mathrm{n}-\mathrm{SH} 2 \mathrm{c}-\mathrm{SH} 3$ region. Perhaps, similar structural and, hence, functional alterations are brought about by distinct mutations of the enzyme. Nevertheless, the results suggest that some of the lesions noticed in the affected animals, such as inflammation in superficial skin layers, may in fact be caused by further activation of PLC $\gamma_{2}{ }^{A l i 5}$ by cool temperatures. An intriguing question to be clarified by future investigation is whether PLC $\gamma_{2}$ activated by other means, e.g. by other mutations or by tyrosine phosphorylation, are also sensitive to cold temperatures.

A more comprehensive comparison of the effects of the various constituents of the SH2n-SH2cSH3-spPHc region, alone or in combination, on PLC $\gamma_{2}$ constitutive activity and sensitivity to cool temperatures is shown in Fig. 8A. Unlike observed previously [31,32], deletion of SH3 also caused an increase in basal activity, which was even slightly higher (approximately 4.1-fold) than that monitored for deletion of SH2c (2.6-fold), but lower than that for deletion of all three SH domains (approximately 7.5-fold). The increases for the variants lacking two SH domains, $\mathrm{PLC} \gamma_{2} \Delta \mathrm{SH} 2 \mathrm{nSH} 2 \mathrm{c}$, $\mathrm{PLC} \gamma_{2} \Delta \mathrm{SH} 2 \mathrm{cSH} 3$, and $\mathrm{PLC} \gamma_{2} \Delta \mathrm{SH} 2 \mathrm{nSH} 3$, were approximately 3.6-, 1.9-, and 2.4-fold, respectively. While deletion of SH2n did not change the temperature sensitivity of $\mathrm{PLC} \gamma_{2}$ relative to the wild-type enzyme and deletion of all three SH domains resulted in a PLC $\gamma_{2}$ mutant largely insensitive to cool temperature, all other deletion mutants were clearly sensitive. Maximal sensitivity (approximately 6.1-fold) was observed for $\mathrm{PLC} \gamma_{2} \Delta \mathrm{SH} 2 \mathrm{cSH} 3$, followed, in that order, by $\Delta \mathrm{SH} 2 \mathrm{nSH} 3, \Delta \mathrm{SH} 2 \mathrm{nSH} 2 \mathrm{c}$, $\triangle \mathrm{SH} 2 \mathrm{c}$, and $\triangle \mathrm{SH}$. Note that the degrees of stimulation by cool temperatures was by far lower for these mutants than the degrees observed for the PLAID PLC $\gamma_{2}$ mutants $\Delta 19$ and $\Delta 20-22$ ( $c f$. Fig. 1). Fig. 8B shows a schematic representation of the deletions within the $\mathrm{SH} 2 \mathrm{n}-\mathrm{SH} 2 \mathrm{c}-\mathrm{SH} 3$ region (aa 515840). 
3.5. Cool-temperature-triggered activation of PLC $\gamma_{2}$ deletion mutants is controlled by, but does not necessarily require the split $\mathrm{PH}$ domain.

PLC $\gamma_{2}$ is activated by tyrosine phosphorylation and by activated Rac GTPases. The experiment shown in Fig. 9A was designed to determine the effect of decreasing temperatures on the ability of constitutively active $\operatorname{Rac} 2^{\mathrm{G} 12 \mathrm{~V}}$ to activate PLC $\gamma_{2} \Delta 19$ in comparison to wild-type PLC $\gamma_{2}$. At $37^{\circ} \mathrm{C}$, Rac2 ${ }^{\mathrm{G} 12 \mathrm{~V}}$ caused similar enhancements of the activity of both enzymes (Figs. 9A, left panel, and S3A). Lowering the incubation temperature, however, took a very different effect on Rac ${ }^{\mathrm{G} 12 \mathrm{~V}}$-mediated activation of the two enzymes. While only minor changes were observed for wild-type PLC $\gamma_{2}$, there was a progressive loss of the stimulatory effect of $\operatorname{Rac} 2^{\mathrm{G} 12 \mathrm{~V}}$ on $\mathrm{PLC} \gamma_{2} \Delta 19$. This loss is unlikely to be due to exhaustion of the inositol phospholipids substrate at lower temperatures, since PLC $\gamma_{2} \Delta 19$ is well capable of producing even higher levels of inositol phosphates when expressed at higher density (Fig. 9A, right panel, and S3B). Likewise, it was unlikely that Rac2 ${ }^{\mathrm{G} 12 \mathrm{~V}}$ became limiting at low temperatures, since stimulation of wild-type PLC $\gamma_{2}$ was well retained even at the lowest temperature, $27^{\circ} \mathrm{C}$.

The activation of PLC $\gamma_{2}$ by Rac is mediated by the internal, split PH domain of the enzyme $[10,24]$. The interdependence of the stimulatory effects of Rac $2^{\mathrm{G} 12 \mathrm{~V}}$ and cooling evident in Figs. 9A and S3 prompted us to determine the role of this domain in PLC $\gamma_{2}$ deletion mutant activation by cooling. Alanine replacement in spPH of PLC $\gamma_{2}$ of $\mathrm{W}^{899}$, which is conserved in all PH domains [33] has previously been shown to result in a loss of PLC $\gamma_{2}$ stimulation by Rac, but not by tyrosine phosphorylation [31]. Figs. 9B and S4A show that the $\mathrm{W}^{899} \mathrm{~A}$ replacement completely abrogated the response of the enzyme to cool temperature activation. Furthermore, replacement of one or the other half of the split PH domain of PLC $\gamma_{2}$ by the corresponding portions of PLC $\gamma_{1}$, previously shown to block activation of the mutant enzymes by Rac, but to take no effect on their catalytic activity [24], also eliminated enzyme activation by cool temperatures. In contrast, replacement of both PH domains halves, which does not convey Rac sensitivity to PLC $\gamma_{2}$ [24], fully rescued the response of PLC $\gamma_{2}$ to cooling. These findings indicate that there is important structural interaction between the $\mathrm{SH} 2 \mathrm{n}-\mathrm{SH} 2 \mathrm{c}-$ $\mathrm{SH} 3$ region and the surrounding sPH sequence. Two residues of the N-terminal half of the PLC $\gamma_{1}$ spPH domain, Y509 and F510 ( $c f$. Fig. 9C), have been shown to be important for the ability of spPHn to cooperate with SH2c to maintain PLC $\gamma_{1}$ in an inactive conformation $[17,34]$. To examine the role of this site in the cool temperature response of $\mathrm{PLC} \gamma_{2}$, the two residues were substituted by alanine residues in PLC $\gamma_{2} \Delta 19$ carrying the entire spPH of PLC $\gamma_{1}$ (PLC $\left.\gamma_{2} \Delta 19-\mathrm{PH} 11\right)$, thus generating the mutant PLC $\gamma_{2} \Delta 19-\mathrm{PH} 11-\mathrm{Y}^{509} \mathrm{~A} / \mathrm{F}^{510} \mathrm{~A}$. Consistent with earlier findings [17,34], there was a slight increase in basal activity of the latter mutant in comparison to $\mathrm{PLC} \gamma_{2} \Delta 19-\mathrm{PH} 11$. Remarkably, 
however, and in striking contrast to $\mathrm{PLC} \gamma_{2} \Delta 19-\mathrm{PH} 11$, there was no response of the mutant to cooling. $\mathrm{Y}^{509}$ and $\mathrm{F}^{510}$ of PLC $\gamma_{1}$ corresponds to $\mathrm{Y}^{495}$ and $\mathrm{C}^{496}$ of PLC $\gamma_{2}$. Most interestingly, alanine replacement of either one of the latter residues within the PLC $\gamma_{2} \Delta 19$ (carrying its own, authentic spPH domain), caused a distinct loss of the enzyme's response to cooling, replacement of both $\mathrm{Y}^{495}$ and $\mathrm{C}^{496}$ led to an almost complete loss of this response (Figs. 9D and S4B). These results indicate that a functional split PH domain, not necessarily the one genuinely contained in $\mathrm{PLC} \gamma_{2}$, is required with the context of the PLAID PLC $\gamma_{2}$ deletion mutants to mediate their activation by cool temperatures.

The observation that $\mathrm{PLC} \gamma_{2} \Delta \mathrm{SH}$, a mutant lacking the entire $\mathrm{SH} 2 \mathrm{n}-\mathrm{SH} 2 \mathrm{c}-\mathrm{SH} 3$ region, displays enhanced basal activity, but is largely insensitive to activation by cold is remarkable, because this mutant lacks all constituents thought to mediate autoinhibition of the enzyme (Fig. 8B). On the one hand, this finding clearly suggests that the activation pattern of the two PLAID mutants, PLC $\gamma_{2} \Delta 19$ and PLC $\gamma_{2} \Delta 20-22$, is distinct from a mere loss of autoinhibition, and indicates, by extension, that it is based on a specific molecular mechanism(s). On the other hand, the observation is rather puzzling, because cold activation appears to be, at the same time, dependent on and independent of specific constituents of the SH2n-SH2c-SH3 region. However, given the importance of the split PH domain for cold activation of PLC $\gamma_{2}$ emerging from the experiments shown in Fig. 9B and D, the possibility remained that activation by cold temperatures is sterically and/or conformationally restricted in the mutant PLC $\gamma_{2} \Delta \mathrm{SH}$ by the (artificial) covalent linkage between the two halves of the split PH domain (cf. Fig. 9C). To examine this possibility, we took advantage of earlier findings suggesting that PLC isozymes can be expressed as two independent polypeptide fragments containing either of the two catalytic subdomains, $\mathrm{X}$ and $\mathrm{Y}[35,36]$. Thus, $\mathrm{PLC} \gamma_{2} \Delta \mathrm{SH}$ was expressed either as a single polypeptide and as two separate chains, encompassing either of the two catalytic subdomains $\mathrm{X}^{\mathrm{PHn}}$ and $\mathrm{Y}^{\mathrm{PHc}}$, either one containing the corresponding half of the split $\mathrm{PH}$ domain, followed by functional analysis at $37{ }^{\circ} \mathrm{C}$ and $31{ }^{\circ} \mathrm{C}$. Figs. 10A and S5 show that expression of the N-terminal or the C-terminal half of PLC $\gamma_{2}$ did not lead to enhanced inositol phosphate formation. In marked contrast, when both halves, $\mathrm{X}^{\mathrm{PHn}}$ and $\mathrm{Y}^{\mathrm{PHc}}$, were coexpressed, basal inositol phosphate formation at $37{ }^{\circ} \mathrm{C}$ was markedly enhanced. More importantly, however, decreasing the incubation temperature to $31{ }^{\circ} \mathrm{C}$ caused a substantial enhancement of PLC activity, in striking contrast to cells expressing the $\Delta \mathrm{SH}$ deletion mutant of PLC $\gamma_{2}$, where no change in activity was observed. These results strongly suggest that the structural element(s) mediating cold activation of PLAID PLC $\gamma_{2}$ mutants reside outside the SH2n-SH2c-SH3 region and that its responsiveness to cool temperatures is blocked by covalent linkage between the two portions of the PLC $\gamma_{2}$ split PH domain.

To examine the requirement of the split $\mathrm{PH}$ domain in itself for cool-temperature-mediated activation of coexpressed $\mathrm{X}^{\mathrm{PHn}}$ and $\mathrm{Y}^{\mathrm{PHc}}$, the coding regions of the split $\mathrm{PH}$ domain halves were 
removed from the two fragments, resulting in fragments $\mathrm{X}$ and $\mathrm{Y}$. The two fragments were expressed

alone or together and functionally analyzed at $31{ }^{\circ} \mathrm{C}$ or $37{ }^{\circ} \mathrm{C}$. Most intriguingly, in contrast to cells expressing either $\mathrm{X}$ or $\mathrm{Y}$ alone, cells coexpressing fragments $\mathrm{X}$ and $\mathrm{Y}$ displayed a marked enhancement of inositol phosphate formation by lowering the incubation temperature to $31{ }^{\circ} \mathrm{C}$ (Fig. 10B). This enhancement was similar in extent as the one observed for $\mathrm{PLC} \gamma_{2} \Delta 20-22$ (approximately 32-fold versus 41-fold). Thus, although the split PH domain appears to control the cool temperature sensitivity of the PLAID PLC $\gamma_{2}$ mutants, it is not required per se for cool-temperature-mediated activation of the enzyme's core constituents. The expression of wild-type and $\triangle 20-22$ mutant PLC $\gamma_{2}$ as well as fragments $\mathrm{X}$ and $\mathrm{Y}$ was similar at $31^{\circ} \mathrm{C}$ and $37{ }^{\circ} \mathrm{C}$, respectively (Fig. S6).

\subsection{The PLAID PLC $\gamma_{2}$ mutants are resistant to activation by EGF receptors endogenously expressed in COS-7 cells.}

The rather puzzling concurrence of gain and apparent loss of function of PLC $\gamma_{2}$ in certain PLAID patient cells [19,37] prompted us to determine the effects of the two PLAID PLC $\gamma_{2}$ mutations on the response of the mutant enzymes to tyrosine kinase receptor activation. To this end, we made use of EGF receptor tyrosine kinases endogenously expressed in COS-7 cells and capable of both regulating several endogenous signalling functions and activating exogenous PLC $\gamma_{2}[38,39,17]$ and examined their ability to stimulate PLC $\gamma_{2}$-mediated inositol phosphate formation. Fig. 11 shows that addition of $100 \mathrm{ng} / \mathrm{ml}$ of EGF caused similar (approximately 12-fold) increases in wild-type PLC $\gamma_{2}$ activity at 37 ${ }^{\circ} \mathrm{C}$ and $31{ }^{\circ} \mathrm{C}$. In contrast, neither PLC $\gamma_{2} \Delta 20-22$ nor PLC $\gamma_{2} \Delta 19$ were affected by addition of EGF, regardless of whether the radiolabeling of cells and their treatment with EGF was done at $37{ }^{\circ} \mathrm{C}$ or 31 ${ }^{\circ} \mathrm{C}$. The inability of EGF to mediate PLC $\gamma_{2}$ PLAID mutant stimulation at $37{ }^{\circ} \mathrm{C}$ was not due to lack of available enzyme substrate, since the two mutants were markedly sensitive to activation by cooling to $31{ }^{\circ} \mathrm{C}$. Additional experiments (not shown) revealed that substrate depletion did also not occur in the presence of the mutant PLC $\gamma_{2}$ enzymes at $31^{\circ} \mathrm{C}$. Fig. S7 shows that the functional changes depicted in Fig. 11 were not due to changes of wild-type or mutant PLC $\gamma_{2}$ expression.

\section{Discussion}

The results presented in this work show that deletion of residues encoded by exons 19 and 20-22 from PLC $\gamma_{2}$ causes both a mild constitutive activation of inositol phosphate formation at $37{ }^{\circ} \mathrm{C}$ and a marked, several-hundred-fold enhancement of this activity in response to very small decreases in temperature upon expression of the mutant enzymes in intact cells. These functional responses are qualitatively and quantitatively similar, if not identical for both types of mutants. While the former changes are consistent with those reported earlier for transfected cells, the latter are much higher than 
the small increases in $\left[\mathrm{Ca}^{2+}\right]_{i}$ observed when peripheral blood B cells of PLAID patients are exposed to cold. In the latter case, differences to normal B cells were only observed at temperatures below 29 ${ }^{\circ} \mathrm{C}$, not exceeding a maximum of an about two-fold increase at $21{ }^{\circ} \mathrm{C}[19]$. The results shown here suggest that the primary defect of the mutant enzymes, i.e. sensitivity to stimulation by cool temperatures, emerges at temperatures only a few degrees below the normal body temperature. These findings are in agreement with clinical findings on patients with a deletion of exons 20-22, where only very subtle cooling, such as the one caused by a single tear rolling down the cheek of an affected family member at room temperature caused symptoms within one minute [20]. In additional experiments (not shown), we found that application of single drops of water (60 $\mu \mathrm{l})$ to human skin caused a transient, evaporative-heat-loss-mediated decrease in skin temperature by about $6{ }^{\circ} \mathrm{C}$. Of note, even at an ambient, comfortable temperature of $27{ }^{\circ} \mathrm{C}$, the temperature in many cutaneous and subcutaneous regions is already somewhat lower than the esophageal core temperature of $37{ }^{\circ} \mathrm{C}$ [40], such that only minimal further temperature decreases by evaporative heat loss may suffice to cause maximal PLC $\gamma_{2}$ activation. The considerable decrease of the stimulatory effect observed at temperatures below $31{ }^{\circ} \mathrm{C}$ (Fig. 3) may explain, together with the decrease in inositol phospholipid synthesis (Fig. 1D) - why PLAID patients are typically negative in the cold stimulation time test (CSTT), involving cooling with ice, and upon cold-water immersion [19,20]. Under these conditions, the cooled tissues may reside at the enzyme-activating temperatures only very transiently, i.e. too shortly for allowing effective activation mutant PLC $\gamma_{2}$. The time course of PLC $\gamma_{2}$ deletion mutant activation and its reversible nature closely matches the clinical observation on PLAID patients of an immediate onset of inflammatory symptoms upon evaporative skin cooling and a somewhat slower resolution of the symptoms developing over the course of 30 minutes of rewarming at room temperature [20]. Mouse $\mathrm{PLC} \gamma_{2}$ carrying a gain-of-function mutation, D993G, in the catalytic region, $\mathrm{PLC} \gamma_{2}{ }^{\mathrm{Ali} 5}$, and causing spontaneous autoinflammation and autoimmunity shows a similar, albeit less dramatic response to cold temperatures. This suggests that some of the lesions noticed in the affected animals, such as inflammation in superficial skin layers, may in fact be caused by further activation of PLC $\gamma_{2}{ }^{\mathrm{Ali}}$ by cool temperatures. An intriguing question to be clarified by future investigation is whether PLC $\gamma_{2}$ activated by other means, e.g. by other mutations [21] or by tyrosine phosphorylation, are also sensitive to cold temperatures.

Three mechanisms, not necessarily mutually exclusive, should be considered to explain the sensitivity of the PLC $\gamma_{2}$ mutants to cold temperatures in intact cells. First, other cold-sensitive molecules endogenously present in COS-7 cells - and, possibly, in mast cells - might indirectly cause activation of the mutants, e.g. via a soluble mediator or via altered protein-protein-interaction patterns. Second, the mutants may be specifically enabled to sense temperature-mediated changes in the physical properties of the plasma membrane phospholipid bilayer containing the enzyme's 
substrate(s). The third possibility is that an intrinsic conformational change is induced in mutant

PLC $\gamma_{2}$ by temperatures between $37{ }^{\circ} \mathrm{C}$ and $31{ }^{\circ} \mathrm{C}$. With regard to the first possibility, we would like to point out that, among the known cold-temperature-sensitive molecules, TRPA1, TRPM8, and TRPC5, the former two responded to cold temperatures only within lower temperature ranges [23] and endogenous expression of the latter two was not evident in COS-7 cells [39-44]. While we cannot at present formally exclude the second mechanism, we note that the phase transition temperature $\left(T_{\mathrm{m}}\right)$ of dipalmitoylphosphatidyl-choline (the most representative lipid in model membrane studies) in artificial phospholipid membrane vesicles is $41^{\circ} \mathrm{C}$ [45] and thus outside the range of temperatures mediating activation of the PLC $\gamma_{2}$ mutants. However, the behavior of native plasma membranes may be different. More experimentation is required to elucidate the exact nature of the interplay among the mechanisms potentially involved in cool-temperature-mediated activation of PLAID PLC $\gamma_{2}$ mutants under conditions of physiological PtdIns $(4,5) P_{2}$ presentation as a substrate to PLC $\gamma_{2}$ in native plasma membranes of intact cells.

If the structural element mediating, directly or indirectly, the sensitivity of PLC $\gamma_{2}$ deletion mutants to cool temperatures in intact cells resides on the enzyme itself, the simplest interpretation of the results would be that removal of the portions encoded by exons 19 or 20-22 causes a loss of an autoinhibition, since the two regions overlap with regions identified before $[11,12,31,32]$ or in this study (cf. Fig. 8) to be autoinhibitory at $37{ }^{\circ} \mathrm{C}$. However, the results shown in Fig. 8 suggest that constitutive activity at $37{ }^{\circ} \mathrm{C}$ and stimulation by cool temperatures are not necessarily correlated with each other. While this would not formally exclude a loss of autoinhibition, acquisition of an autostimulatory mechanism sensitive to decreasing temperatures appears as an alternative explanation. At first glance, a structural element residing in the SH domain region of PLC $\gamma_{2}$ would appear a likely candidate for triggering such a stimulation. However, the deletion experiments shown in Fig. 8A revealed that none of the constituents of the entire $\mathrm{SH} 2 \mathrm{n}-\mathrm{SH} 2 \mathrm{c}-\mathrm{SH} 3$ region is specifically required for enzyme activation by cool temperatures and that even a deletion mutant lacking both of the short partial repeats shared between the two SH2 domains ( $\left.\mathrm{PLC} \gamma_{2} \Delta \mathrm{SH} 2 \mathrm{nSH} 2 \mathrm{c}\right)$ is activated by incubation at $31{ }^{\circ} \mathrm{C}$.

Thus, the possibility remains that cool-temperature-sensitivity in intact cells resides either in the split PH domain or in the remainder of the enzyme, and that this sensitivity is specifically kept in check by either the intact, native $\mathrm{SH}$ region, by its $\mathrm{SH} 2 \mathrm{c}-\mathrm{SH} 3$ portion, or by a covalent linkage between the two split PH domain halves. At first sight, the fact that the cool-temperature-sensitivity is lost when non-homonymous split PH domain halves are present in PLC $\gamma_{2}$, when the tertiary structure of the $\mathrm{PH}$ domain is disrupted by the $\mathrm{W}^{899} \mathrm{~A}$ mutation [17], or when two residues of its $\mathrm{N}$-terminal half, $\mathrm{Y}^{509}$ and $\mathrm{F}^{510}$, are replaced by alanine residues, supports an important regulatory role of the split 
PH domain. The latter residues have recently been mapped, by NMR titration analysis, to the interface of spPH and SH2c and suggested to be involved in SH2c-mediated autoinhibition [11]. The fact that removal of the two residues is also effective in the absence of almost the entire $\mathrm{SH} 2 \mathrm{c}$ domain in PLC $\gamma_{2} \Delta 19$ is difficult to reconcile with an important role of a spPH-SH2c interaction in cooltemperature regulation of mutant PLC $\gamma_{2}$. However, chemical shift perturbations observed in NMR experiments probing protein-protein-interactions may imply structural reorientation of residues upon binding rather than direct involvement in the interaction surface [46]. This and the weak interaction between the two domains observed before [32] is consistent with additional functions of these two spPH domain residues. Interestingly, $\mathrm{Y}^{509}$ of PLC $\gamma_{1}$ corresponds to $\mathrm{Y}^{495}$ of PLC $\gamma_{2}$, which is mutated to $\mathrm{C}^{495}$ in PLC $\gamma_{2}{ }^{\text {Ali14 }}$ and the double mutant PLC $\gamma_{2}{ }^{\text {Alis/Ali14 }}$. The considerable stimulatory effect of the Ali14 mutation on the stimulation of PLC $\gamma_{2}{ }^{\mathrm{Ali5}}$ by cool temperature ( $c f$. Fig. 7, left panel) suggests there may loss- and gain-of function mutations in this locus with regard to cool-temperature sensitivity of PLC $\gamma_{2}$. Collectively, the results discussed up until this point suggest a new regulatory role of the PLC $\gamma_{2}$ split PH domain in mutant enzyme activation by cool temperatures. However, and quite surprisingly, the results shown in Fig. 10B strongly suggest that the split PH domain is not required as such for cool-temperature-mediated activation of mutant PLC $\gamma_{2}$.

A model summarizing and schematically conceptualizing the responses of the PLAID PLC $\gamma_{2}$ and their further truncated variants to cooling from $37{ }^{\circ} \mathrm{C}$ to $31^{\circ} \mathrm{C}$ is shown in Fig. $10 \mathrm{C}-\mathrm{H}$. We would like to point out that these schematic views are limited by the fact that they solely rely on measurements of PLC $\gamma_{2}$ enzyme activity and that they await confirmation by direct structural analysis or by other types of independent experimental evidence. Nevertheless, at least for the PLAID PLC $\gamma_{2}$ mutants, our results suggest a dynamic, regulatory role of spPH in controlling the cool temperature response of these mutants. It is tempting to speculate that the interaction of $\mathrm{spPH}$ with activated Rac is lost during that response ( $c f$. Fig. 9A). Of interest, the spPH domains of PLC $\gamma$ have been suggested before to undergo dynamic changes leading to formation of intermolecular $\mathrm{PH}$ domains regulating agonist-mediated $\mathrm{Ca}^{2+}$ entry into cells [47-49], although this has remained somewhat controversial [9].

The marked sensitivity of the two PLAID PLC $\gamma_{2}$ mutants to cool temperatures may explain the gain-of-function symptoms observed in PLAID patients such as cold urticaria $[19,20]$ and skin granulomas [50]. They are likely to be caused by cold-temperature-mediated activation of PLC $\gamma_{2}$ in cutaneous mast cells, neutrophils, and monocytes, where the enzyme plays important roles in FceR-, integrin-, and Fc $\gamma$ R-mediated inflammatory skin reactions [51,52]. Symptomatic allergic and autoimmune disease, occurring in $56 \%$ and $26 \%$ of PLAID patients and potentially precipitated by enhanced basal $\left(37^{\circ} \mathrm{C}\right)$ or cool-temperature-mediated activation of PLC $\gamma_{2}$ in mast and other immune cells, may also fall into this category. The latter may include B cells and dendritic cells. Loss-of- 
function symptoms, such as antibody deficiency, recurrent sinopulmonary infection, and symptoms resembling certain forms of common variable immunodeficiency [53], detected in $75 \%, 44 \%$, and 11 $\%$, respectively, of PLAID patients, are more difficult to explain. However, at least in the heterologous expression system used here, the two PLAID mutants appeared to be resistant to stimulation by activation of endogenous EGF receptors, both at $\operatorname{cool}\left(31^{\circ} \mathrm{C}\right)$ and physiologic $\left(37^{\circ} \mathrm{C}\right)$ temperatures (Fig. 11). These results suggest that resistance to receptor stimulation may, at least in part, be an intrinsic property of the PLAID mutant enzymes themselves or of components endogenously present in COS-7 cells. This is an important issue, since we expect, but certainly need to prove, that observations reported herein in transfected COS-7 cells will be relevant for, e.g., B cells with endogenous PLC $\gamma_{2}$ expression. As for the B cell context, recent results suggest that the $\mathrm{SH} 2 \mathrm{c}$ domain of PLC $\gamma_{2}$ plays a critical role in stabilizing the early BCR signaling complex, such that PLC $\gamma_{2}$ mutants lacking a functional cSH2 domain such as $\operatorname{PLC} \gamma_{2} \Delta 19$ and PLC $\gamma_{2} \Delta 20-22$ may act in a dominantnegative manner to prevent the formation of stable, signaling-competent BCR clusters consisting of Syk, BLNK, Btk, and PLC $\gamma_{2}$ [37]. Furthermore, association of BCR with the inhibitor of $\mathrm{Ca}^{2+}$ signaling, Cbl, was dysregulated in B cells expressing PLC $\gamma_{2} \Delta 20-22$. These results notwithstanding, it is well known that constant antigen receptor occupancy and signaling, including an increased basal concentration of intracellular $\mathrm{Ca}^{2+}\left(\left[\mathrm{Ca}^{2+}\right]_{\mathrm{i}}^{\text {basal }}\right)$ mediates maintenance of $\mathrm{B}$ cell anergy, which is characterized by the persistence in the periphery of B cells unresponsive to immunogen [54-58]. A defect leading to impaired BCR-induced increases in $\left[\mathrm{Ca}^{2+}\right]_{\mathrm{i}}$ has been described for type Ia patients with common variable immunodeficiency (Freiburg classification) and shown to be associated with a reduction in $\operatorname{IgD} \operatorname{IgM}{ }^{-} \mathrm{CD}^{2} 7^{+}$class-switched memory B cells, hypogammaglobulinemia, and autoimmune dysregulation [59], all of which are observed in PLAID patients. In normal B cells, anergy is rapidly reversed after dissociation of self antigen, e.g. by using hapten competition, and these cells regain antigen responsiveness [52]. In PLAID B cells, $\left[\mathrm{Ca}^{2+}\right]_{\mathrm{i}}^{\text {basal }}$ would be expected to be elevated, either chronically due to constitutively enhanced PLC $\gamma_{2}$ mutant activity at $37^{\circ} \mathrm{C}$ or intermittently during passage through cool body regions of the patient, causing reversible reductions of B cell responsiveness. Some of the trans-inhibitory mechanisms observed in anergic B cells, inhibiting the signaling of G-protein-coupled chemoattractant receptors [59], may be operative even in other immune cells, such as neutrophils, potentially contributing to the loss-of-immune-response phenotype, e.g. reduced directed migration, observed in PLAID patients [50]. Anergic mechanisms are also in effect in human mast cells in response to persistent cell activation, changing the cells' set points for further activation [60]. These mechanisms could explain why cold urticaria is not generally observed in PLAID patients in all regions where the temperature on the skin should be low enough to cause mutant PLC $\gamma_{2}$ activation [37]. In human skin, most mast cells are present immediately below the dermo-epidermal junction [61] and are, hence, exposed to temperatures very similar to those 
prevailing on the skin. Small negative deviations from the set point temperature developing over short time periods may be the relevant trigger of cold urticarial lesions in PLAID patients.

An interesting question raised by the dramatic functional consequence of the PLCG2 deletions observed in PLAID patients is whether the genomic regions encompassing exons 19 through 22 are subject to alternative processing of pre-messenger RNA, leading to exclusion of residues encoded by exons 19 and/or 20-22 from the mature PLC $\gamma_{2}$ protein. This appears as an important issue, since almost $90 \%$ of human genes undergo alternative splicing with a minor isoform frequency of $15 \%$ or more, with variations, intraindividually, between tissues and between individuals [62]. Alternative RNA splicing has been shown to be pervasive across immune system lineages [63]. Intriguingly, one of the two changes observed for PLC $\gamma_{2}$-encoding mRNA in mouse $\mathrm{CD} 19^{+} \mathrm{B}$ cells is skipping of exons 20-22. The marked similarity between the genomic organization of the mouse Plcg2 and the human PLCG2 genes raises the possibility that this alteration may also exist in humans to convey cooltemperature-sensitivity to $\mathrm{PLC} \gamma_{2}$ in certain cell types and/or particular individuals. Cold environmental temperatures are associated with a number of human disease states, including, e.g., exercise-induced asthma and acute cold-induced coronary events [64,65]. Cold-mediated activation of variant PLC $\gamma_{2}$ in these states, e.g. in mast cells, appears as an intriguing possibility.

\section{Conclusions}

(i) The two human PLAID PLC $\gamma_{2}$ mutants PLC $\gamma_{2} \Delta 19$ and PLC $\gamma_{2} \Delta 20-22$ are strongly (> 100-fold), rapidly, and reversibly activated in intact cells by cooling the cells by only a few degrees. (ii) The underlying mechanism(s) is distinct from a mere loss of SH-region-mediated autoinhibition and dependent on both the integrity and the pliability of the spPH domain. (iii) The results suggest a new mechanism of PLC $\gamma$ activation with unique thermodynamic features and assign a novel regulatory role to its spPH domain.

Supplementary data to this article can be found online. 


\title{
Funding
}

Work in P.G.'s laboratory is funded by grants from the Deutsche Forschungsgemeinschaft (DFG) (SFB 1074, TP A8). The contribution of J.K. and H.K. was supported by project Z1 of SFB 1074. A.S. was a fellow of the DFG Research Training Group GRK1041 and the International Graduate School in Molecular Medicine Ulm (IGradU) funded within the Excellence Initiative of the German Federal and State Governments.

\author{
Author contributions \\ A.S., C.W., M.W., J.H., P.V., J.K., D.F., H.K., and G.H. performed the experiments and analyzed \\ the data. P.G. provided overall direction and wrote the manuscript with input from J.M. and the other \\ authors.
}

\section{Conflict of interest}

The authors declare that they have no conflicts of interest with the contents of this article.

\section{Acknowledgements}

The expert technical assistance of Susanne Gierschik and Norbert Zanker is greatly appreciated. Special gratitude goes to Armin Buehler for custom designing and constructing the incubation chambers. We are grateful to Drs. Bertil Hille, Tibor Rohacs, Eleonora Zakharian, Hal M. Hoffman, and Nicholas G. Kounis, and to Elisabeth Hermkes for very helpful discussions. 


\section{References}

1. G. Kadamur, E.M. Ross, Mammalian phospholipase C, Annu. Rev. Physiol. 75 (2013) 127-154.

2. M.R. Jezyk, J.T. Snyder, S. Gershberg, D.K. Worthylake, T.K. Harden, J. Sondek, Crystal structure of Rac1 bound to its effector phospholipase C- $\beta 2$, Nat. Struct. Mol. Biol. 13 (2006) 1135-1140.

3. S.N. Hicks, M.R. Jezyk, S. Gershburg, J.P. Seifert, T.K. Harden, J. Sondek, General and versatile autoinhibition of PLC isozymes, Mol. Cell 31 (2008) 383-394.

4. G.L. Waldo, T.K. Ricks, S.N. Hicks, M.L. Cheever, T. Kawano, K. Tsuboi, X. Wang, C. Montell, T. Kozasa, J. Sondek, T.K. Harden, Kinetic scaffolding mediated by a phospholipase C- $\beta$ and $\mathrm{G}_{\mathrm{q}}$ signaling complex, Science 330 (2010) 974-980.

5. A.M. Lyon, V.M. Tesmer, V.D. Dhamsania, D.M. Thal, J. Gutierrez, S. Chowdhury, K.C. Suddala, J.K. Northup, J.J. Tesmer, An autoinhibitory helix in the C-terminal region of phospholipase C- $\beta$ mediates $G \alpha_{q}$ activation, Nat. Struct. Mol. Biol. 18 (2011) 999-1005.

6. J.I. Wilde, S.P. Watson, Regulation of phospholipase $\mathrm{C} \gamma$ isoforms in haematopoietic cells: why one, not the other? Cell. Signal. 13 (2001) 691-701.

7. T. Piechulek, T. Rehlen, C. Walliser, P. Vatter, B. Moepps, P. Gierschik, Isozyme-specific stimulation of phospholipase C- $\gamma_{2}$ by Rac GTPases, J. Biol. Chem. 280 (2005) 38923-38931.

8. C. Walliser, K. Tron, K. Clauss, O. Gutman, A.Y. Kobitski, M. Retlich, A. Schade, C. Rocker, Y.I. Henis, G.U. Nienhaus, P. Gierschik, Rac-mediated stimulation of phospholipase C- $\gamma_{2}$ amplifies B cell receptor-induced calcium signaling, J. Biol. Chem. (2015)

9. W. Wen, J. Yan, M. Zhang, Structural characterization of the split pleckstrin homology domain in phospholipase C- $\gamma 1$ and its interaction with TRPC3, J. Biol. Chem. 281 (2006) 12060-12068.

10. T.D. Bunney, O. Opaleye, S.M. Roe, P. Vatter, R.W. Baxendale, C. Walliser, K.L. Everett, M.B. Josephs, C. Christow, F. Rodrigues-Lima, P. Gierschik, L.H. Pearl, M. Katan, Structural insights into formation of an active signaling complex between Rac and phospholipase C- $\gamma_{2}$, Mol. Cell 34 (2009) 223-233.

11. T.D. Bunney, D. Esposito, C. Mas-Droux, E. Lamber, R.W. Baxendale, M. Martins, A. Cole, D. Svergun, P.C. Driscoll, M. Katan, Structural and functional integration of the PLC $\gamma$ interaction domains critical for regulatory mechanisms and signaling deregulation, Structure 20 (2012) 20622075 .

12. N. Hajicek, T.H. Charpentier, J.R. Rush, T.K. Harden, J. Sondek, Autoinhibition and phosphorylation-induced activation of phospholipase C- $\gamma$ isozymes, Biochemistry 52 (2013) 4810-4819.

13. S. Behjati, P.S. Tarpey, H. Sheldon, I. Martincorena, L.P. Van, G. Gundem, D.C. Wedge, M. Ramakrishna, S.L. Cooke, N. Pillay, H.K. Vollan, E. Papaemmanuil, H. Koss, T.D. Bunney, C. Hardy, O.R. Joseph, S. Martin, L. Mudie, A. Butler, J.W. Teague, M. Patil, G. Steers, Y. Cao, C. 
Gumbs, D. Ingram, A.J. Lazar, L. Little, H. Mahadeshwar, A. Protopopov, G.A. Al Sannaa, S.

Seth, X. Song, J. Tang, J. Zhang, V. Ravi, K.E. Torres, B. Khatri, D. Halai, I. Roxanis, D. Baumhoer, R. Tirabosco, M.F. Amary, C. Boshoff, U. McDermott, M. Katan, M.R. Stratton, P.A. Futreal, A.M. Flanagan, A. Harris, P.J. Campbell, Recurrent PTPRB and PLCG1 mutations in angiosarcoma, Nat. Genet. 46 (2014) 376-379.

14. J.P. Vaqué, G. Gomez-Lopez, V. Monsalvez, I. Varela, N. Martinez, C. Perez, O. Dominguez, O. Grana, J.L. Rodriguez-Peralto, S.M. Rodriguez-Pinilla, C. Gonzalez-Vela, M. Rubio-Camarillo, E. Martin-Sanchez, D.G. Pisano, E. Papadavid, T. Papadaki, L. Requena, J.A. Garcia-Marco, M. Mendez, M. Provencio, M. Hospital, D. Suarez-Massa, C. Postigo, S.D. San, M. Lopez-Hoyos, P.L. Ortiz-Romero, M.A. Piris, M. Sanchez-Beato, PLCG1 mutations in cutaneous T-cell lymphomas, Blood 123 (2014) 2034-2043.

15. P. Yu, R. Constien, N. Dear, M. Katan, P. Hanke, T.D. Bunney, S. Kunder, L. QuintanillaMartinez, U. Huffstadt, A. Schroder, N.P. Jones, T. Peters, H. Fuchs, M.H. de Angelis, M. Nehls, J. Grosse, P. Wabnitz, T.P. Meyer, K. Yasuda, M. Schiemann, C. Schneider-Fresenius, W. Jagla, A. Russ, A. Popp, M. Josephs, A. Marquardt, J. Laufs, C. Schmittwolf, H. Wagner, K. Pfeffer, G.C. Mudde, Autoimmunity and inflammation due to a gain-of-function mutation in phospholipase $\mathrm{C} \gamma 2$ that specifically increases external $\mathrm{Ca}^{2+}$ entry, Immunity 22 (2005) 451-465.

16. K. Abe, H. Fuchs, A. Boersma, W. Hans, P. Yu, S. Kalaydjiev, M. Klaften, T. Adler, J. CalzadaWack, I. Mossbrugger, B. Rathkolb, J. Rozman, C. Prehn, M. Maraslioglu, Y. Kametani, S. Shimada, J. Adamski, D.H. Busch, I. Esposito, M. Klingenspor, E. Wolf, W. Wurst, V. GailusDurner, M. Katan, S. Marschall, D. Soewarto, S. Wagner, M.H. de Angelis, A novel $N$-ethyl- $N$ nitrosourea-induced mutation in Phospholipase $C \gamma 2$ causes inflammatory arthritis, metabolic defects, and male infertility in vitro in a murine model, Arthritis Rheum. 63 (2011) 1301-1311.

17. K.L. Everett, T.D. Bunney, Y. Yoon, F. Rodrigues-Lima, R. Harris, P.C. Driscoll, K. Abe, H. Fuchs, M.H. de Angelis, P. Yu, W. Cho, M. Katan, Characterization of phospholipase C $\gamma$ enzymes with gain-of-function mutations, J. Biol. Chem. 284 (2009) 23083-23093.

18. M. Elvers, R. Pozgaj, I. Pleines, F. May, M.J. Kuijpers, J.M. Heemskerk, P. Yu, B. Nieswandt, Platelet hyperreactivity and a prothrombotic phenotype in mice with a gain-of-function mutation in phospholipase C $\gamma 2$, J. Thromb. Haemost. 8 (2010) 1353-1363.

19. M.J. Ombrello, E.F. Remmers, G. Sun, A.F. Freeman, S. Datta, P. Torabi-Parizi, N. Subramanian, T.D. Bunney, R.W. Baxendale, M.S. Martins, N. Romberg, H. Komarow, I. Aksentijevich, H.S. Kim, J. Ho, G. Cruse, M.Y. Jung, A.M. Gilfillan, D.D. Metcalfe, C. Nelson, M. O'Brien, L. Wisch, K. Stone, D.C. Douek, C. Gandhi, A.A. Wanderer, H. Lee, S.F. Nelson, K.V. Shianna, E.T. Cirulli, D.B. Goldstein, E.O. Long, S. Moir, E. Meffre, S.M. Holland, D.L. Kastner, M. Katan, H.M. Hoffman, J.D. Milner, Cold urticaria, immunodeficiency, and autoimmunity related to PLCG2 deletions, N. Engl. J. Med. 366 (2012) 330-338.

20. C. Gandhi, C. Healy, A.A. Wanderer, H.M. Hoffman, Familial atypical cold urticaria: description of a new hereditary disease, J. Allergy Clin. Immunol. 124 (2009) 1245-1250.

21. Q. Zhou, G.S. Lee, J. Brady, S. Datta, M. Katan, A. Sheikh, M.S. Martins, T.D. Bunney, B.H. Santich, S. Moir, D.B. Kuhns, D.A. Priel, A. Ombrello, D. Stone, M.J. Ombrello, J. Khan, J.D. Milner, D.L. Kastner, I. Aksentijevich, A hypermorphic missense mutation in PLCG2, encoding phospholipase $\mathrm{C} \gamma 2$, causes a dominantly inherited autoinflammatory disease with immunodeficiency, Am. J. Hum. Genet. 91 (2012) 713-720.

22. B. Boisson, P. Quartier, J.L. Casanova, Immunological loss-of-function due to genetic gain-offunction in humans: autosomal dominance of the third kind, Curr. Opin. Immunol. 32 (2015) 90105. 
23. D.E. Clapham, C. Miller, A thermodynamic framework for understanding temperature sensing by transient receptor potential (TRP) channels, Proc. Natl. Acad. Sci. U. S. A. 108 (2011) 1949219497.

24. C. Walliser, M. Retlich, R. Harris, K.L. Everett, M.B. Josephs, P. Vatter, D. Esposito, P.C. Driscoll, M. Katan, P. Gierschik, T.D. Bunney, Rac regulates its effector phospholipase $\mathrm{C} \gamma_{2}$ through interaction with a split pleckstrin homology domain, J. Biol. Chem. 283 (2008) 3035130362.

25. G.T. Spierenburg, F.T. Oerlemans, J.P. van Laarhoven, C.H. de Bruyn, Phototoxicity of N-2hydroxyethylpiperazine- $N$ '-2-ethanesulfonic acid-buffered culture media for human leukemic cell lines, Cancer Res. 44 (1984) 2253-2254.

26. B. Hille, Ion Channels of Excitable Membranes, third ed., Sinauer Associates, Sunderland, USA, 2001.

27. S.L. Meyer, Propagation of error and least squares, in: Data Analysis for Scientists and Engineers, Peer Management Consultants, Evanston, USA, 1975, pp. 39-48.

28. S.B. Lee, A.K. Rao, K.H. Lee, X. Yang, Y.S. Bae, S.G. Rhee, Decreased expression of phospholipase C- $\beta 2$ isozyme in human platelets with impaired function, Blood 88 (1996) 16841691.

29. R. Milkman, B. Hille, Analysis of some temperature effects on Drosophila pupae, Biol. Bull. 131 (1966) 331-345.

30. Y. Homma, T. Takenawa, Inhibitory effect of $\operatorname{src}$ homology (SH) 2/SH3 fragments of phospholipase $\mathrm{C}-\gamma$ on the catalytic activity of phospholipase $\mathrm{C}$ isoforms: identification of a novel phospholipase C inhibitor region, J. Biol. Chem. 267 (1992) 21844-21849.

31. K.L. Everett, A. Buehler, T.D. Bunney, A. Margineanu, R.W. Baxendale, P. Vatter, M. Retlich, C. Walliser, H.B. Manning, M.A. Neil, C. Dunsby, P.M. French, P. Gierschik, M. Katan, Membrane environment exerts an important influence on Rac-mediated activation of phospholipase C $\gamma 2$, Mol. Cell. Biol. 31 (2011) 1240-1251.

32. A. Gresset, S.N. Hicks, T.K. Harden, J. Sondek, Mechanism of phosphorylation-induced activation of phospholipase C- $\gamma$ isozymes, J. Biol. Chem. 285 (2010) 35836-35847.

33. P.J. Parker, B.A. Hemmings, P. Gierschik, PH domains and phospholipases - a meaningful relationship? Trends Biochem. Sci. 19 (1994) 54-55.

33. K. DeBell, L. Graham, I. Reischl, C. Serrano, E. Bonvini, B. Rellahan, Intramolecular regulation of phospholipase C- $\gamma 1$ by its C-terminal Src homology 2 domain, Mol. Cell. Biol. 27 (2007) 854863.

34. D.A. Horstman, K. DeStefano, G. Carpenter, Enhanced phospholipase C- $\gamma 1$ activity produced by association of independently expressed $\mathrm{X}$ and $\mathrm{Y}$ domain polypeptides, Proc. Natl. Acad. Sci. U. S. A. 93 (1996) 7518-7521.

36. W. Zhang, E.J. Neer, Reassembly of phospholipase C- $\beta_{2}$ from separated domains: analysis of basal and G protein-stimulated activities, J. Biol. Chem. 276 (2001) 2503-2508.

37. J. Wang, H. Sohn, G. Sun, J.D. Milner, S.K. Pierce, The autoinhibitory C-terminal SH2 domain of phospholipase C- $\gamma 2$ stabilizes B cell receptor signalosome assembly, Sci. Signal. 7 (2014) ra89. 
38. O.A. Coso, M. Chiariello, J.C. Yu, H. Teramoto, P. Crespo, N. Xu, T. Miki, J.S. Gutkind, The small GTP-binding proteins Rac1 and Cdc42 regulate the activity of the JNK/SAPK signaling pathway, Cell 81 (1995) 1137-1146.

39. M. Matsuda, H.F. Paterson, R. Rodriguez, A.C. Fensome, M.V. Ellis, K. Swann, M. Katan, Real time fluorescence imaging of PLC gamma translocation and its interaction with the epidermal growth factor receptor, J. Cell Biol. 153 (2001) 599-612.

40. P. Webb, Temperatures of skin, subcutaneous tissue, muscle and core in resting men in cold, comfortable and hot conditions, Eur. J. Appl. Physiol. Occup. Physiol. 64 (1992) 471-476.

41. A. Riccio, A.D. Medhurst, C. Mattei, R.E. Kelsell, A.R. Calver, A.D. Randall, C.D. Benham, M.N. Pangalos, mRNA distribution analysis of human TRPC family in CNS and peripheral tissues, Mol. Brain Res. 109 (2002) 95-104.

42. P. Varnai, B. Thyagarajan, T. Rohacs, T. Balla, Rapidly inducible changes in phosphatidylinositol 4,5-bisphosphate levels influence multiple regulatory functions of the lipid in intact living cells, J. Cell Biol. 175 (2006) 377-382.

43. B.T. Kawasaki, Y. Liao, L. Birnbaumer, Role of $S r c$ in C3 transient receptor potential channel function and evidence for a heterogeneous makeup of receptor- and store-operated $\mathrm{Ca}^{2+}$ entry channels, Proc. Natl. Acad. Sci. U. S. A. 103 (2006) 335-340.

44. F. Mahieu, G. Owsianik, L. Verbert, A. Janssens, S.H. De, B. Nilius, T. Voets, TRPM8independent menthol-induced $\mathrm{Ca}^{2+}$ release from endoplasmic reticulum and Golgi, J. Biol. Chem. 282 (2007) 3325-3336.

45. J.R. Silvius, Thermotropic phase transitions of pure lipids in model membranes and their modulation by membrane proteins, in: J.C. Jost, O.H. Griffith (Eds.), Lipid-Protein Interactions, John Wiley and Sons, New York, USA, 1982, pp. 239-281.

46. M.R. O'Connell, R. Gamsjaeger, J.P. Mackay, The structural analysis of protein-protein interactions by NMR spectroscopy, Proteomics 9 (2009) 5224-5232.

47. R.L. Patterson, D.B. van Rossum, D.L. Ford, K.J. Hurt, S.S. Bae, P.G. Suh, T. Kurosaki, S.H. Snyder, D.L. Gill, Phospholipase C- $\gamma$ is required for agonist-induced $\mathrm{Ca}^{2+}$ entry, Cell 111 (2002) 529-541.

48. D.B. van Rossum, R.L. Patterson, S. Sharma, R.K. Barrow, M. Kornberg, D.L. Gill, S.H. Snyder, Phospholipase $\mathrm{C} \gamma 1$ controls surface expression of TRPC 3 through an intermolecular PH domain, Nature 434 (2005) 99-104.

49. G. Caraveo, D.B. van Rossum, R.L. Patterson, S.H. Snyder, S. Desiderio, Action of TFII-I outside the nucleus as an inhibitor of agonist-induced calcium entry, Science 314 (2006) 122-125.

50. O.M. Aderibigbe, D.L. Priel, C.C. Lee, M.J. Ombrello, V.H. Prajapati, M.G. Liang, J.J. Lyons, D.B. Kuhns, E.W. Cowen, J.D. Milner, Distinct cutaneous manifestations and cold-induced leukocyte activation associated with PLCG2 mutations, JAMA Dermatol. 151 (2015) 627-634.

51. R. Wen, S.T. Jou, Y. Chen, A. Hoffmeyer, D. Wang, Phospholipase C $\gamma 2$ is essential for specific

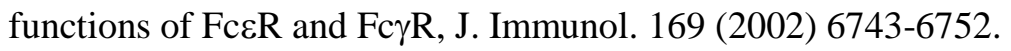


52. Z. Jakus, E. Simon, D. Frommhold, M. Sperandio, A. Mocsai, Critical role of phospholipase C $\gamma 2$ in integrin and Fc receptor-mediated neutrophil functions and the effector phase of autoimmune arthritis, J. Exp. Med. 206 (2009) 577-593.

53. U. Salzer, K. Warnatz, H.H. Peter, Common variable immunodeficiency - an update, Arthritis Res. Ther. 14 (2012) 223.

54. S.B. Gauld, R.J. Benschop, K.T. Merrell, J.C. Cambier, Maintenance of B cell anergy requires constant antigen receptor occupancy and signaling, Nat. Immunol. 6 (2005) 1160-1167.

55. J.I. Healy, R.E. Dolmetsch, L.A. Timmerman, J.G. Cyster, M.L. Thomas, G.R. Crabtree, R.S. Lewis, C.C. Goodnow, Different nuclear signals are activated by the B cell receptor during positive versus negative signaling, Immunity. 6 (1997) 419-428.

56. R.J. Benschop, K. Aviszus, X. Zhang, T. Manser, J.C. Cambier, L.J. Wysocki, Activation and anergy in bone marrow B cells of a novel immunoglobulin transgenic mouse that is both hapten specific and autoreactive, Immunity 14 (2001) 33-43.

57. J. Zikherman, R. Parameswaran, A. Weiss, Endogenous antigen tunes the responsiveness of naive B cells but not T cells, Nature 489 (2012) 160-164.

58. C. Foerster, N. Voelxen, M. Rakhmanov, B. Keller, S. Gutenberger, S. Goldacker, J. Thiel, S. Feske, H.H. Peter, K. Warnatz, B cell receptor-mediated calcium signaling is impaired in B lymphocytes of type Ia patients with common variable immunodeficiency, J. Immunol. 184 (2010) 7305-7313.

59. A. Brauweiler, K. Merrell, S.B. Gauld, J.C. Cambier, Acute and chronic exposure of immature B cells to antigen leads to impaired homing and SHIP1-dependent reduction in stromal cell-derived factor-1 responsiveness, J. Immunol. 178 (2007) 3353-3357.

60 D.W. MacGlashan, Jr., Self-termination/anergic mechanisms in human basophils and mast cells, Int. Arch. Allergy Immunol. 150 (2009) 109-121.

61. T. Cowen, P. Trigg, R.A. Eady, Distribution of mast cells in human dermis: development of a mapping technique, Br. J. Dermatol. 100 (1979) 635-640.

62. E.T. Wang, R. Sandberg, S. Luo, I. Khrebtukova, L. Zhang, C. Mayr, S.F. Kingsmore, G.P. Schroth, C.B. Burge, Alternative isoform regulation in human tissue transcriptomes, Nature 456 (2008) 470-476.

63. A. Ergun, G. Doran, J.C. Costello, H.H. Paik, J.J. Collins, D. Mathis, C. Benoist, Differential splicing across immune system lineages, Proc. Natl. Acad. Sci. U. S. A. 110 (2013) 14324-14329.

64. K.-H. Carlsen, K.C.L. Carlsen, Exercise-induced asthma, Paediatr. Respir. Rev. 3 (2002) 154160.

65. P.D. Thompson, B.A. Franklin, G.J. Balady, S.N. Blair, D. Corrado, N.A. Estes, III, J.E. Fulton, N.F. Gordon, W.L. Haskell, M.S. Link, B.J. Maron, M.A. Mittleman, A. Pelliccia, N.K. Wenger, S.N. Willich, F. Costa, Exercise and acute cardiovascular events placing the risks into perspective: a scientific statement from the American Heart Association Council on Nutrition, Physical Activity, and Metabolism and the Council on Clinical Cardiology, Circulation 115 (2007) 2358-2368.

66. S.L. Meyer, Propagation of error and least squares, in: Data Analysis for Scientists and Engineers, Peer Management Consultants, Evanston, USA, 1975, pp. 39-48. 


\section{Figure legends}

Fig. 1. The PLC $\gamma_{2}$ deletion mutants PLC $\gamma_{2} \Delta 19$ and PLC $\gamma_{2} \Delta 20-22$ are specifically activated by cool temperatures. (A) Domain organization of the PLC $\gamma$ isoforms. The positions of the two deletions $\Delta 19$ and $\Delta 20-22$ are indicated. $a a$, amino acids. (B) COS-7 cells were transfected with $500 \mathrm{ng}$ each per well of either empty vector ( $\boldsymbol{\square})$, or vector encoding either wild-type $\operatorname{PLC} \gamma_{2}(\bullet), \operatorname{PLC} \gamma_{2} \Delta 19$ ( $\left.\boldsymbol{\nabla}\right)$, or PLC $\gamma_{2} \Delta 20-22$ ( $\Delta$ ). Twenty-four hours after transfection, the cells were incubated for $20 \mathrm{~h}$ with myo$\left[2-{ }^{3} \mathrm{H}\right]$ inositol at the indicated temperatures and inositol phosphate formation was then determined. The levels of inositol phosphate formation at $37{ }^{\circ} \mathrm{C}$ are shown in expanded scale on the right vertical axis (open symbols). (C) Expression of wild-type and mutant PLC $\gamma_{2}$ isozymes in the experiment shown in Fig. 1B. Cells from one well each were washed once with $0.2 \mathrm{ml}$ of Dulbecco's PBS and then lysed by addition of $100 \mu 1$ of SDS-PAGE sample preparation buffer. The samples were subjected to SDSPAGE and immunoblotting was performed using an antibody reactive against the c-Myc epitope on PLC $\gamma_{2}$. (D) The activation of PLC $\gamma_{2}$ deletion mutants by cool temperatures is not explained by changes in cellular levels of inositol phospholipids. COS-7 cells were transfected with $2 \mu \mathrm{g}$ each per well of empty vector (Control), vector encoding wild-type PLC $\gamma_{2}$ (WT), or PLC $\gamma_{2} \Delta 19$ (419). Twentyfour hours after transfection, the cells were incubated for a further $20 \mathrm{~h}$ in individual incubation chambers with myo-[2- $\left.{ }^{3} \mathrm{H}\right]$ inositol at the indicated temperatures. The amount of $\left[{ }^{3} \mathrm{H}\right]$ inositol present in the culture medium after radiolabeling of the cells ( $\mathbf{a})$ and the cellular formation of inositol phospholipids $(\bullet)$ was then determined as described in Experimental Procedures. The data was analyzed by non-linear least square curve fitting to a polynominal second order (quadratic) equation. (E) The expression of wild-type PLC $\gamma_{2}$ and PLC $\gamma_{2} \Delta 19$ was examined by subjecting cells from one well each to analysis by SDS-PAGE and immunoblotting using antibodies reactive against the c-Myc epitope.

Fig. 2. The activation of PLC $\gamma_{2} \Delta 19$ and PLC $\gamma_{2} \Delta 20-22$ by subphysiological temperatures occurs after protein synthesis and is reversible. (A) COS-7 cells were transfected with $500 \mathrm{ng}$ each per well of either vector encoding wild-type $\operatorname{PLC} \gamma_{2}, \operatorname{PLC} \gamma_{2} \Delta 19$, or $\operatorname{PLC} \gamma_{2} \Delta 20-22$. Twenty-four hours after transfection, the cells were incubated for a further $20 \mathrm{~h}$ at $31{ }^{\circ} \mathrm{C}$ or $37^{\circ} \mathrm{C}$ in individual incubation chambers with myo-[2- $\left.{ }^{3} \mathrm{H}\right]$ inositol, as indicated in the absence or presence of $100 \mu \mathrm{g} / \mathrm{ml}$ cycloheximide $(C H X)$. (B) Expression of wild-type and mutant PLC $\gamma_{2}$ isozymes in the experiment shown in panel $A$. The control samples (Co.) were taken at the end of the initial 24-h-transfection phase. Cells from one well each were analyzed by SDS-PAGE and immunoblotting using an antibody 
reactive against the c-Myc epitope. We note that despite its effect on $\operatorname{PLC} \gamma_{2}$ protein abundance, cycloheximide had only a minor effect on the increased formation of inositol phosphates by the two deletion enzymes at $31{ }^{\circ} \mathrm{C}$ versus $37{ }^{\circ} \mathrm{C}$ (panel A). We think that this is due to the fact that the upper limits of available phospholipid substrate were reached in this experiment. Hence, the levels inositol phosphate formation in the samples containing the deletion mutants assayed at $31{ }^{\circ} \mathrm{C}$ may have exceeded those determined in panel $A$ under conditions of unlimited substrate supply. (C) COS-7 cells were transfected with $500 \mathrm{ng}$ each per well of either vector encoding wild-type PLC $\gamma_{2}$, PLC $\gamma_{2} \Delta 19$, or PLC $\gamma_{2} \Delta 20-22$. Twenty hours after transfection the cells were pre-incubated for four hours in individual incubation chambers at $31^{\circ} \mathrm{C}(31 \rightarrow 31 ; 31 \rightarrow 37)$ or $37^{\circ} \mathrm{C}(37 \rightarrow 37)$. The cells were then incubated for another $20 \mathrm{~h}$ with $m y o-\left[2-{ }^{3} \mathrm{H}\right]$ inositol in individual incubation chambers at $31{ }^{\circ} \mathrm{C}$ $(31 \rightarrow 31)$ or $37^{\circ} \mathrm{C}(31 \rightarrow 37 ; 37 \rightarrow 37)$. (D) Expression of wild-type and mutant PLC $\gamma_{2}$ isozymes in the experiment shown in panel $C$. (E) Time course. COS-7 cells were transfected with $500 \mathrm{ng}$ each per well of either vector encoding wild-type $\operatorname{PLC} \gamma_{2}(\bullet), \operatorname{PLC} \gamma_{2} \Delta 19$ ( $\Delta$ ), or $\operatorname{PLC} \gamma_{2} \Delta 20-22(\boldsymbol{\nabla})$. Cells were transfected and radiolabeled and inositol phosphate formation was then determined. At the indicated time points, the cells were shifted from $37{ }^{\circ} \mathrm{C}$ to $31^{\circ} \mathrm{C}$ and back to $37{ }^{\circ} \mathrm{C}$, respectively. Open symbols, incubation at $37{ }^{\circ} \mathrm{C}$ throughout. $(F)$ Expression of wild-type and mutant PLC $\gamma_{2}$ isozymes in the experiment shown in panel $E$. Cells from one well each were analyzed by SDS-PAGE and immunoblotting using an antibody reactive against the c-Myc epitope.

Fig. 3. Determination of the 10-degree temperature coefficients, $Q_{10}$. The data shown in Fig. 1B on the cool temperature responses of cells expressing wild-type PLC $\gamma_{2}$ (WT), PLC $\gamma_{2} \Delta 19$ (419), and PLC $\gamma_{2} \Delta 20-22$ (420-22) was taken to determine the $Q_{10}$ values of these responses as detailed in Experimental Procedures. The individual temperatures $T_{i}$ were plotted against $\log _{10}\left(\frac{A_{i}}{A_{\text {ref }}}\right)$, with the maximum activity of $\operatorname{PLC} \gamma_{2} \Delta 19$ at $31{ }^{\circ} \mathrm{C}$ chosen as the reference activity $A_{\text {ref }}$ and reference temperature, $T_{\text {ref }}$, respectively. The data of the linear components was analyzed by non-linear least square curve fitting to a polynominal first order (straight line) equation. The slopes of the curves of PLC $\gamma_{2} \Delta 19$ and PLC $\gamma_{2} \Delta 20-22$ were not significantly different by global curve fitting using shared parameters from each other and, between $25{ }^{\circ} \mathrm{C}$ and $31{ }^{\circ} \mathrm{C}$, from the slope obtained for wild-type $\mathrm{PLC} \gamma_{2}(\mathrm{P}=0.9356$ and $\mathrm{P}=0.2121$, respectively $)$.

Fig. 4. Cool-temperature-mediated activation of $\operatorname{PLC} \gamma_{2} \Delta 19$ and $\operatorname{PLC} \gamma_{2} \Delta 20-22$ is distinct from loss of SH-region-mediated autoinhibition. (A) The temperature sensitivities of the PLAID PLC $\gamma_{2}$ deletion mutants are unique. COS-7 cells were transfected with $500 \mathrm{ng}$ each per well of vector encoding either wild-type $\operatorname{PLC} \gamma_{1}(\bullet), \operatorname{PLC} \gamma_{2} \Delta 19(\nabla), \operatorname{PLC} \gamma_{2} \Delta 20-22(\triangle)$ or mutants of PLC $\gamma_{1}$ carrying deletions corresponding to those in $\operatorname{PLC} \gamma_{2}$ and referred to as $\operatorname{PLC} \gamma_{1} " \Delta 19 "(\boldsymbol{\nabla})$ and $\operatorname{PLC} \gamma_{1} " \Delta 20-22 "$ ( $\Delta$ ). (B) 
The effects of deletions within the SH2n-SH2c-SH3 region on cool temperature regulation of PLC $\gamma_{2}$ are specific. COS-7 cells were transfected with $50 \mathrm{ng}$ each per well of vector encoding either wildtype $\operatorname{PLC} \gamma_{2}(\bullet), \operatorname{PLC} \gamma_{2} \Delta 20-22(\boldsymbol{\Delta})$, or PLC $\gamma_{2} \Delta \mathrm{PCI}(\boldsymbol{\bullet})$ (left panel), or with $10 \mathrm{ng}$ each per well of vector encoding either wild-type $\operatorname{PLC} \gamma_{2} \Delta \mathrm{SA}(\circ), \operatorname{PLC} \gamma_{2} \Delta \mathrm{SH}$ ( $\square$ ), or $\mathrm{PLC} \gamma_{2} \Delta \mathrm{SH} 2_{\mathrm{C}}$ (open diamonds), or $50 \mathrm{ng}$ each per well of vector encoding PLC $\gamma_{2} \Delta \mathrm{PCI}(\mathbf{m})$ as a control (right panel). The very similar responses of cells expressing PLC $\gamma_{2} \Delta \mathrm{PCI}$ shows that the results shown in the two panels are comparable.

Fig. 5. Basal activities of wild-type and mutant PLC $\gamma_{2}$ isozymes at $37{ }^{\circ} \mathrm{C}$. (A) COS-7 cells were transfected with either $500 \mathrm{ng}$ each per well of empty vector (Co., control) or increasing amounts (10 ng, $150 \mathrm{ng}$, and $500 \mathrm{ng}$ ) of vector encoding wild-type PLC $\gamma_{2}(W T), \operatorname{PLC} \gamma_{2} \Delta 19$ ( $\left.\Delta 19\right), \operatorname{PLC} \gamma_{2} \Delta 20-22$ ( $\Delta 20-22), \operatorname{PLC} \gamma_{2} \Delta \mathrm{PCI}(\Delta P C I), \operatorname{PLC} \gamma_{2} \Delta \mathrm{SH} 2 \mathrm{c}(\Delta S H 2 c), \operatorname{PLC} \gamma_{2} \Delta \mathrm{SH}(\Delta S H)$, or PLC $\gamma_{2} \Delta \mathrm{SA}(\Delta S A)$. Twenty-four hours after transfection, the cells were incubated for $20 \mathrm{~h}$ at $37{ }^{\circ} \mathrm{C}$ with myo-[2$\left.{ }^{3} \mathrm{H}\right]$ inositol and inositol phosphate formation was then determined. (B) Expression of wild-type and mutant PLC $\gamma_{2}$ isozymes in the experiment shown in panel $A$. Cells from one well each were analyzed by SDS-PAGE and immunoblotting using antibodies reactive against the c-Myc epitope (upper panel) or $\beta$-actin (lower panel).

Fig. 6. The deletions of PLCG2 exons 19 and 20-22 synergize to promote basal and cool-temperaturemediated activation of PLC $\gamma_{2}$. Left panel, COS-7 cells were transfected as indicated at the abscissa with $500 \mathrm{ng}$ each per well of either vector encoding wild-type PLC $\gamma_{2}(W T)$, or $500 \mathrm{ng}, 10 \mathrm{ng}$, or $20 \mathrm{ng}$ of vector encoding PLC $\gamma_{2} \Delta 19$ (419), PLC $\gamma_{2} \Delta 20-22$ (420-22), or PLC $\gamma_{2} \Delta 19-22$ (419-22). Twenty-four hours after transfection, the cells were incubated for a further $20 \mathrm{~h}$, as indicated at the abscissa at 31 ${ }^{\circ} \mathrm{C}$ or $37{ }^{\circ} \mathrm{C}$, in individual incubation chambers with myo-[2- $\left.{ }^{3} \mathrm{H}\right]$ inositol. Inositol phosphate formation was then determined as described under Experimental Procedures. The significance of differences between means \pm standard errors was assessed by using the unpaired $t$ test with two-tailed $\mathrm{P}$ values with or without Welch's correction as appropriate, as contained in GraphPad InStat ${ }^{\circledR}$, version 3.10. Two effects are said to be synergistic, if the effect of two components tested in combination is statistically significantly higher than the sum $(+)$ of the individual effects $(* *, 0.001<\mathrm{P}<0.01$; ***, $\mathrm{P}$ $<0.001)$. Right panel, COS-7 cells were transfected with $500 \mathrm{ng}$ of vector encoding wild-type PLC $\gamma_{2}$

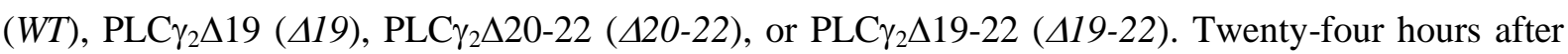
transfection, the cells were incubated for a further $20 \mathrm{~h}$. Cells from one well each were then analyzed by immunoblotting using an antibody reactive against the c-Myc epitope.

Fig. 7. Effect of cool temperatures on the activities of PLC $\gamma_{2}{ }^{A l i 5}, \operatorname{PLC} \gamma_{2}{ }^{A l i 14}$ and PLC $\gamma_{2}{ }^{A l i 5 / 14}$. Left panel, COS-7 cells were transfected with $500 \mathrm{ng}$ each per well of either empty control vector, or vector 
encoding either wild-type PLC $\gamma_{2}, \operatorname{PLC} \gamma_{2}{ }^{A l i 5}, \operatorname{PLC} \gamma_{2}{ }^{A l i 14}$, or PLC $\gamma_{2}{ }^{A l i 5 / A l i 14}$. Twenty-four hours after transfection, the cells were incubated for $20 \mathrm{~h}$ in individual incubation chambers with myo-[2${ }^{3} \mathrm{H}$ ]inositol at $31^{\circ} \mathrm{C}$ or $37^{\circ} \mathrm{C}$. Middle and right panel, COS-7 cells were transfected as indicated with 500 ng each per well of vector encoding either wild-type PLC $\gamma_{2}(\circ), \operatorname{PLC} \gamma_{2} \Delta 20-22$ ( $\Delta$ ), PLC $\gamma_{2}{ }^{A l i 5}$

$\operatorname{PLC} \gamma_{2}{ }^{A l i 14}(\diamond)$, or PLC $\gamma_{2}{ }^{A l i 5 / A l i 14}(\bullet)$. Twenty-four hours after transfection, the cells were incubated for $20 \mathrm{~h}$ in individual incubation chambers with myo-[2- $\left.{ }^{3} \mathrm{H}\right]$ inositol at the indicated temperatures. In the right panel, cells that had been transfected with vector encoding PLC $\gamma_{2}{ }^{\text {Ali5/Ali14 }}$ were also analyzed as a control. The response of these cells was very similar, both in qualitative and quantitative terms (not shown), to the response of the PLC $\gamma_{2}{ }^{A l i 5 / A l i 14}$-expressing cells shown in the left and in the center panel, indicating that the results shown in the three panels are comparable.

Fig. 8. Functional effects of deletions within the SH2n-SH2c-SH3 region. (A) COS-7 cells were transfected as indicated with $500 \mathrm{ng}$ each per well of empty control vector or vector encoding wildtype PLC $\gamma_{2}$, or with $10 \mathrm{ng}$ each per well of vector encoding PLC $\gamma_{2} \Delta \mathrm{SH} 2 \mathrm{n}, \operatorname{PLC} \gamma_{2} \Delta \mathrm{SH} 2 \mathrm{c}, \mathrm{PLC} \gamma_{2} \Delta \mathrm{SH} 3$, PLC $\gamma_{2} \Delta \mathrm{SH} 2 \mathrm{nSH} 2 \mathrm{c}, \operatorname{PLC} \gamma_{2} \Delta \mathrm{SH} 2 \mathrm{cSH} 3, \operatorname{PLC} \gamma_{2} \Delta \mathrm{SH} 2 \mathrm{nSH} 3$, or PLC $\gamma_{2} \Delta \mathrm{SH}$. Twenty-four hours after transfection, the cells were incubated for a further $20 \mathrm{~h}$ in individual incubation chambers at $37{ }^{\circ} \mathrm{C}$ or $31{ }^{\circ} \mathrm{C}$. (B) Schematic representation of the deletions within the SH2n-SH2c-SH3 region (aa 515-840). The positions of the two partial repeats detected within the two $\mathrm{SH} 2$ domains

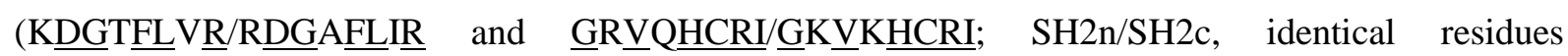
underlined) and of the various deletions used in this study are indicated.

Fig. 9. Cool-temperature-triggered activation of PLAID PLC $\gamma_{2}$ deletion mutants is mediated by the split PH domain. (A) Activation of PLC $\gamma_{2} \Delta 19$ by Rac2 $2^{\mathrm{G} 12 \mathrm{~V}}$ is diminished at cool temperatures. Left panel, COS-7 cells were cotransfected with $500 \mathrm{ng}$ each per well of vector encoding either wild-type $\operatorname{PLC} \gamma_{2}(\boldsymbol{\square}, \square)$ or $100 \mathrm{ng}$ of vector encoding $\operatorname{PLC} \gamma_{2} \Delta 19(\bullet, \circ)$ together with 25 ng per well of either empty vector $(\square, \bigcirc)$ or vector encoding $\operatorname{Rac} 2^{\mathrm{G} 12 \mathrm{~V}}(\boldsymbol{\square}, \bullet)$. There was no effect on inositol phosphate formation upon expression of $\operatorname{Rac}^{\mathrm{G} 12 \mathrm{~V}}$ in the absence of PLC $\gamma_{2}$ isozymes (not shown). Right panel, COS-7 cells were transfected with either 500 ng per well of vector encoding wild-type PLC $\gamma_{2}(\square)$ or increasing amounts of vector encoding PLC $\gamma_{2} \Delta 19$ (०). (B) The split PH domain mediates activation of PLC $\gamma_{2} \Delta 19$ by cold. COS-7 cells were transfected with $500 \mathrm{ng}$ each per well of vector encoding either wild-type PLC $\gamma_{2}, \operatorname{PLC} \gamma_{2} \Delta 19$, PLC $\gamma_{2} \Delta 19^{\text {W899A }}$, PLC $\gamma_{2} \Delta 19-$ PH12, PLC $\gamma_{2} \Delta 19-\mathrm{PH} 21$, PLC $\gamma_{2} \Delta 19-\mathrm{PH} 11$, PLC $\gamma_{2}$-PH11, or PLC $\gamma_{2} \Delta 19-\mathrm{PH} 11^{\mathrm{Y} 509 \mathrm{~A} / \mathrm{F} 510 \mathrm{~A}}$. (C) Three-dimensional structures of the split PH domains of PLC $\gamma_{1}$ [2FJL [9]] and PLC $\gamma_{2}$ [2W2X [10]], as analyzed and visualized using the PyMOL Molecular Graphics System. The positions of the residues mutated in $(B)$ and the site of insertion of the SH2nSH2c-SH3 region in wild-type PLC $\gamma_{2}$, covalently linked in PLC $\gamma_{2} \Delta \mathrm{SH}$ are indicated. (D) A functional 
spPH domain is required for the temperature sensitivity of PLC $\gamma_{2} \Delta 19$. COS-7 cells were transfected

with $500 \mathrm{ng}$ each per well of vector encoding either wild-type $\operatorname{PLC} \gamma_{2}, \operatorname{PLC} \gamma_{2}{ }^{\mathrm{Y} 495 \mathrm{~A}}$, PLC $\gamma_{2}{ }^{\mathrm{C} 496 \mathrm{~A}}$, $\operatorname{PLC} \gamma_{2}{ }^{\mathrm{Y} 495 \mathrm{~A} / \mathrm{C} 496 \mathrm{~A}}$, PLC $\gamma_{2} \Delta 19, \operatorname{PLC} \gamma_{2} \Delta 19^{\mathrm{Y} 495 \mathrm{~A}}, \operatorname{PLC} \gamma_{2} \Delta 19^{\mathrm{C} 496 \mathrm{~A}}$, or PLC $\gamma_{2} \Delta 19^{\mathrm{Y} 495 \mathrm{~A} / \mathrm{C} 496 \mathrm{~A}}$.

Fig. 10. Cool temperature sensitivity of $\mathrm{PLC} \gamma_{2} \Delta \mathrm{SH}$ mutant is restored by expression of the enzyme as two separate chains. (A) COS-7 cells were transfected with 500 ng each per well of either empty vector, $500 \mathrm{ng}$ of vector encoding wild-type PLC $\gamma_{2}, 10 \mathrm{ng}$ of vector encoding PLC $\gamma_{2} \Delta \mathrm{SH}$, or $250 \mathrm{ng}$ of vector encoding $\mathrm{PLC} \gamma_{2}-\mathrm{X}^{\mathrm{PHn}}$ or $\mathrm{PLC} \gamma_{2}-\mathrm{Y}^{\mathrm{PHc}}$ (both encompassing the respective halves of the split $\mathrm{PH}$ domain), or cotransfected with $250 \mathrm{ng}$ of vector encoding PLC $\gamma_{2}-\mathrm{X}^{\mathrm{PHn}}$ together with $250 \mathrm{ng}$ of vector encoding PLC $\gamma_{2}-\mathrm{Y}^{\mathrm{PHc}}$. (B) The split PH domain is not essential for the cool temperature sensitivity of PLC $\gamma_{2}$ expressed as two separate chains. COS-7 cells were transfected with $500 \mathrm{ng}$ each per well of either empty vector $(C o$.$) , or vector encoding wild-type PLC \gamma_{2}(W T), \operatorname{PLC} \gamma_{2}-X(X)$, or PLC $\gamma_{2}$-Y $(Y)$ (the latter two lacking the respective halves of the split PH domain) (all four vectors at $500 \mathrm{ng}$ per well), or cotransfected with $100 \mathrm{ng}$ each per well of vectors encoding PLC $\gamma_{2}$-X or PLC $\gamma_{2}-\mathrm{Y}$. PLC $\gamma_{2} \Delta 20-22$ (420-22) (500 ng vector per well) was analysed for comparison. ( $C$ - $H$ ) Model of the activation of PLAID PLC $\gamma_{2}$ mutants, exemplified by PLC $\gamma_{2} \Delta 20-22$, and their deletion mutants by cool temperature. (C) Wild-type PLC $\gamma_{2}$ is autoinhibited in its basal state by constituent(s) of its SH domain region and does not respond to cooling (-). (D) The $\Delta 20-22$ deletion within the SH2n-SH2c-SH3 region causes a reorientation of the SH domain region, allowing the enzyme to be markedly activated $(++)$ by cool temperatures in a process depending on the integrity of spPH. Only minor functional changes are caused by the deletion at $37{ }^{\circ} \mathrm{C}$ (not shown). (E) Covalent linkage of the two PH domain halves in the constitutively active (+) deletion mutant PLC $\gamma_{2} \Delta$ SA prevents further activation by cooling. $(F)$ Disengaging the two spPH halves from the tight and stable covalent linkage allows cool temperature activation of the bipartite enzyme (++). $(G$ and $H)$ Coexpression of fragments $\mathrm{X}$ and $\mathrm{Y}$ yields enzyme that is constitutively active at $37{ }^{\circ} \mathrm{C}$ (at suitable expression levels, not shown) (+). Cooling to $31 \mathrm{oC}$ results in marked further activation $(++)$. Note that cool temperature activation of the bipartite PLC $\gamma_{2}$ mutants occurs in the absence of any of the SH2n-SHc-SH3 constituents ( $F$ and $H$ ).

Fig. 11. The PLC $\gamma_{2}$ deletion mutants $\Delta 20-22$ and $\Delta 19$ are resistant to stimulation by EGF. (A) COS-7 cells were transfected with vectors encoding either wild-type PLC $\gamma 2$ (WT) (500 ng per well), PLC $\gamma_{2} \Delta 20-22$ (420-22), or PLC $\gamma_{2} \Delta 19$ ( $\left.\Delta 19\right)$ (both at $100 \mathrm{ng}$ per well). Eighteen hours after transfection, the cells were incubated for a further $24 \mathrm{~h}$ as indicated at either $31{ }^{\circ} \mathrm{C}$ or $37{ }^{\circ} \mathrm{C}$ with myo$\left[2-{ }^{3} \mathrm{H}\right]$ inositol and $10 \mathrm{mM} \mathrm{LiCl}$ in the absence of serum and then treated for $60 \mathrm{~min}$ at the same temperatures in the presence of $10 \mathrm{mM} \mathrm{LiCl}$ with $100 \mathrm{ng} / \mathrm{ml} \mathrm{EGF}$, followed by determination of 
inositol phosphate formation. Background inositol phosphate formation in response to addition of EGF was determined in parallel on cells transfected with empty vector and subtracted from the individual values, with appropriate consideration of error propagation [66]. Additional experiments showed that the stimulatory effect of EGF on wild-type PLC $\gamma_{2}$ activity was concentration-dependent with half-maximal and maximal effects at approximately $10 \mathrm{ng} / \mathrm{ml}$ and $50 \mathrm{ng} / \mathrm{ml}$, respectively, and was almost completely blocked (- $95 \%$ ) by the EGFR inhibitor cetuximab (not shown). 


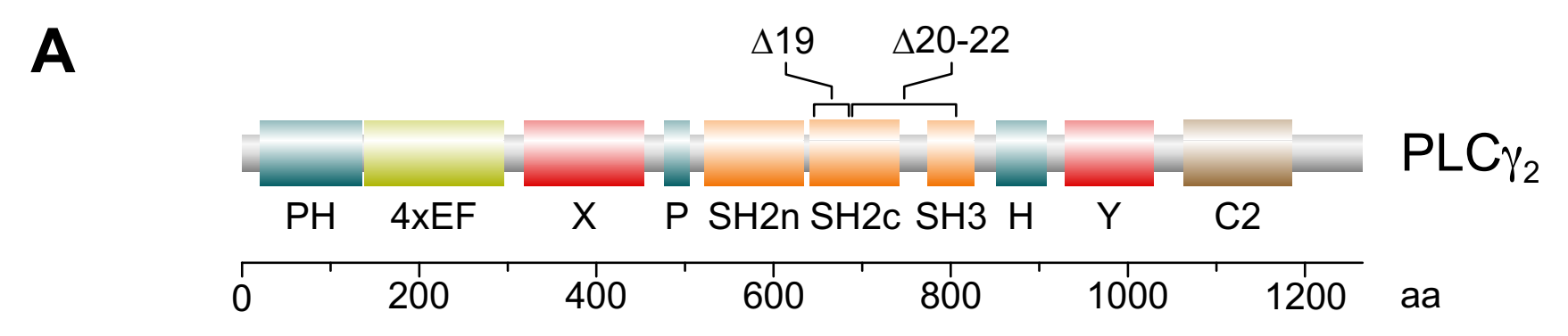

B

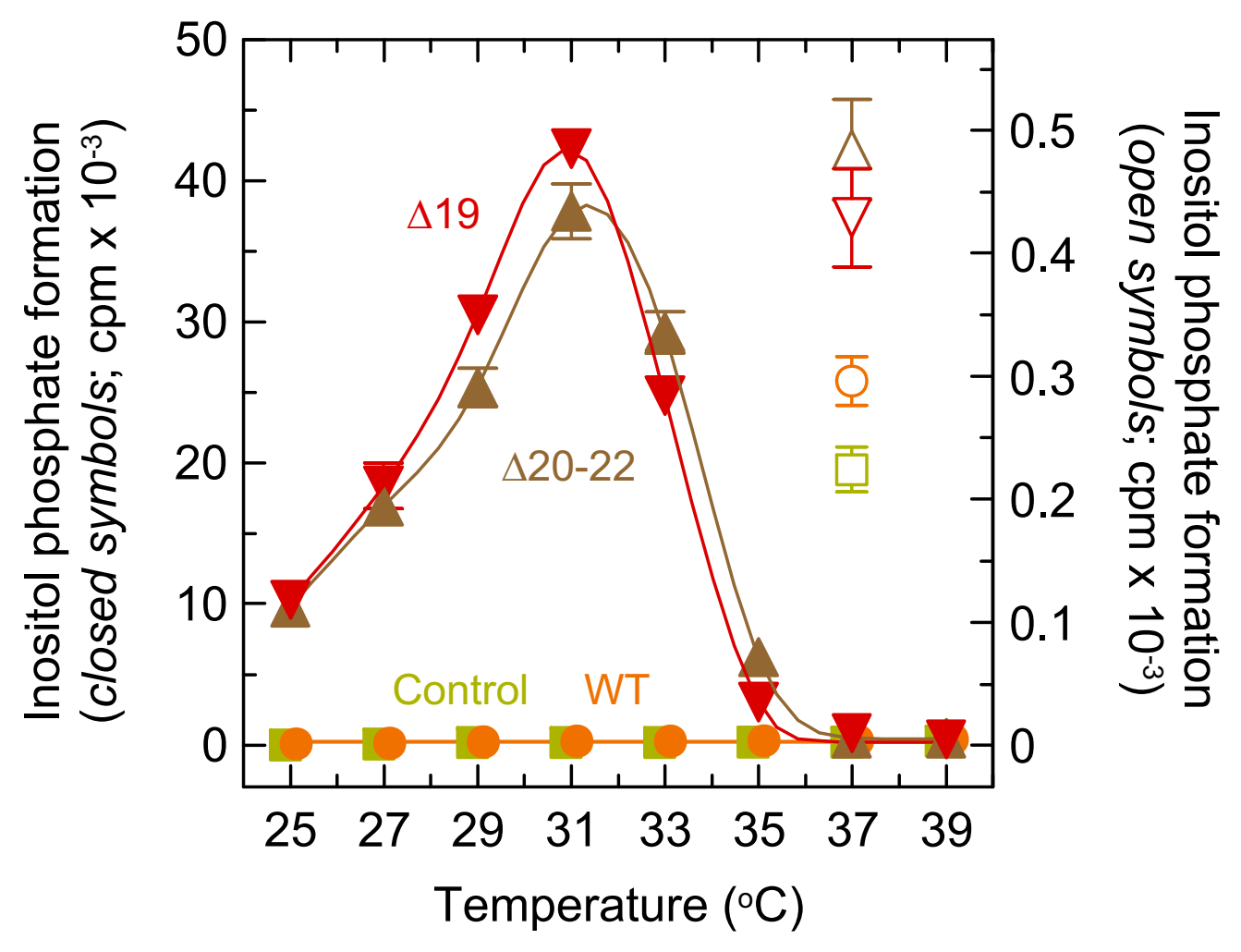

C

$$
\begin{array}{lllllllll}
1 & 2 & 3 & 4 & 5 & 6 & 7 & 8 & \\
& & & & & & & & \\
\text { Control }
\end{array}
$$

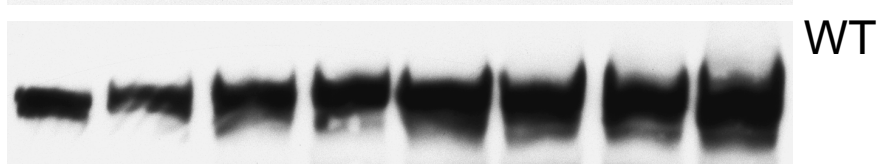

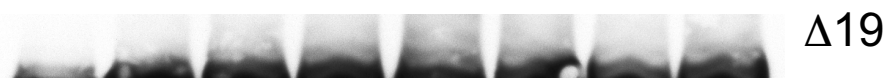

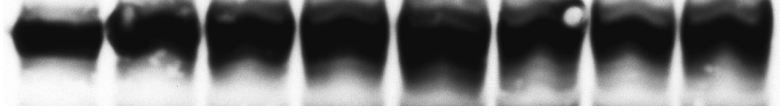

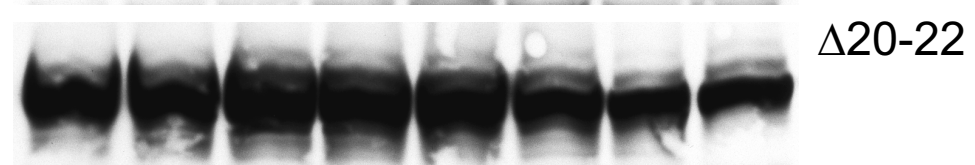

$\begin{array}{llllllll}25 & 27 & 29 & 31 & 33 & 35 & 37 & 39\end{array}$

Temperature $\left({ }^{\circ} \mathrm{C}\right)$

Fig. 1-I 
D

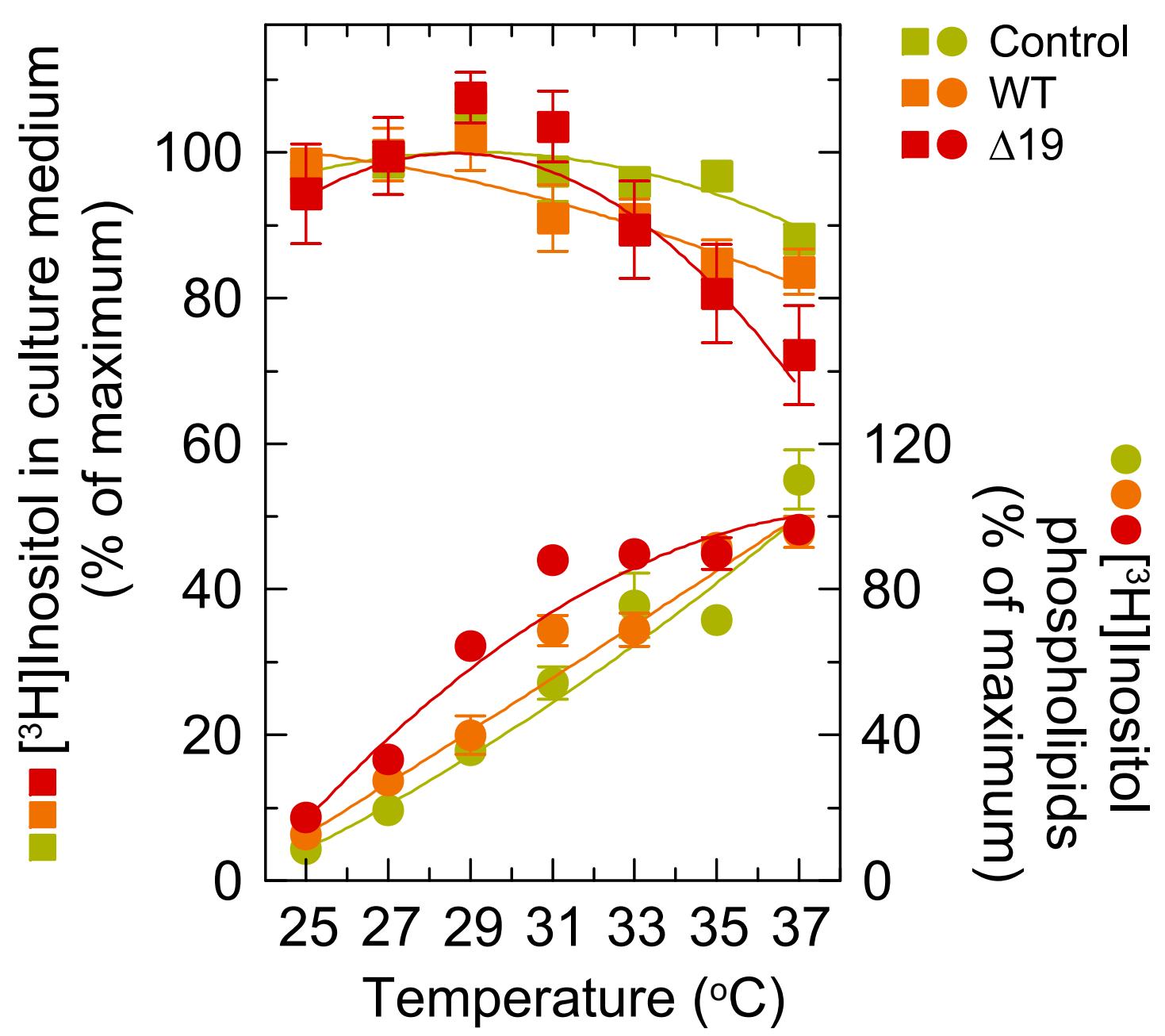

E

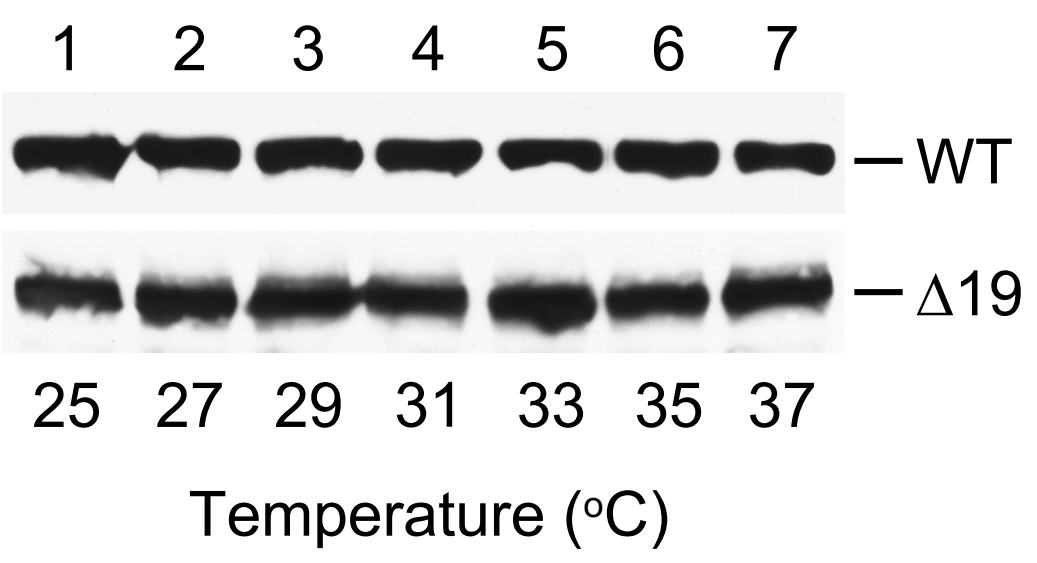

Fig. 1-II 
A

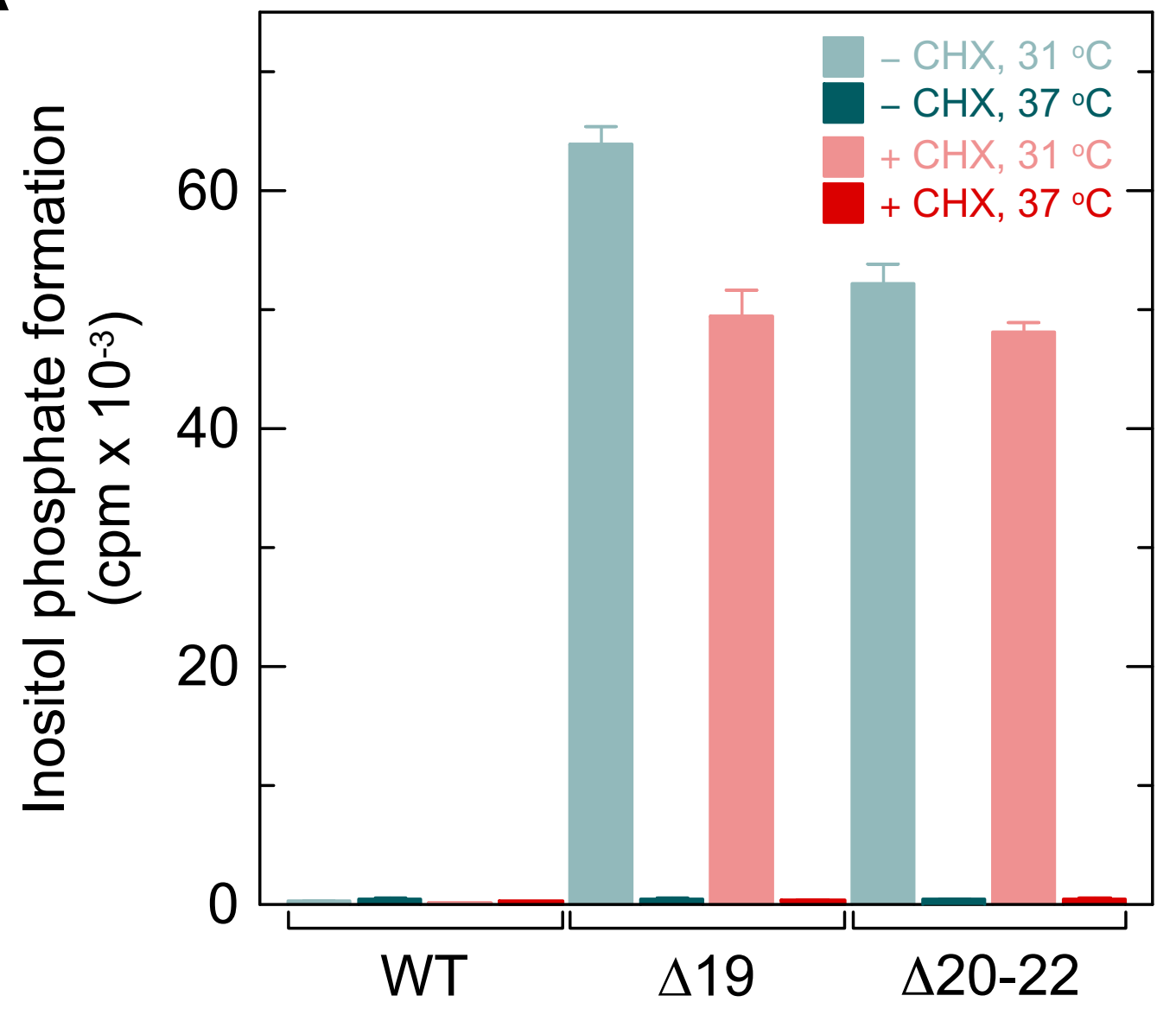

B

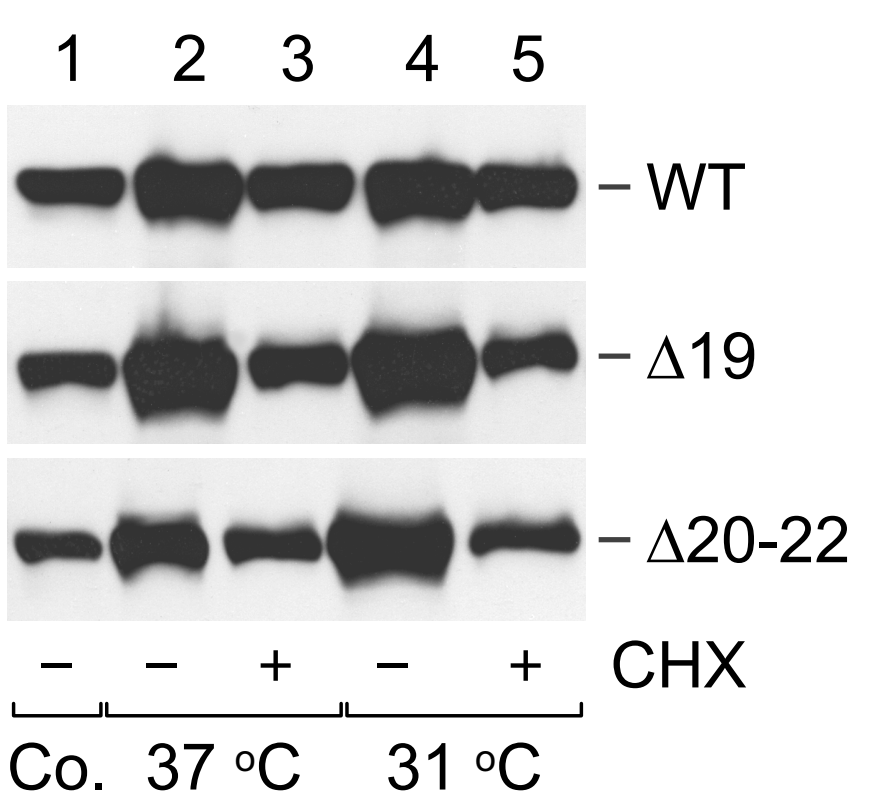

Fig. 2-I 
C

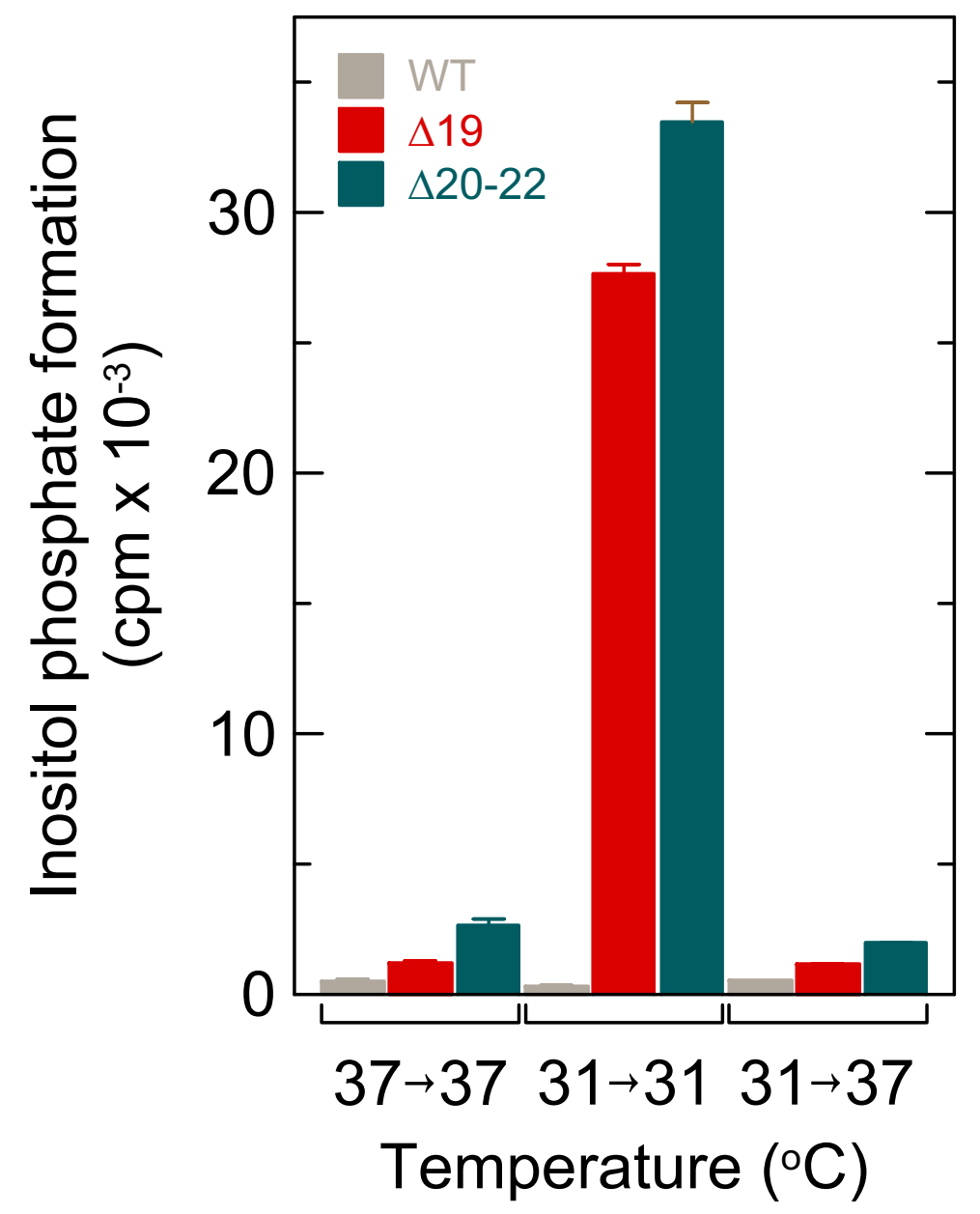

D
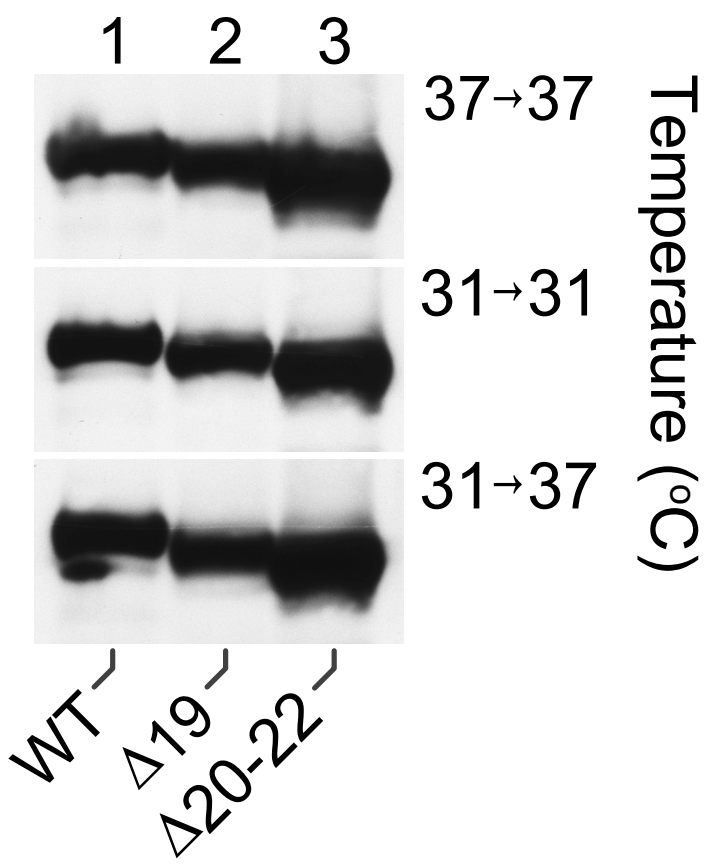

Fig. 2-II 

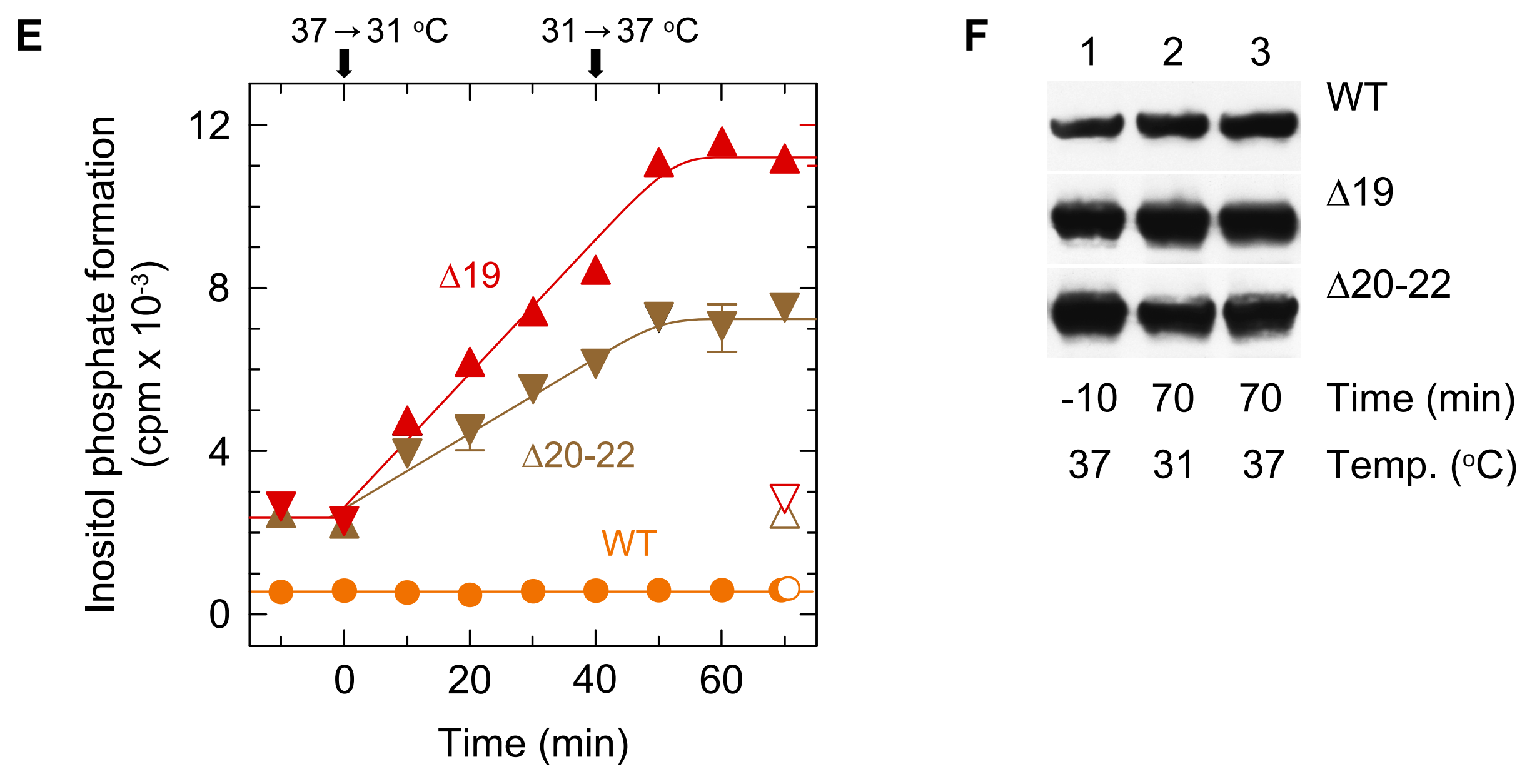

Fig. 2-III 


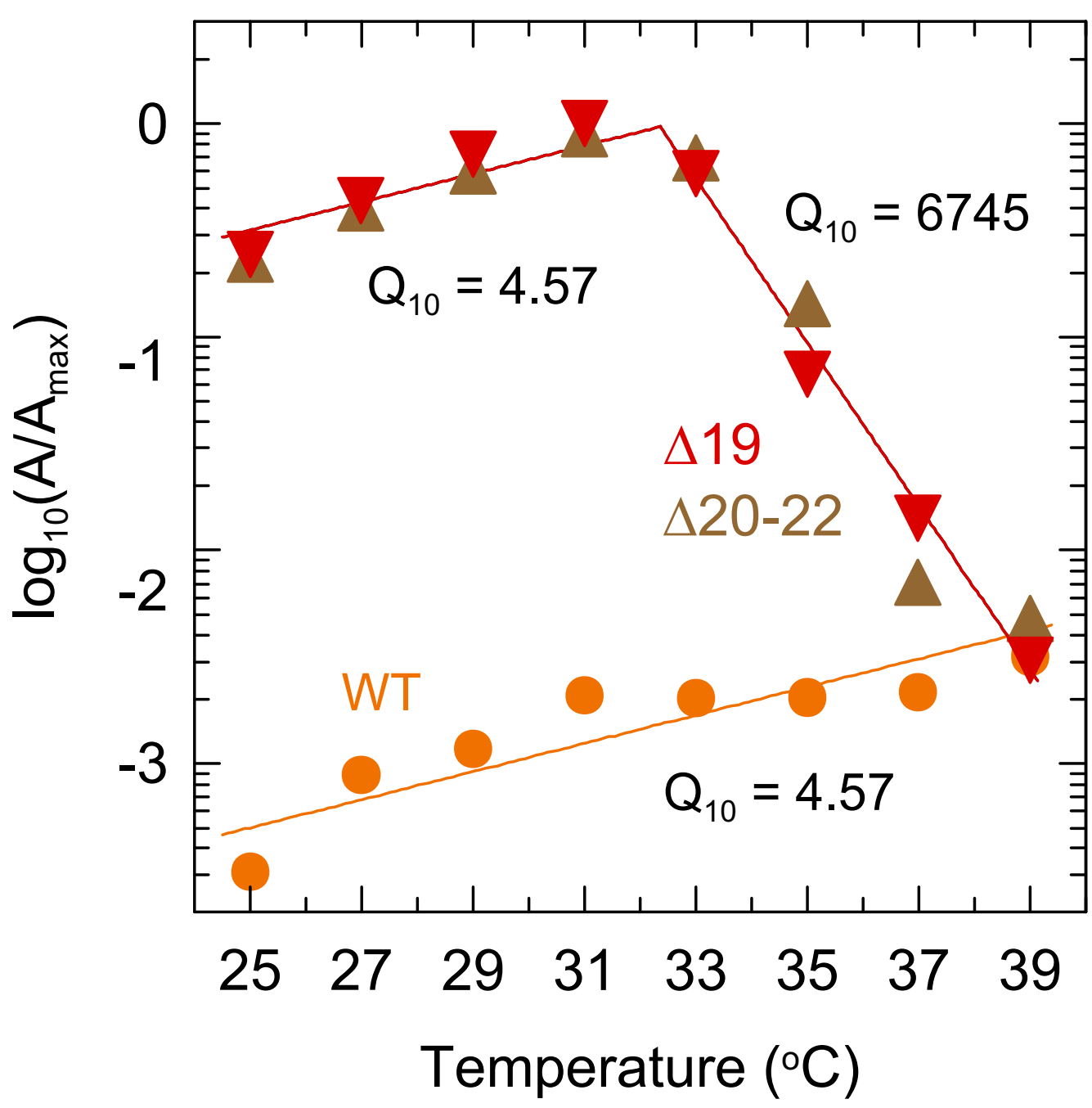

Fig. 3 
A

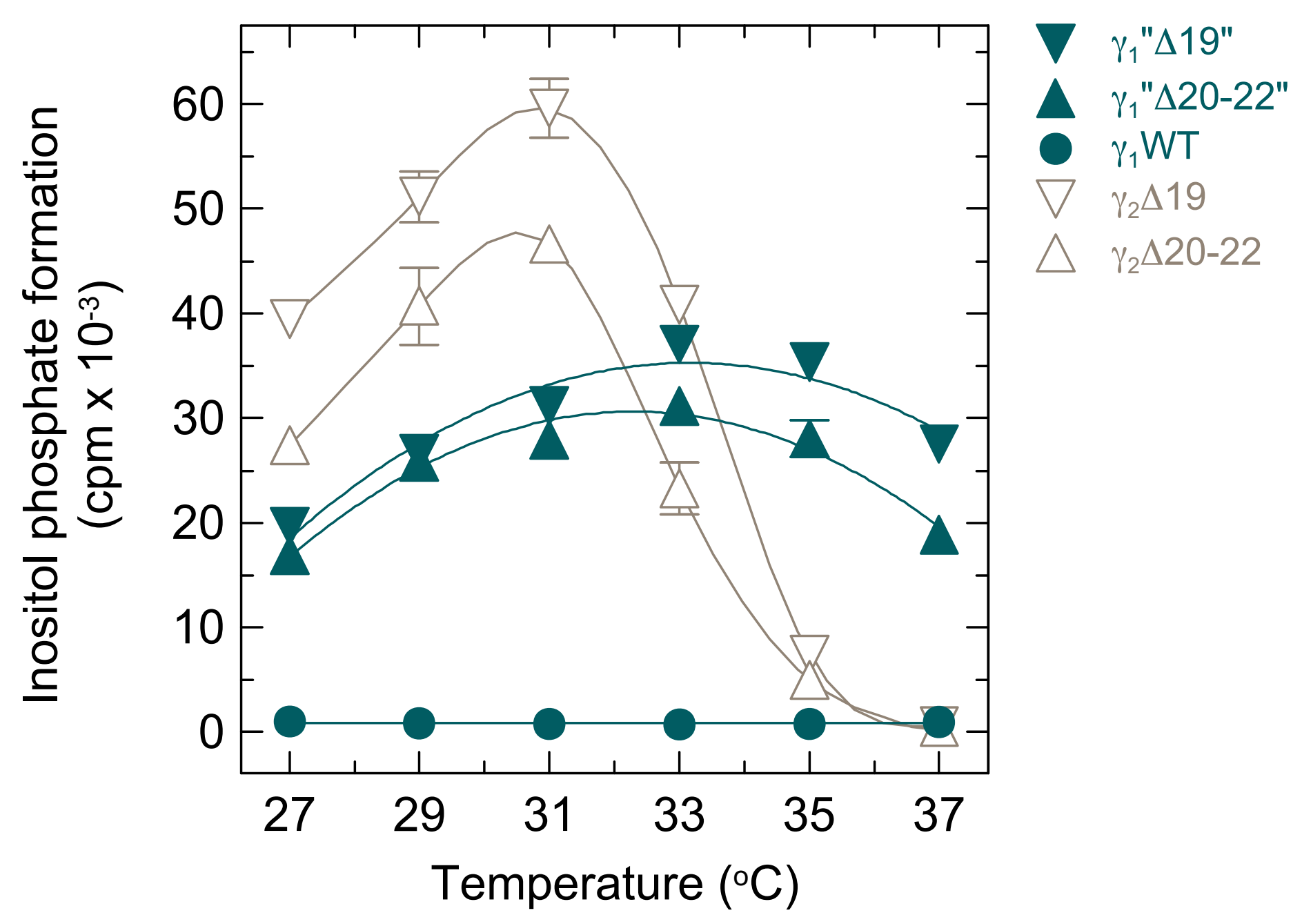

Fig. 4-I 
B

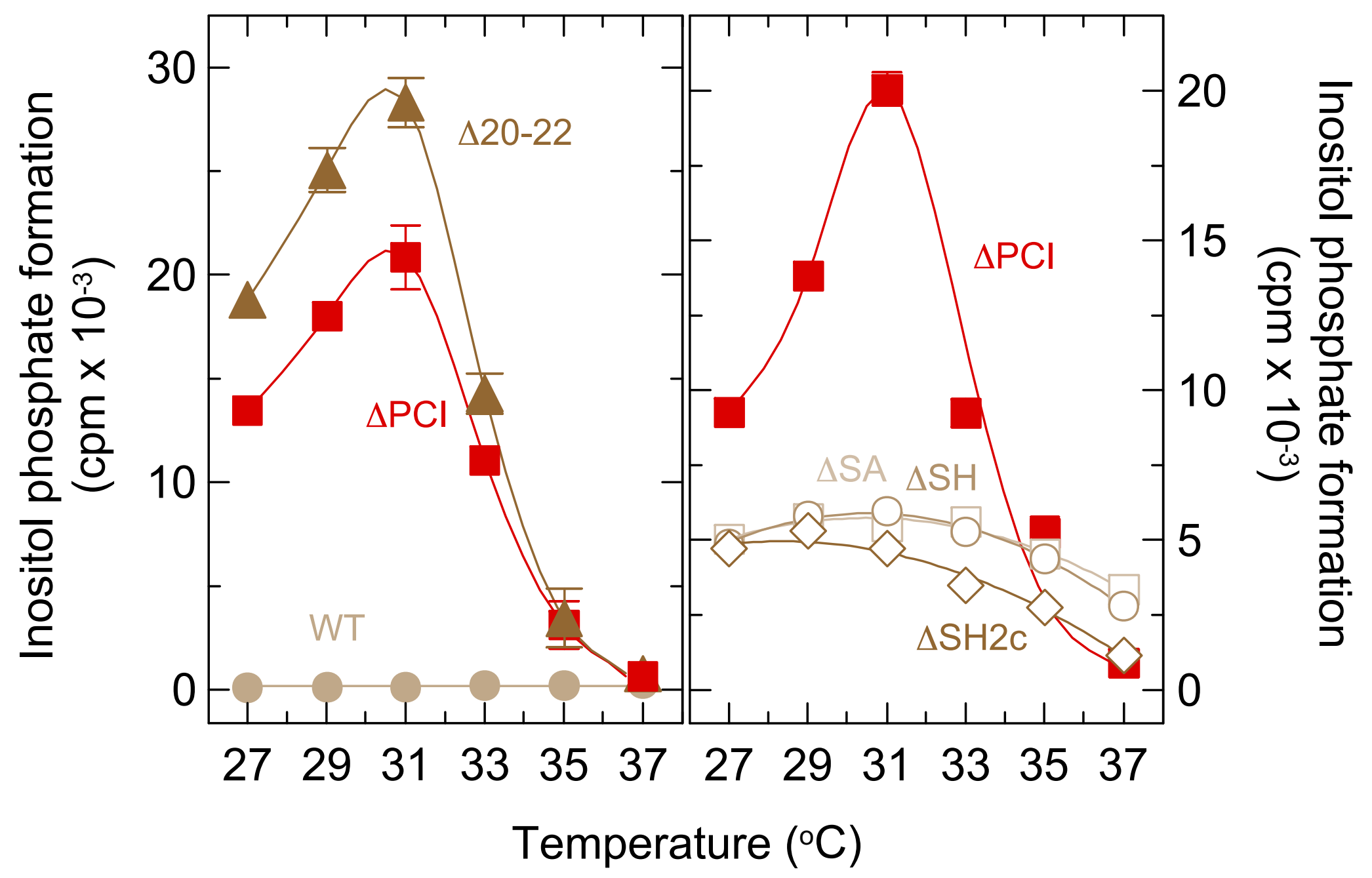

Fig. 4-II 
A

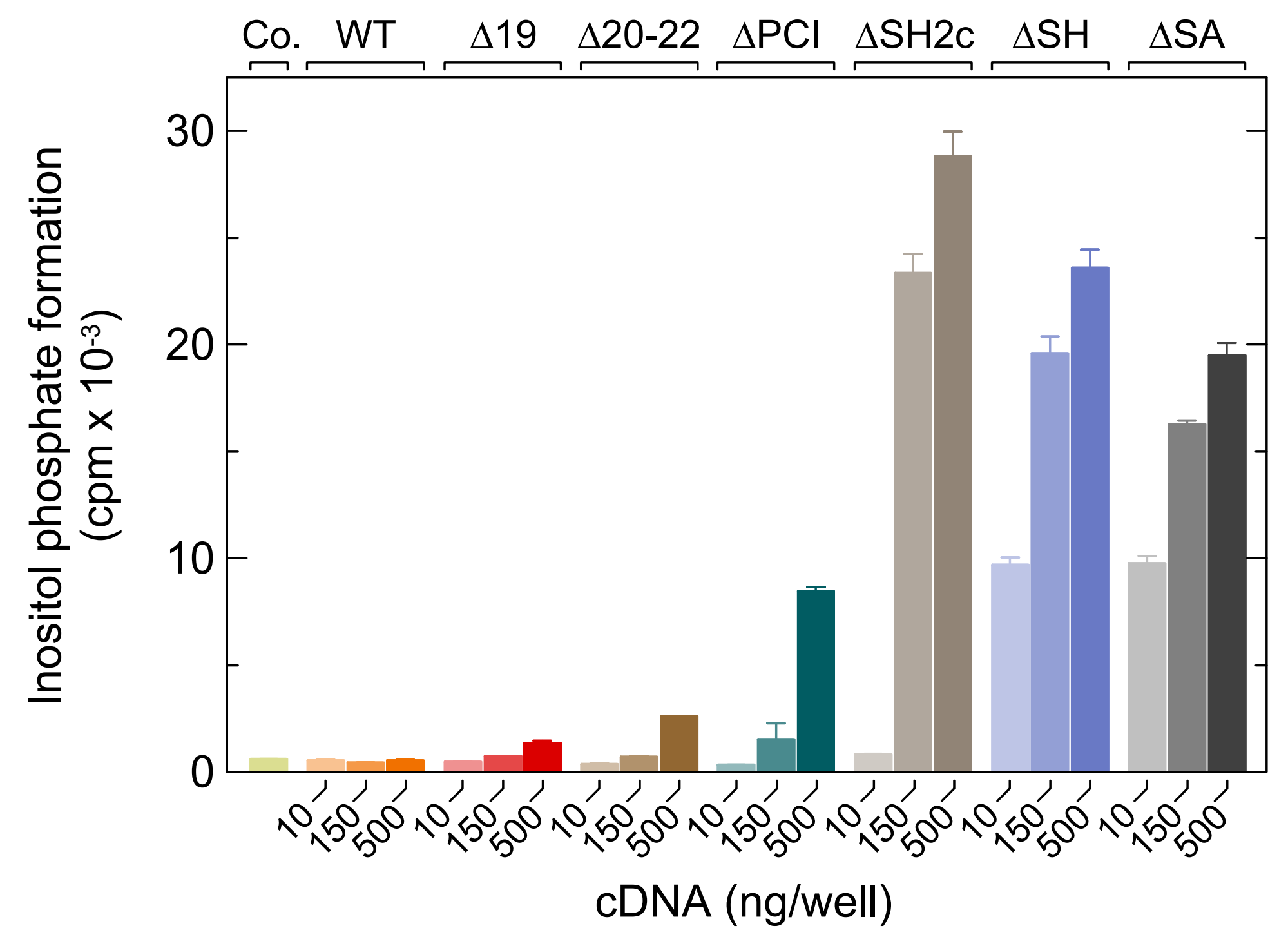

Fig. 5-I 
B

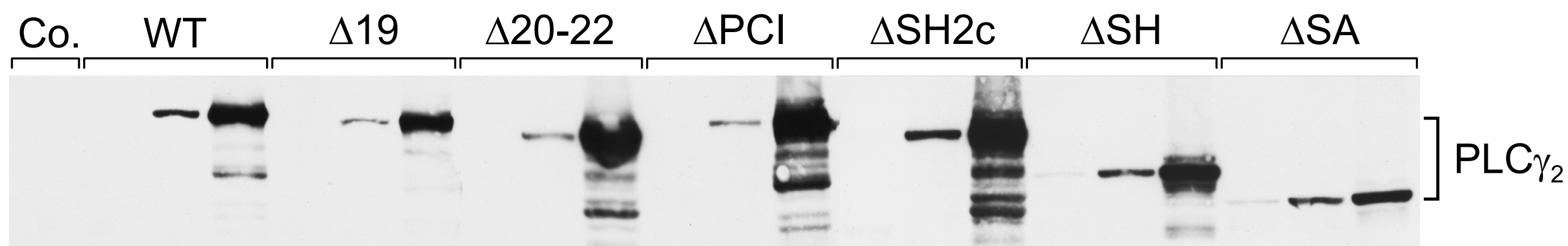

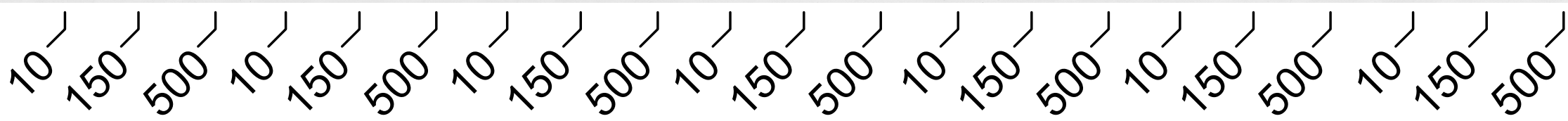

$$
\begin{aligned}
& \text { cDNA (ng/well) }
\end{aligned}
$$

Fig. 5-II 


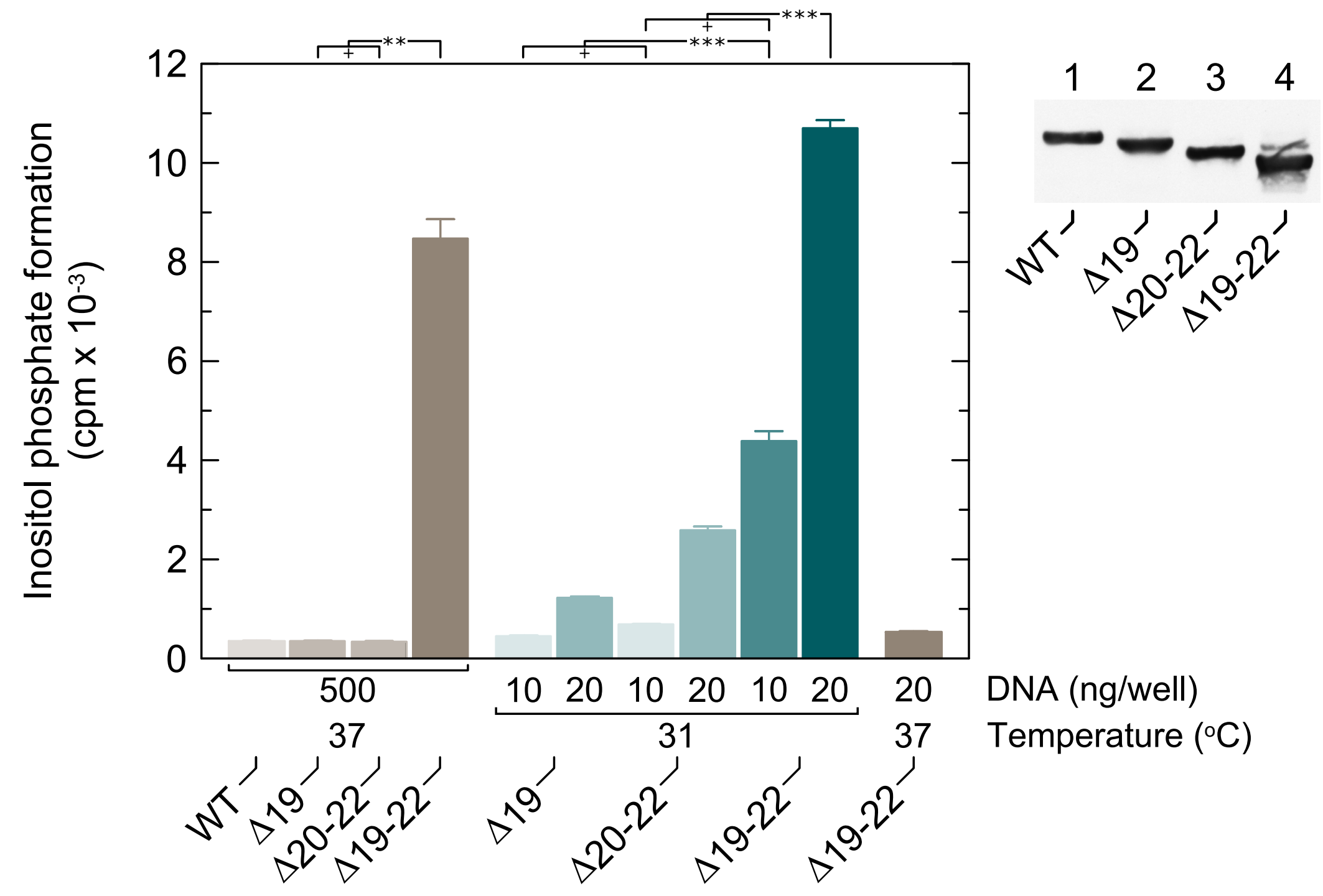

Fig. 6 


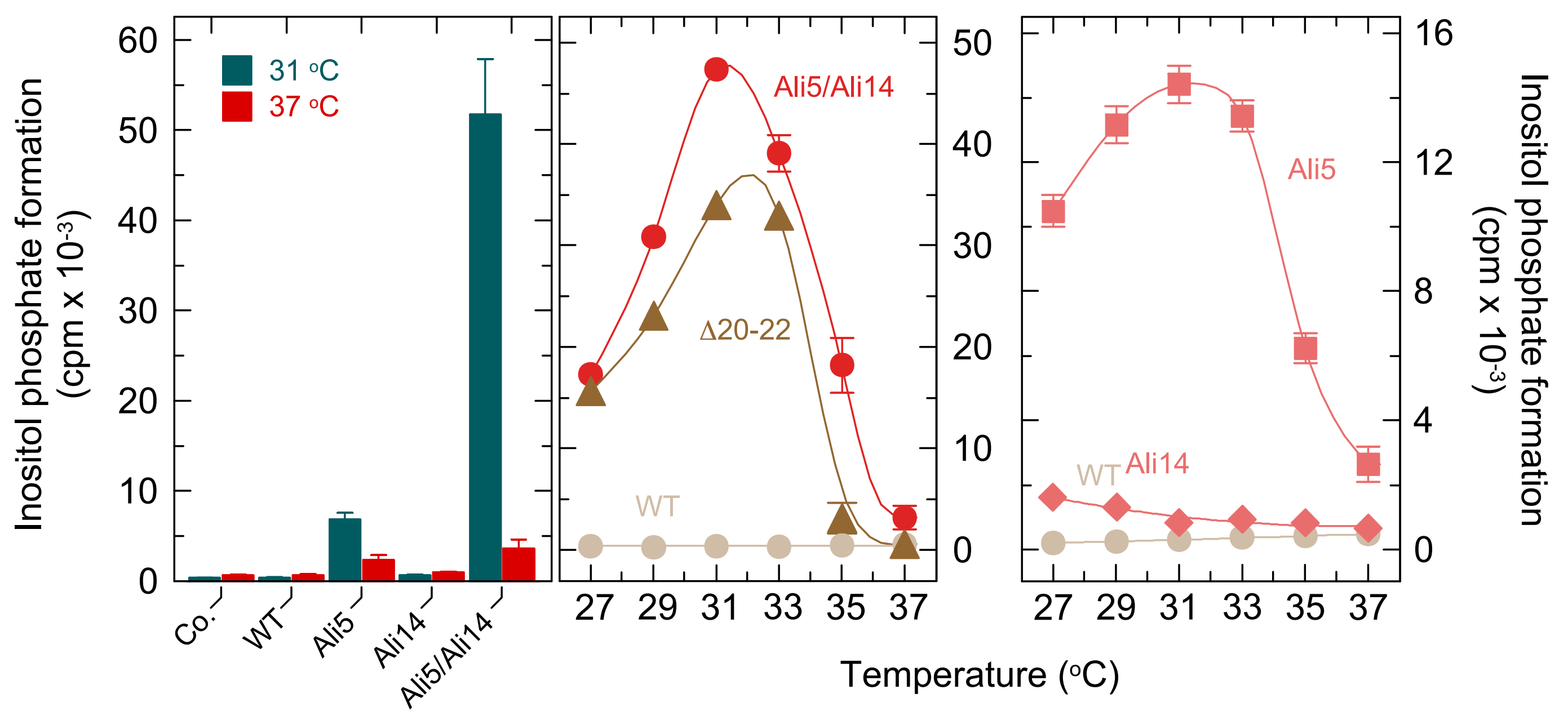

Fig. 7 
A

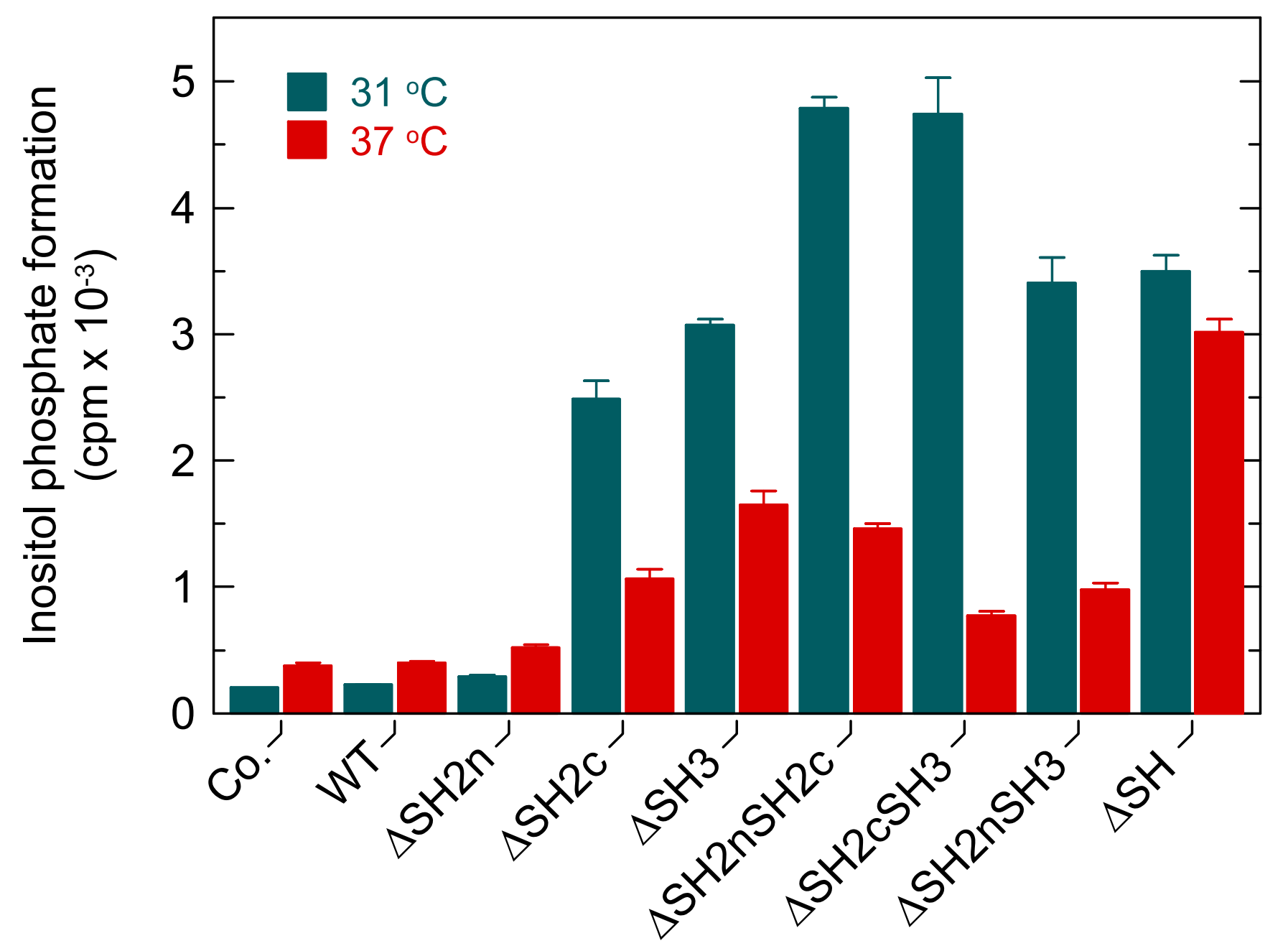

Fig. 8-I 


\section{B}

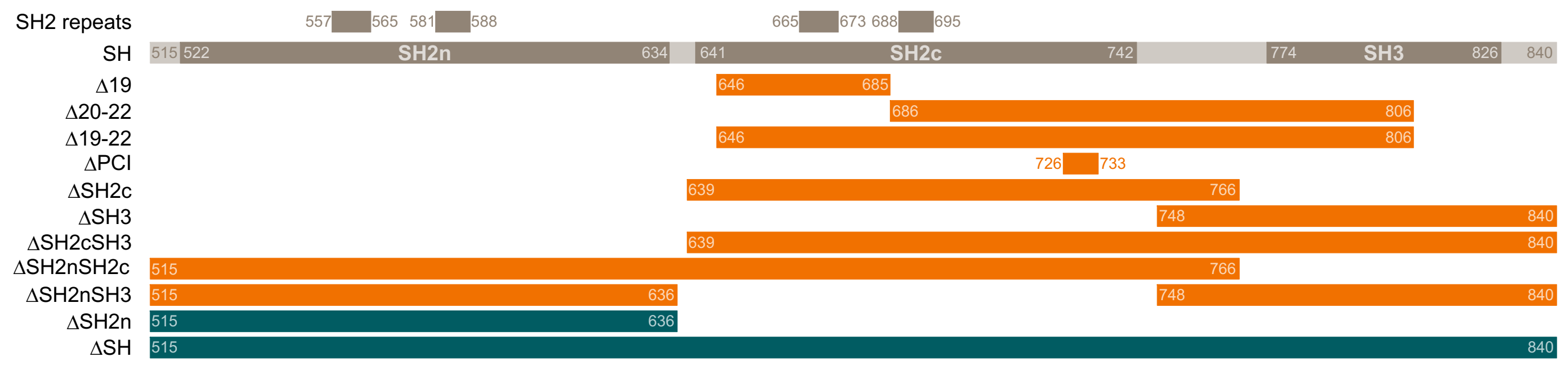

activation by cold $\square$ no activation by cold

Fig. 8-II 
A

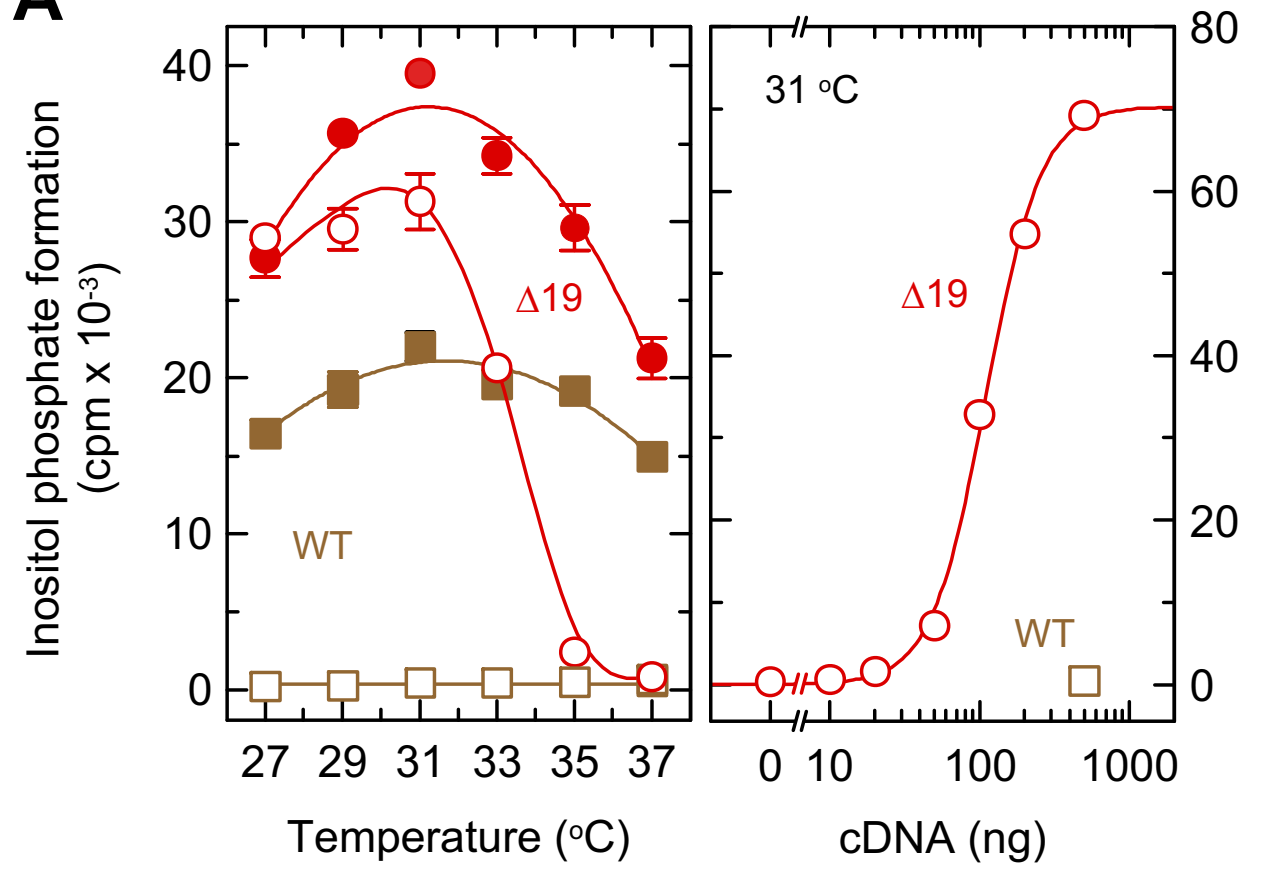

B

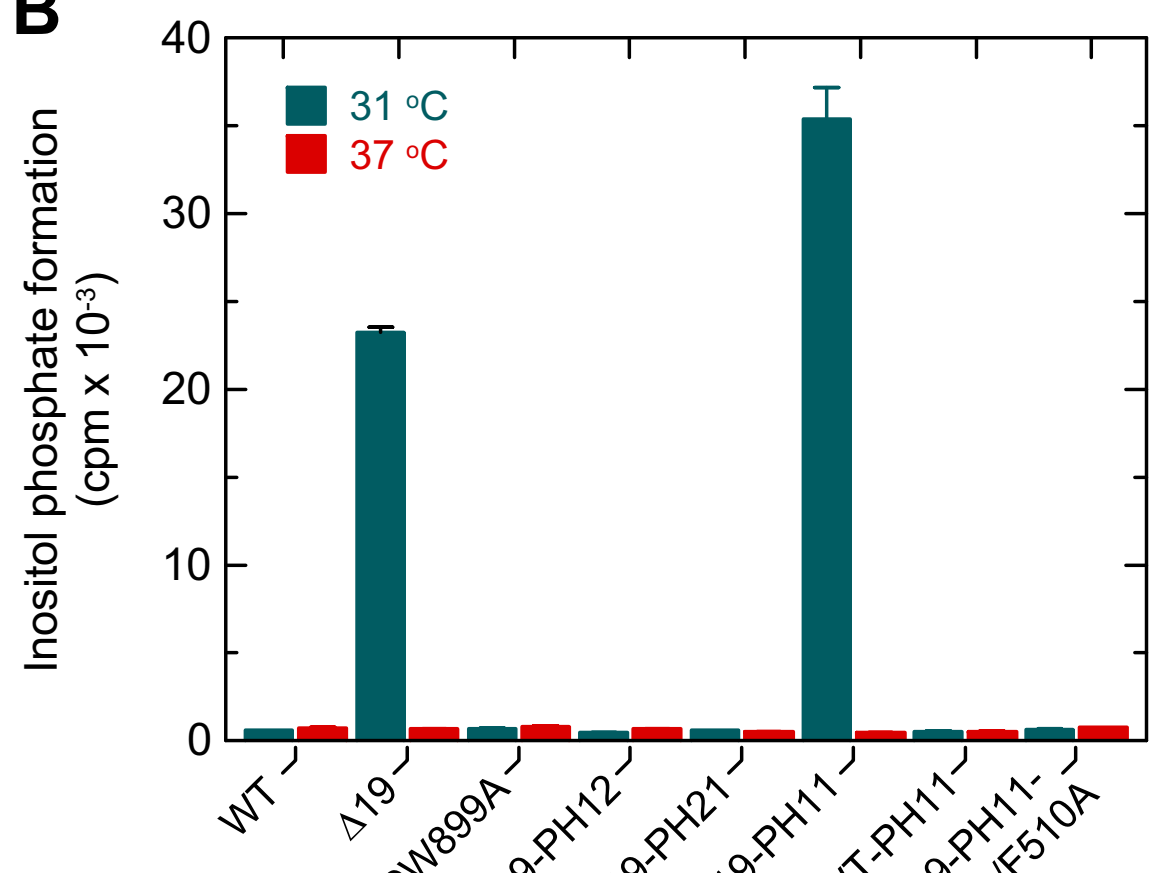

Fig. 9-I
C

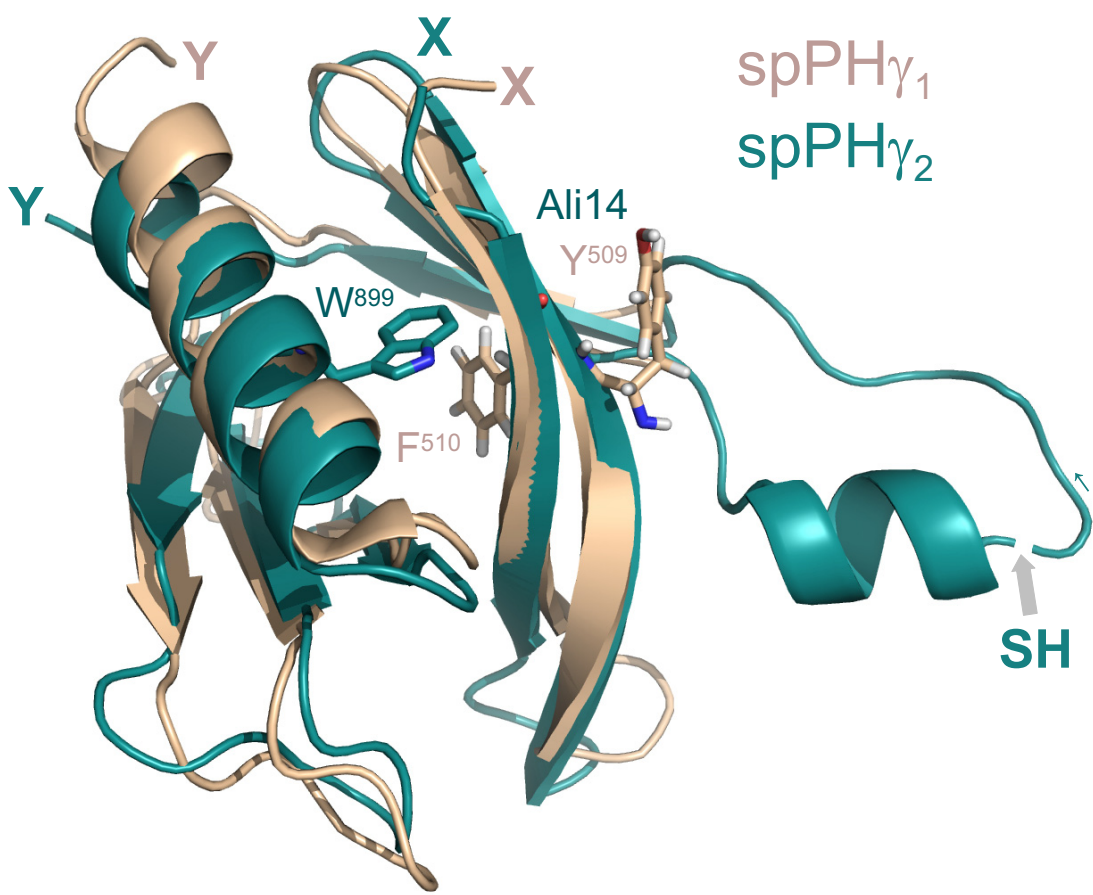

D

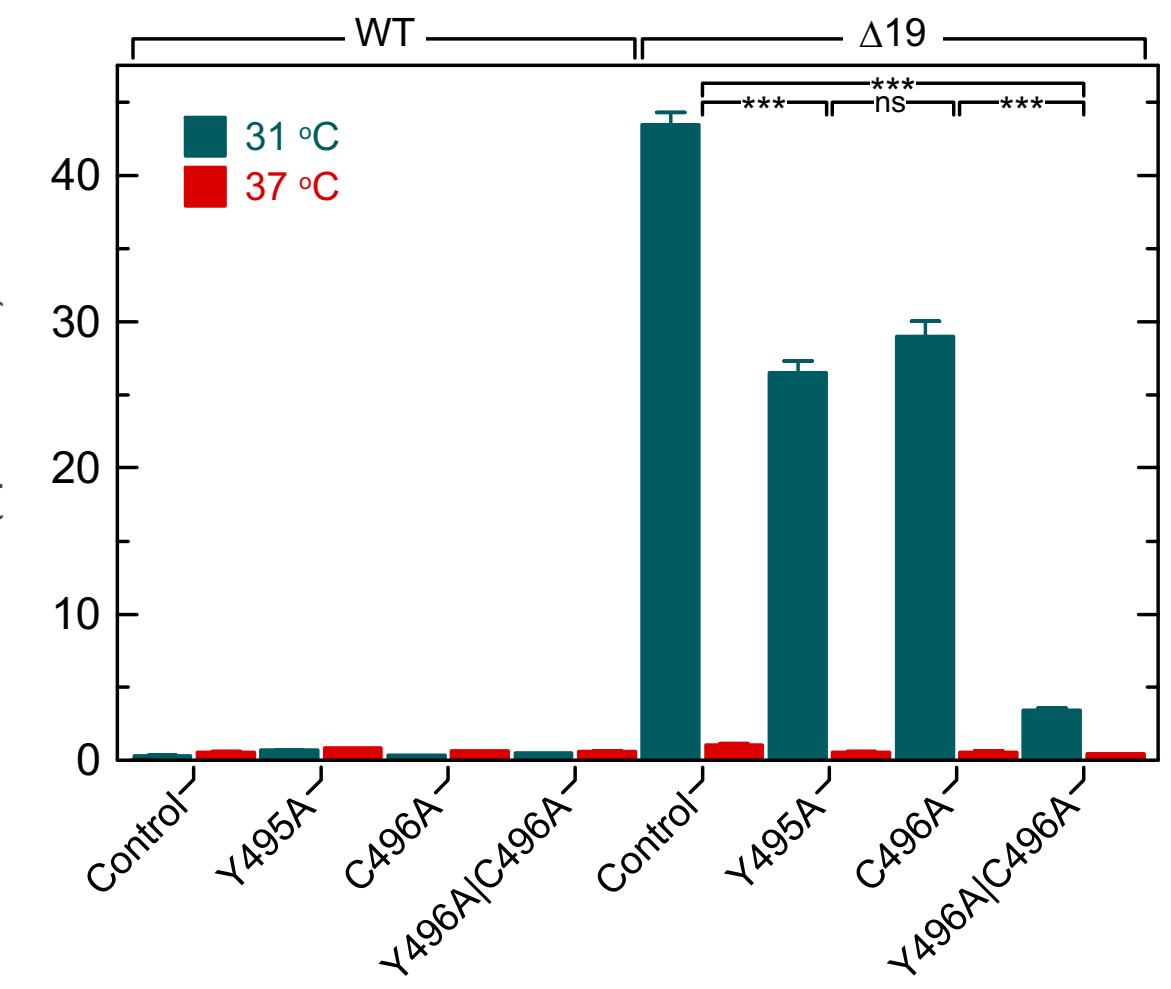


A

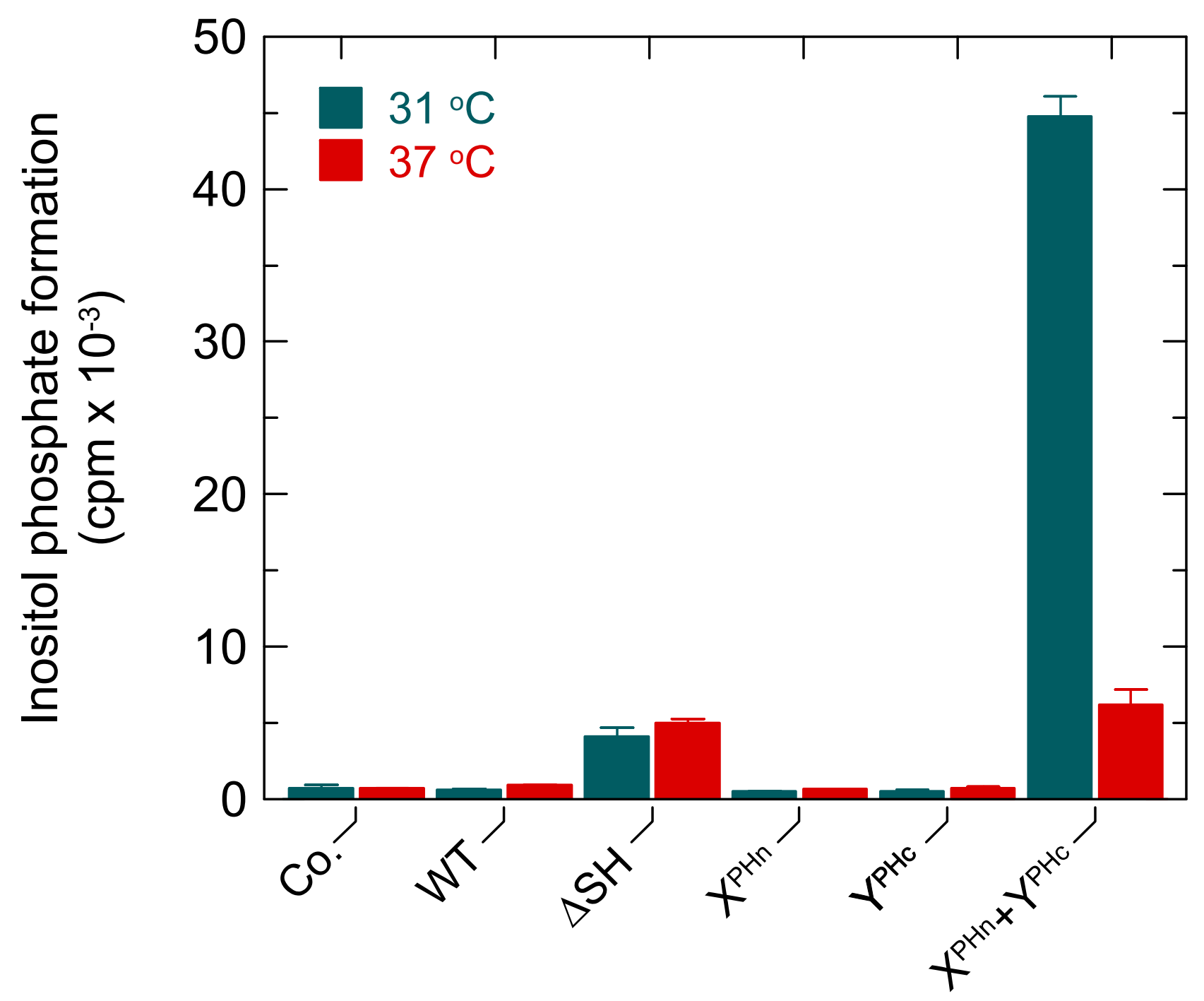

Fig. 10-I 
B

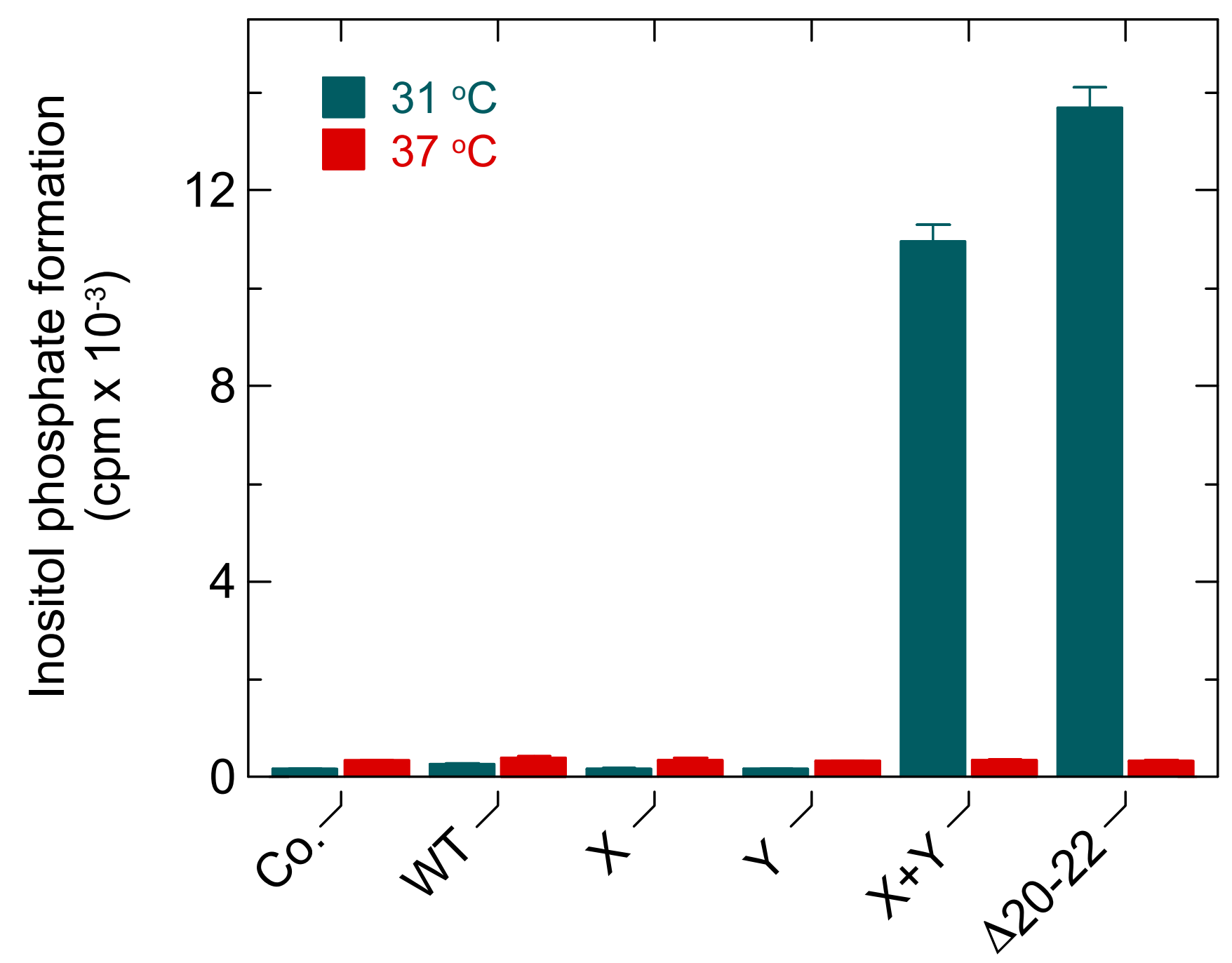

Fig. 10-II 


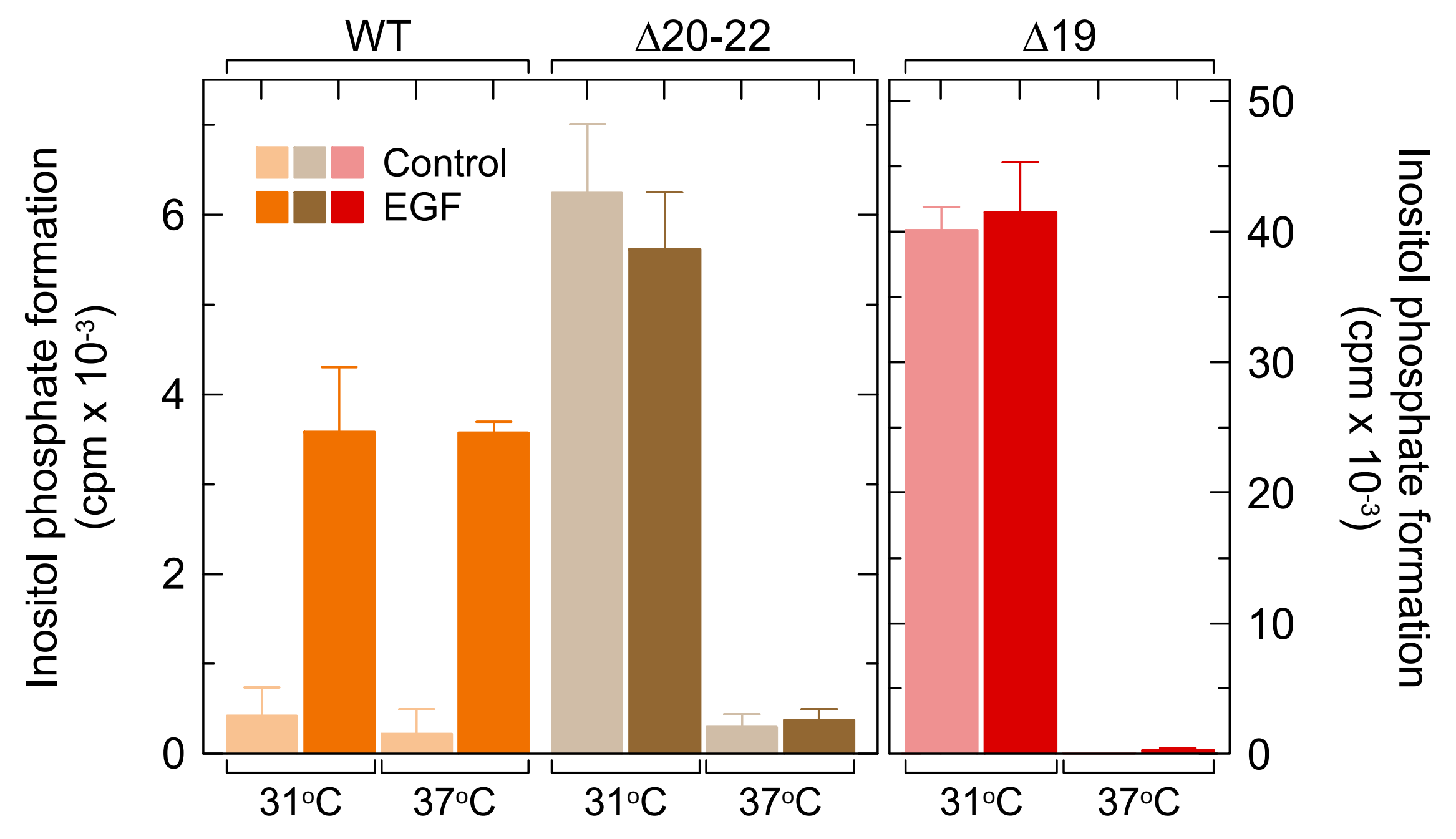

Fig. 11 
C

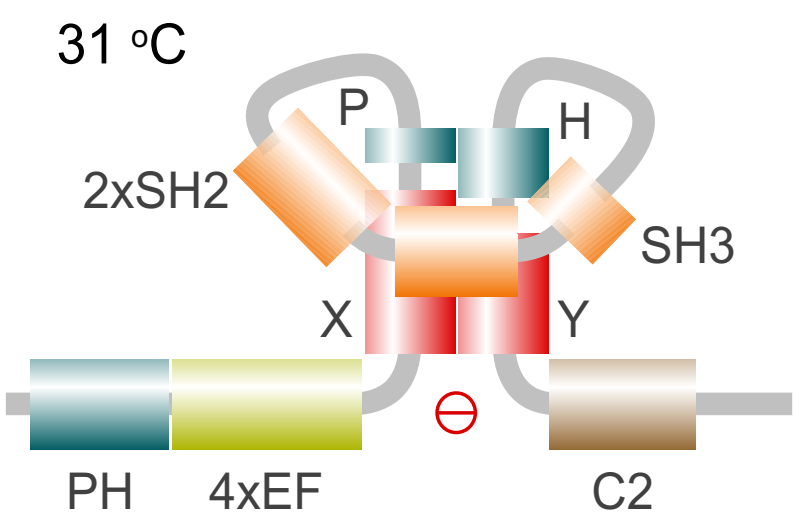

E

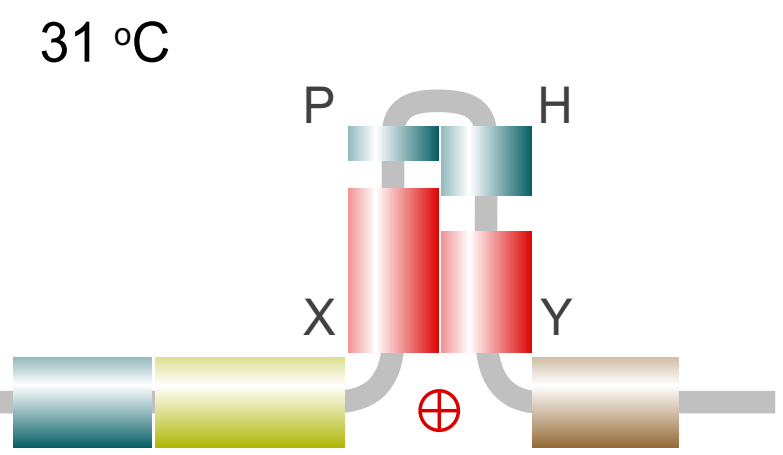

$\mathbf{G}$

$37^{\circ} \mathrm{C}$

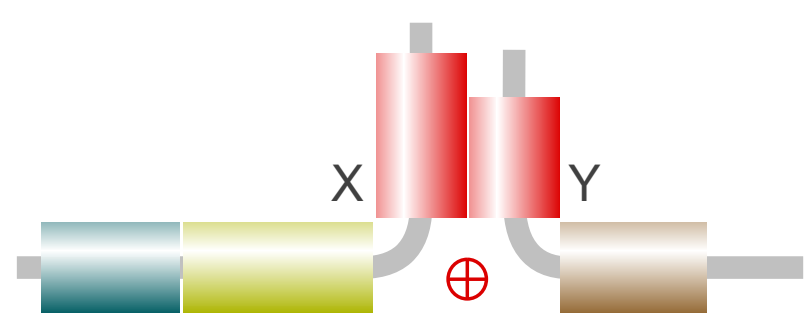

D

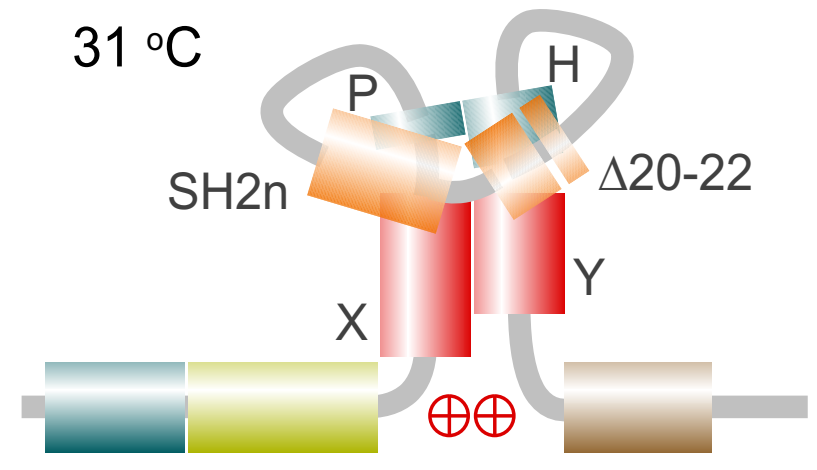

$\mathbf{F}$

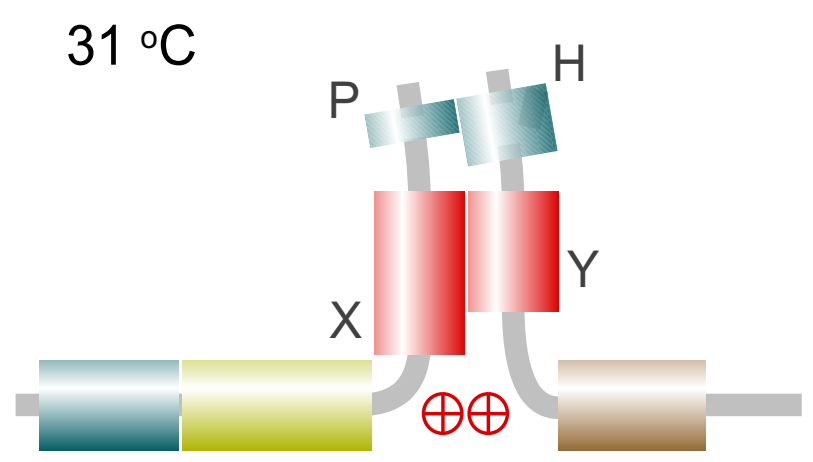

H

$31^{\circ} \mathrm{C}$

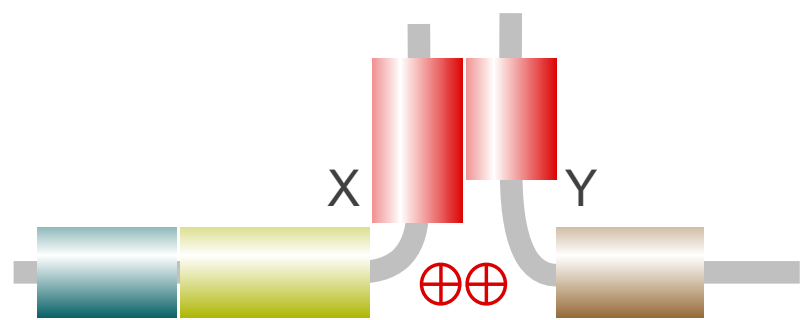




\section{SUPPLEMENTARY MATERIAL \\ Cool-temperature-mediated activation of phospholipase C- $\gamma_{2}$ in the human hereditary disease PLAID}

Anja Schade, Claudia Walliser, Martin Wist, Jennifer Haas, Petra Vatter, Johann M. Kraus, Davide Filingeri, George Havenith, Hans A. Kestler, Joshua D. Milner, Peter Gierschik

\section{Supplementary figures S1-S5}

Fig. S1. Expression of wild-type and mutant PLC $\gamma$ isozymes in Figs. 4A and 4B

Fig. S2. Expression of wild-type and mutant PLC $\gamma$ isozymes in Fig. 5

Fig. S3. Expression of wild-type and mutant PLC $\gamma$ isozymes in Fig. 9A

Fig. S4. Expression of wild-type and mutant PLC $\gamma$ isozymes in Figs. 9B and 9D

Fig. S5. Expression of wild-type and mutant PLC $\gamma_{2}$ isozymes and portions thereof in Fig. 10A Fig. S6. Expression of wild-type and mutant PLC $\gamma_{2}$ isozymes and portions thereof in Fig. 10A Fig. S7. Expression of wild-type and mutant PLC $\gamma_{2}$ isozymes in Fig. 11 


\section{Supplementary Fig. S1}

A

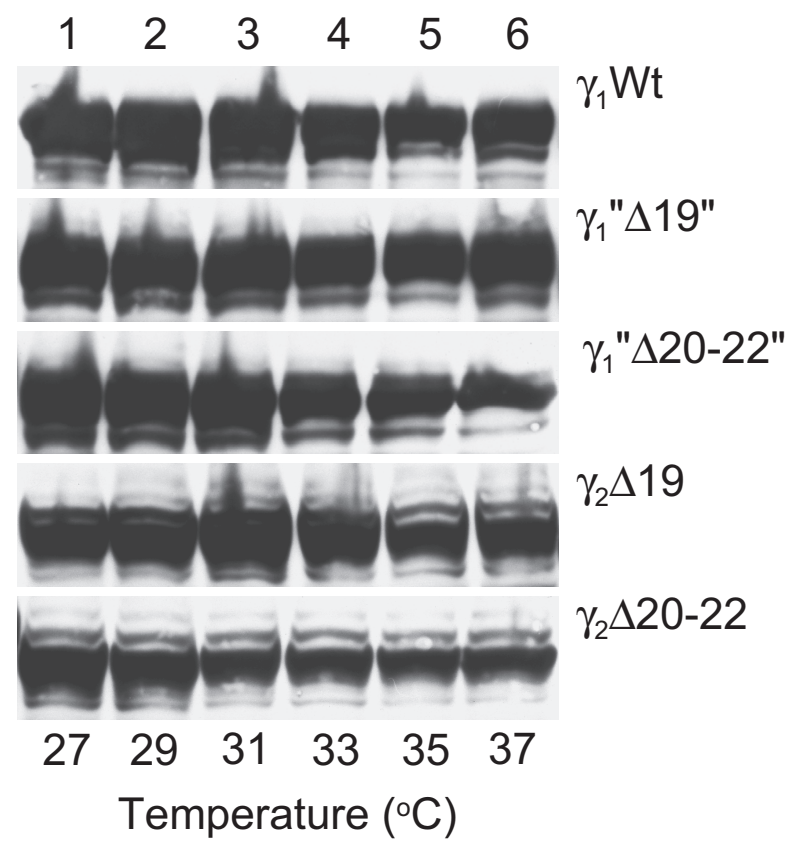

B

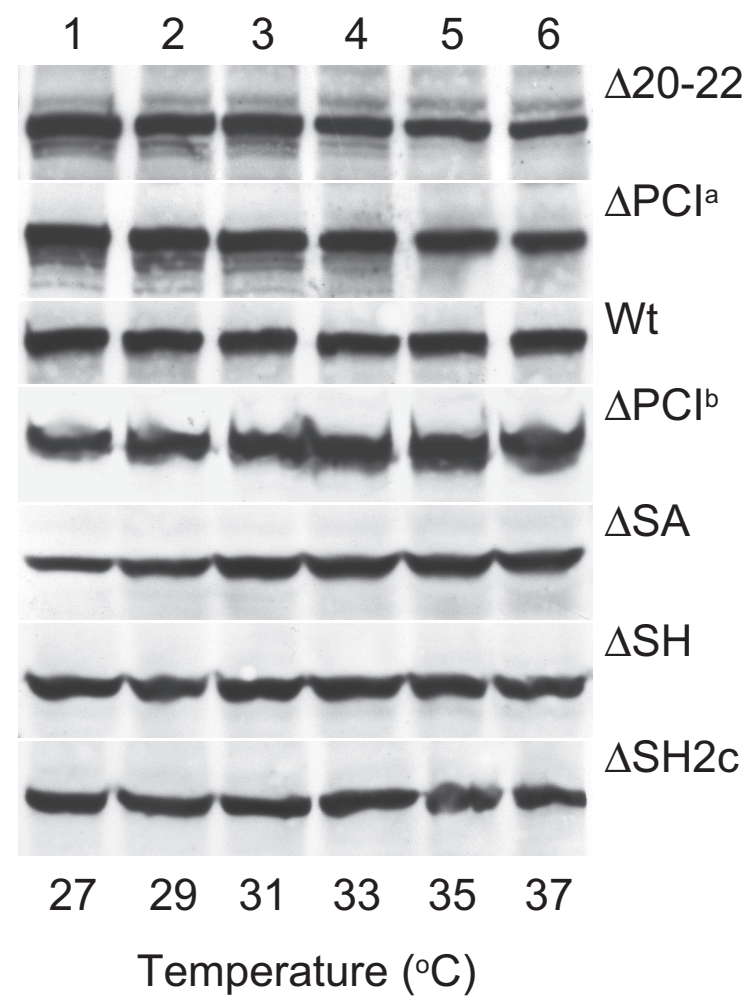

Fig. S1. (A) Expression of wild-type and mutant PLC $\gamma_{1}$ and PLC $\gamma_{2}$ isozymes in the experiment shown in Fig. 4A. (B) Expression of wild-type and mutant PLC $\gamma_{2}$ isozymes in the experiment shown in Fig. 4B. Cells from one well each were washed once with $0.2 \mathrm{ml}$ of Dulbecco's PBS and then lysed by addition of $100 \mu 1$ of SDS-PAGE sample preparation buffer. The samples were subjected to SDS-PAGE and immunoblotting was performed using an antibody reactive against the c-Myc epitope on PLC $\gamma_{1}$ or PLC $\gamma_{2}$. 


\section{Supplementary Fig. S2}

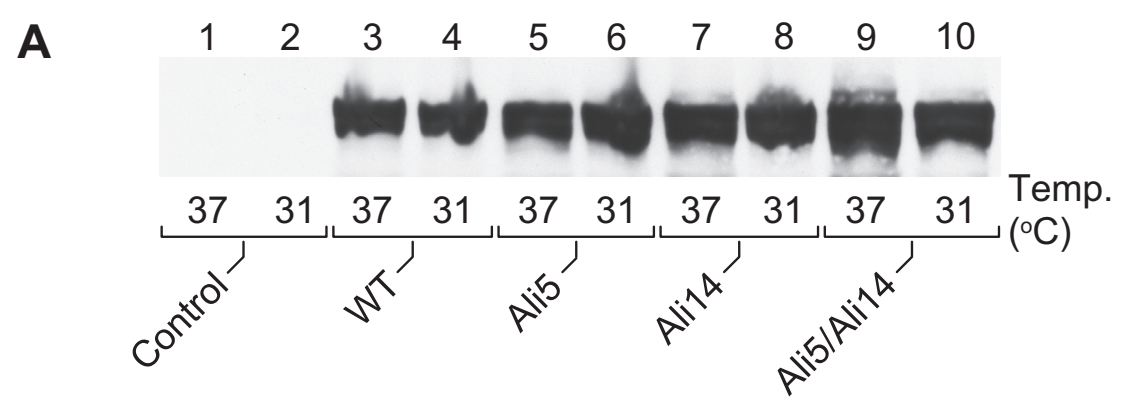

B

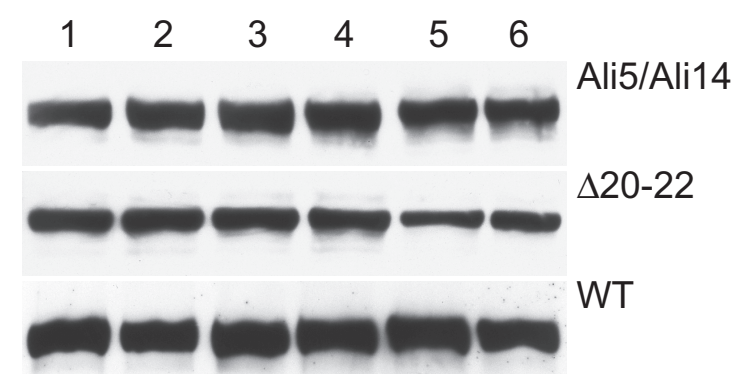

$\begin{array}{llllll}27 & 29 & 31 & 33 & 35 & 37\end{array}$

Temperature $\left({ }^{\circ} \mathrm{C}\right)$
C

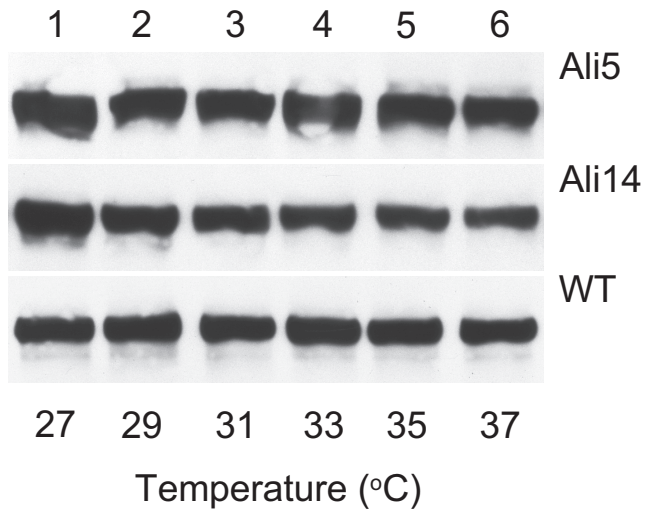

Fig. S2. Expression of wild-type and mutant PLC $\gamma_{2}$ isozymes in the experiment shown in Fig. 5, left panel, $(A)$, center panel, $(B)$, and right panel, $(C)$. Cells from one well each were analyzed by SDS-PAGE and immunoblotting using an antibody reactive against the c-Myc epitope. 


\section{Supplementary Fig. \$3}
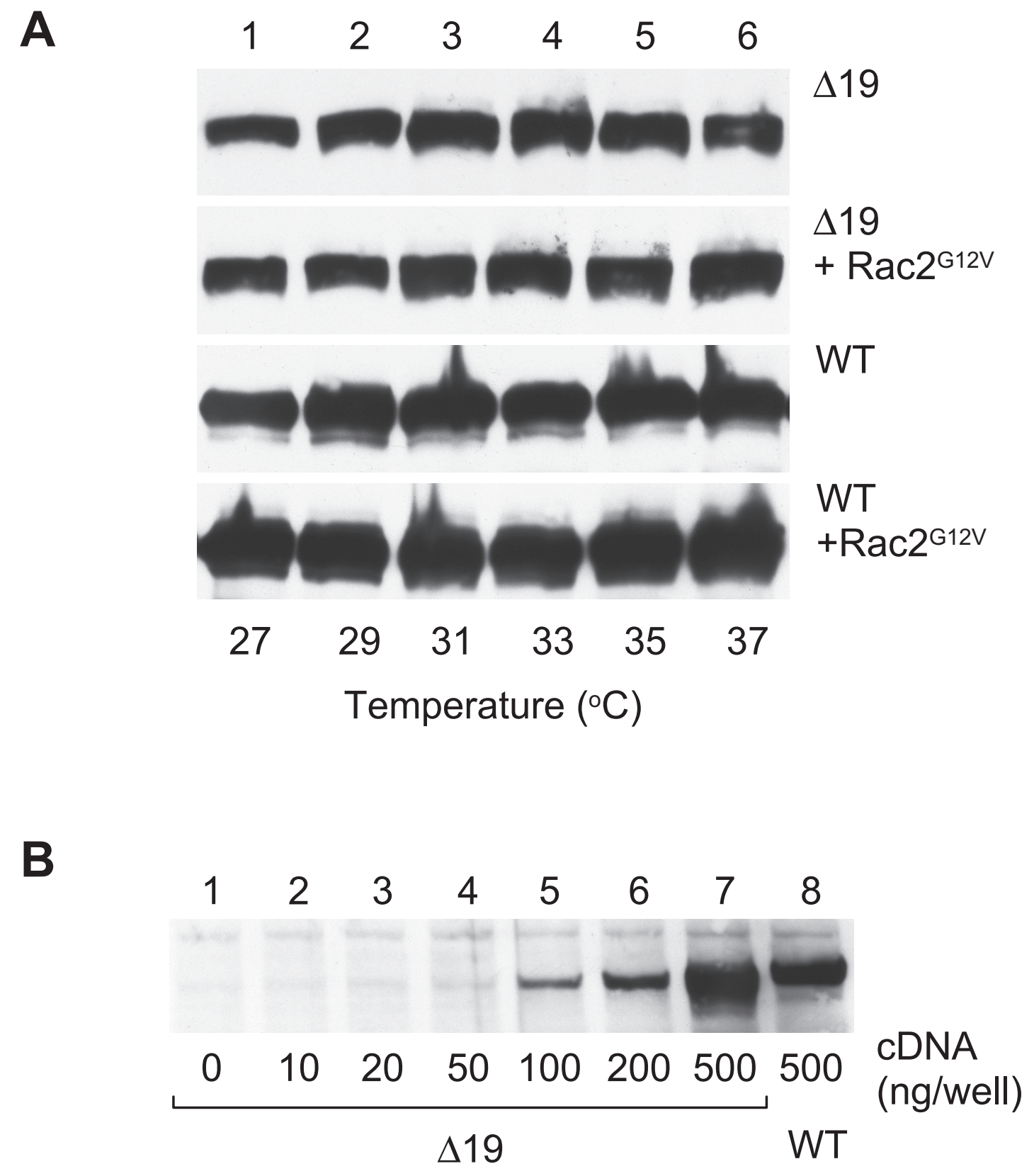

Fig. S3. Expression of wild-type and mutant PLC $\gamma_{2}$ isozymes in the experiment shown in Figs. 9A, left panel, $(A)$ and 9A, right panel, $(B)$. Cells from one well each were analyzed by SDSPAGE and immunoblotting using an antibody reactive against the c-Myc epitope. 


\section{Supplementary Fig. S4}

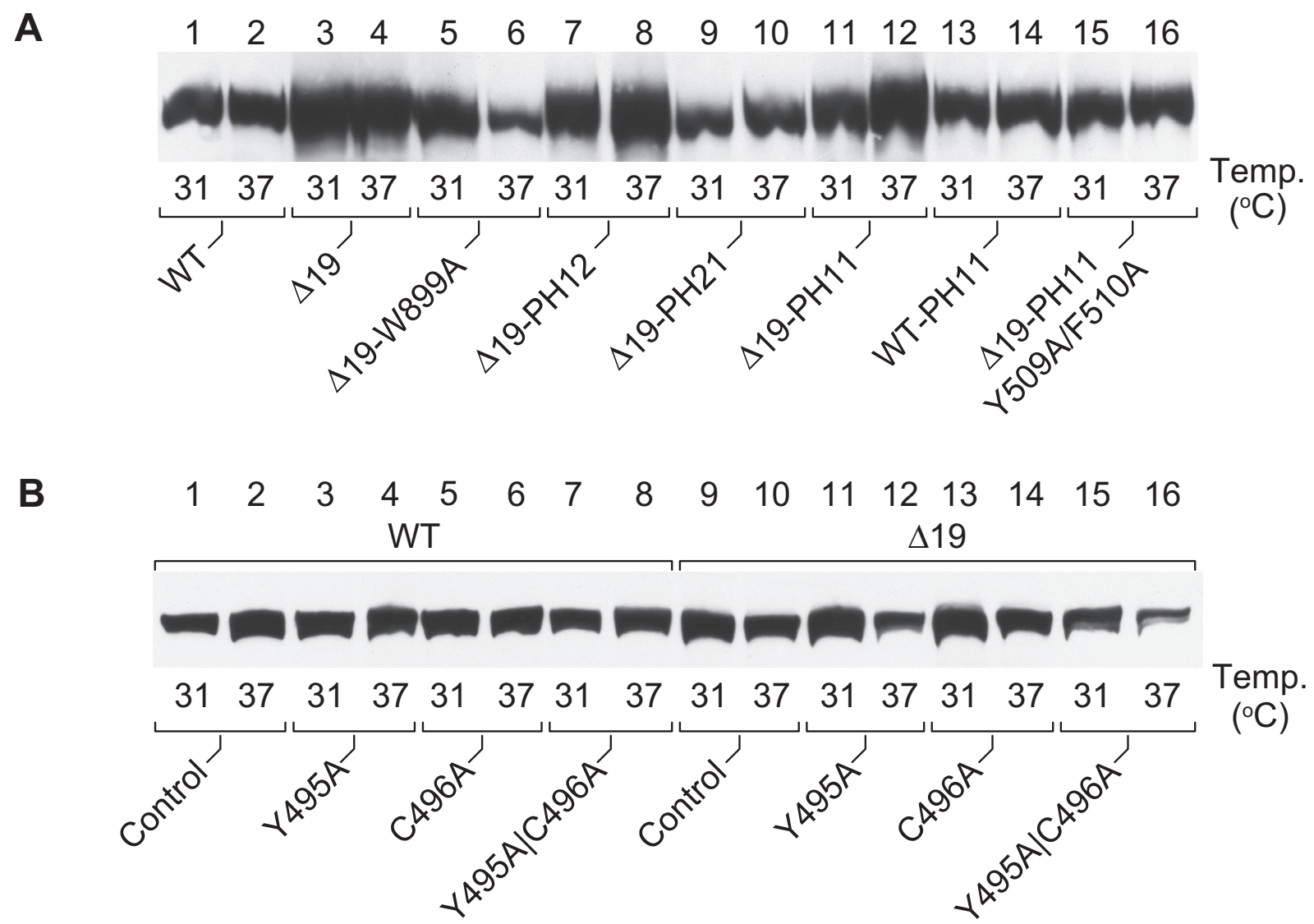

Fig. S4. Expression of wild-type and mutant PLC $\gamma_{2}$ isozymes in the experiment shown in Figs. 9B $(A)$ and 9D $(B)$. Cells from one well each were analyzed by SDS-PAGE and immunoblotting using an antibody reactive against the c-Myc epitope. 


\section{Supplementary Fig. S5}

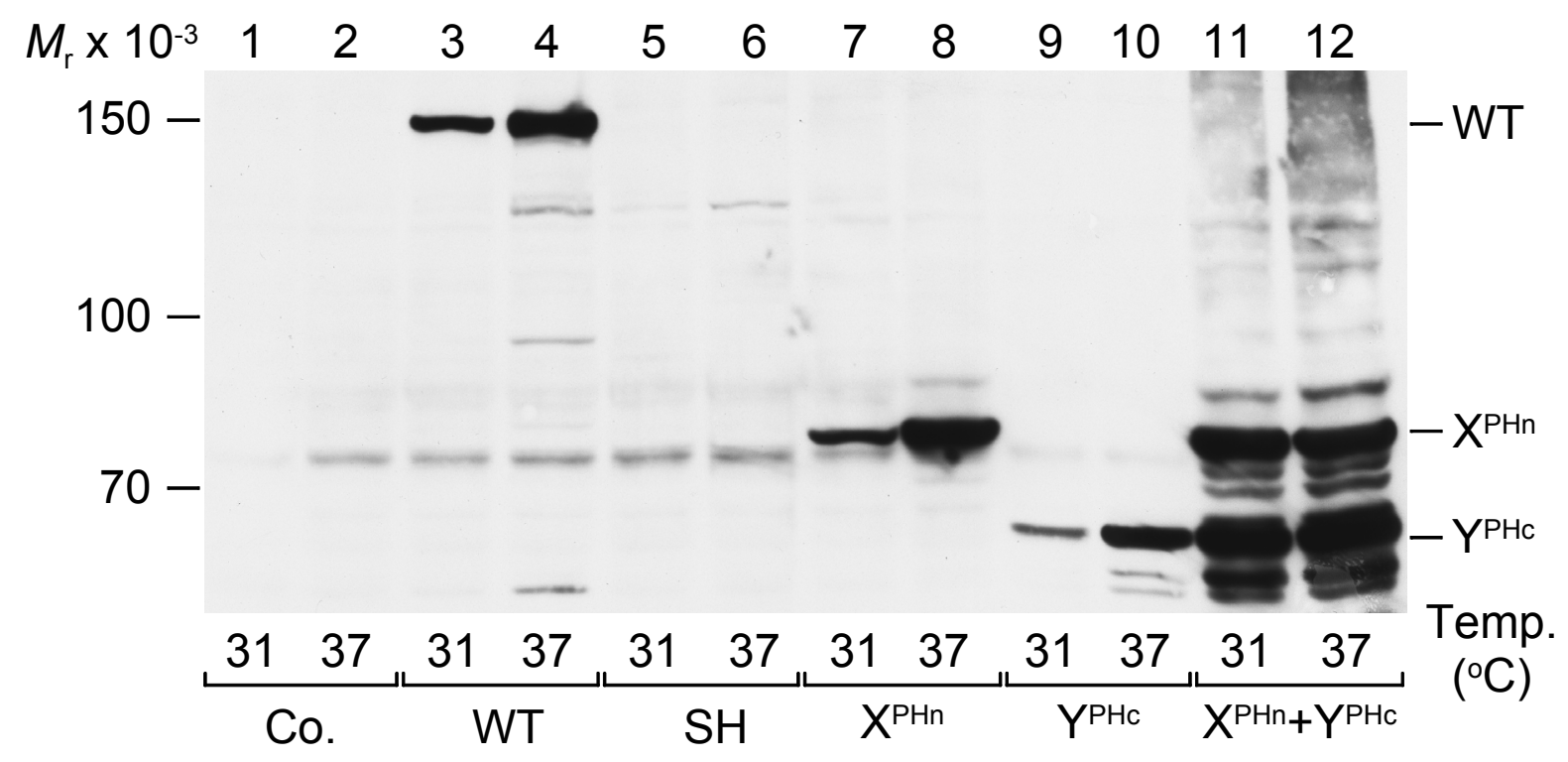

Fig. S5. Expression of wild-type and mutant PLC $\gamma_{2}$ isozymes as well as portions thereof in the experiment shown in Fig. 10A. Cells from one well each were analyzed by SDS-PAGE and immunoblotting using an antibody reactive against the c-Myc epitope. 


\section{Supplementary Fig. S6}

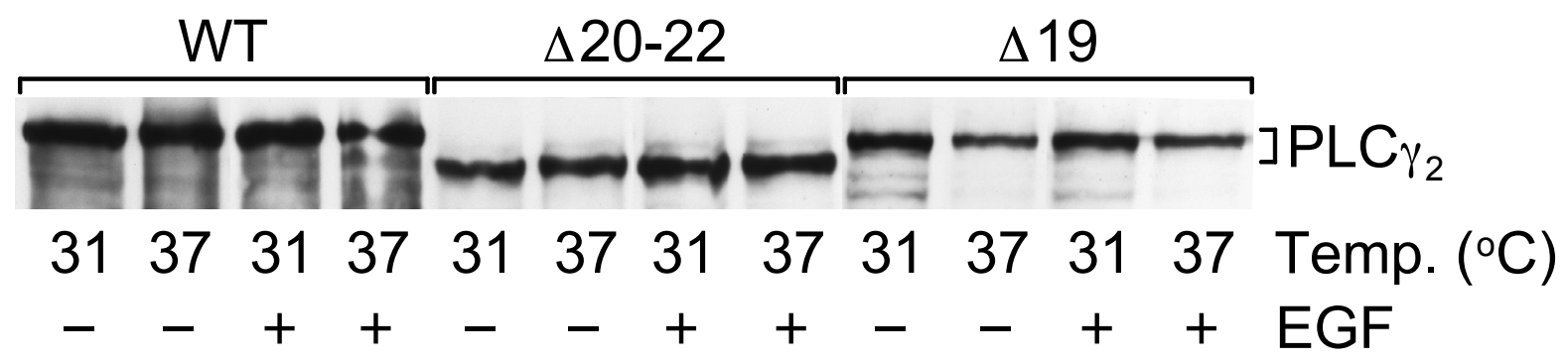

Fig. S6. Expression of wild-type and mutant PLC $\gamma_{2}$ isozymes as well as portions thereof in the experiment shown in Fig. 10B. Cells from one well each were analyzed by SDS-PAGE and immunoblotting using an antibody reactive against the c-Myc epitope. 
Supplementary Fig. S7

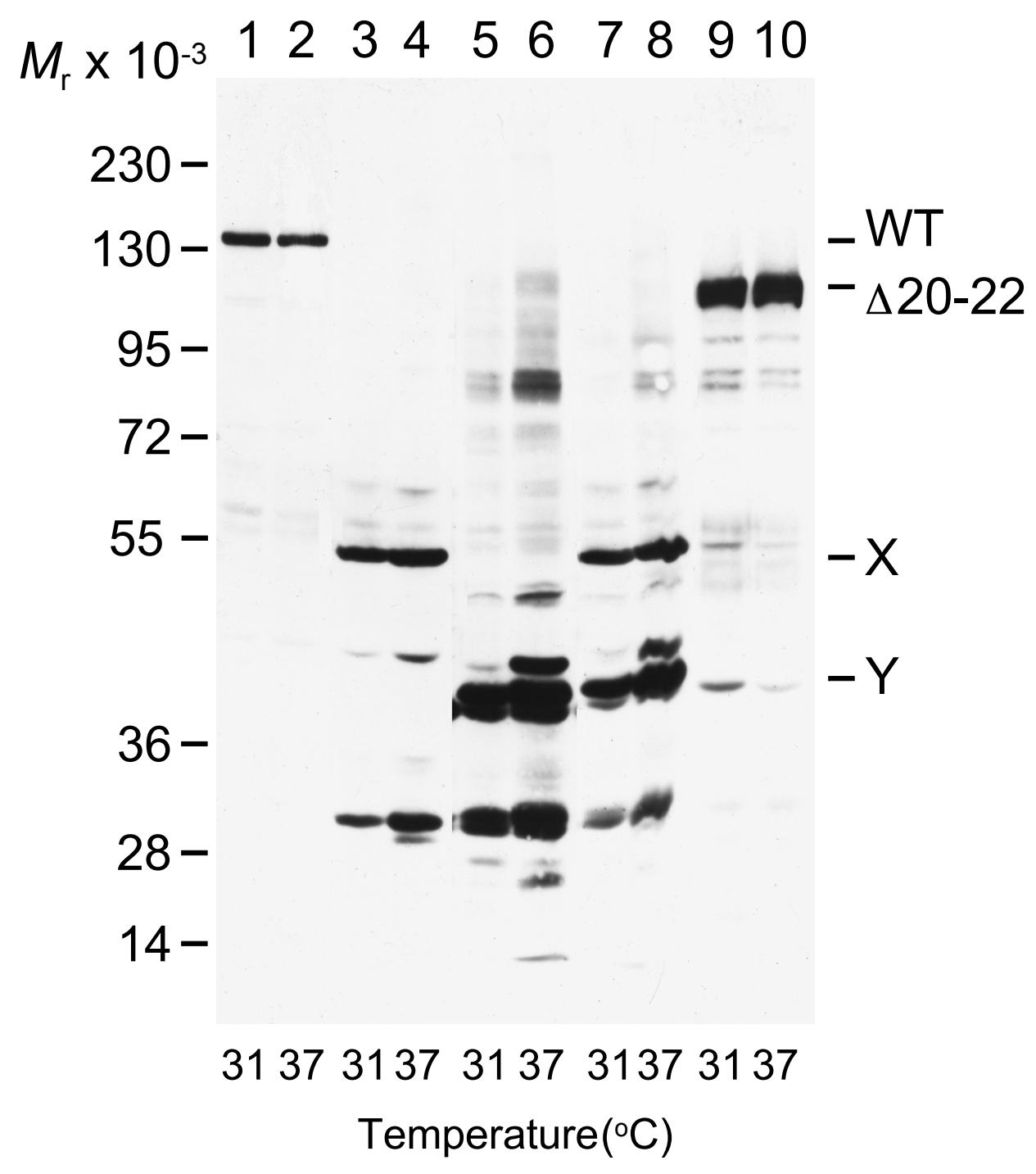

Fig. S7. Expression of wild-type and mutant PLC $\gamma_{2}$ isozymes in the experiment shown in Fig. 11. Cells from one well each were analyzed by SDS-PAGE and immunoblotting using an antibody reactive against the c-Myc epitope. 